\author{
UNIVERSIDADE DE SÃO PAULO \\ ESCOLA DE COMUNICAÇÕES E ARTES
}

DENISE PERES SALES

\title{
CRITÉRIOS DE AVALIAÇÃO DA PRODUÇÃO CIENTÍFICA EM CIÊNCIAS SOCIAIS APLICADAS: inquirindo as bases de dados
}




\title{
CRITÉRIOS DE AVALIAÇÃO DA PRODUÇÃO CIENTÍFICA EM CIÊNCIAS SOCIAIS APLICADAS: inquirindo as bases de dados
}

\begin{abstract}
Dissertação apresentada ao Curso de Pós-Graduação em Ciência da Informação, da Escola de Comunicações e Artes da Universidade de São Paulo, como exigência para a obtenção do título de Mestre em Ciência da Informação.
\end{abstract}

Área de concentração: Cultura e Informação.

Linha de Pesquisa: Gestão de Dispositivos de Informação.

Orientação: Prof. Dr. Rogério Mugnaini. 
Autorizo a reprodução e a divulgação total ou parcial deste trabalho, por qualquer meio convencional ou eletrônico, para fins de estudo e pesquisa, desde que citada a fonte.

Sales, Denise Peres

Critérios de avaliação da produção científica em ciências sociais aplicadas: inquirindo as bases de dados / Denise Peres Sales; orientação do Prof. Dr. Rogério Mugnaini. São Paulo: s.n, 2013.

115f.; il.

Dissertação (Mestrado)--Universidade de São Paulo, 2013.

1.Periódicos científicos 2. Base de Dados 3. Critérios 4. Política científica 5. Capes 6. Qualis I. Título II. Mugnaini, Rogério, orient. 
SALES, Denise Peres

Critérios de avaliação da produção científica em ciências sociais aplicadas: inquirindo as bases de dados

Aprovado em:

Dissertação apresentada ao Curso de Pós-Graduação em Ciência da Informação, da Escola de Comunicações e Artes da Universidade de São Paulo, como exigência para a obtenção do título de Mestre em Ciência da Informação.

\section{Banca Examinadora}

Prof. Dr.: Instituição:

Julgamento: Assinatura:

Prof. Dr. Instituição:

Julgamento: Assinatura:

Prof. Dr.: Instituição:

Julgamento: Assinatura: 
"A tarefa não é tanto ver aquilo que ninguém viu, mas pensar o que ninguém ainda pensou sobre aquilo que todo mundo vê."

(Arthur Schopenhauer) 
Agradeço a Deus... 


\section{AGRADECIMENTOS}

Agradeço primeiramente a Deus, por ter me dado força nos piores momentos deste percurso. Sem acreditar e sem ter fé, eu não chegaria a lugar algum.

Ao meu orientador Prof. Dr. Rogério Mugnaini, pela compreensão, orientação e valiosa ajuda na finalização deste trabalho.

Ao meu querido e amado Guilherme Magossi, por estar sempre ao meu lado nesta dura jornada. Obrigada pelo amor e carinho e também por entender minha ausência.

À amiga querida Mônica de Fátima Loureiro-Alves, que, além das orações e do apoio incondicional de amiga-irmã, desempenhou o importante e fundamental papel de minha co-orientadora, revisando, sugerindo, conversando e realizando generosa colaboração para finalização do texto. Sem ela eu não teria conseguido chegar ao final desta longa e dolorosa jornada.

À amiga Adriana Luccisano, pelo apoio em todos os momentos, força incondicional, incansáveis momentos de orações e leituras e também por estar sempre à disposição para me auxiliar, seja com seus gestos de conforto, seja com palavras de carinho e/ou pelos doces olhares que diziam mais que mil palavras.

À amiga Letícia Martins, pelo apoio de equipe e pela generosidade nas leituras e sugestões do trabalho.

À amiga Giovanna Britto, pelas conversas motivadoras e pelas inúmeras orações.

Ao SciELO, pela oportunidade de trabalhar em tão importante base de dados e aprender muito a cada dia.

Às professoras Nair Yumiko Kobashi e Mirian Rejowski, pelas sugestões no momento da qualificação.

À Capes, pela disponibilidade dos dados em seu sítio.

À Cláudia Malinverni, pelo trabalho duro e dedicado na revisão desta dissertação.

À amiga Filipa Pinto pelas palavras de incentivo e auxílio na tradução.

Aos meus pais Nivaldo e Doraci, pelo apoio de toda vida. 


\section{RESUMO}

SALES, D. P. Critérios de avaliação da produção científica em ciências sociais aplicadas: inquirindo as bases de dados. 2013. 115f. Dissertação (Mestrado em Ciência da Informação) - Escola de Comunicações e Artes, Universidade de São Paulo, São Paulo.

O processo de avaliação dos programas de pós-graduação brasileiros foi iniciado pela Capes na década de 1970, consolidando-se com o sistema Qualis, cujo objetivo é classificar os milhares de cursos existentes atualmente no país. Mais especificamente, são nomeadas comissões de área, cujo papel consiste na definição e aplicação de critérios para assegurar o mérito científico dos programas, no que tange à sua proposta, ao seu corpo docente, à titulação de novos mestres e doutores e à publicação da pesquisa em veículos reconhecidos. Como um reflexo do que vem acontecendo mundialmente, o periódico científico se sobressai em relação aos outros tipos de documento, como decorrência de um processo histórico que culminou nas bases de dados, tornando-se a principal fonte de informação para avaliação de produção científica. Esta pesquisa teve como objetivo geral contribuir com o processo de avaliação da produção científica nacional, por meio de análise das fontes de informação que compõem os critérios de classificação dos periódicos utilizados nas áreas de ciências sociais aplicadas. Os objetivos específicos foram: 1) identificar as fontes de informação que podem ser classificadas efetivamente como base de dados, segundo critérios específicos que permitam atestar a qualidade científica e/ou editorial periódico; 2) identificar as fontes de informação que possuem critérios de seleção específicos que permitam atestar a qualidade científica e/ou editorial dos periódicos e os disponibilizam em seus sites; 3 ) analisar o uso que tem sido feito dessas fontes nas diferentes áreas de avaliação dos programas de pós-graduação. Os resultados permitiram observar que das 17 fontes de informação analisadas somente 7 foram reconhecidas como bases de dados e declaram utilizar critérios de seleção de periódicos. Todas as fontes de informação que não mencionam critério de seleção eram utilizadas pela área de Ciências Sociais Aplicadas I, no triênio de 2007-2009, consistindo de fontes temáticas de Ciência da Informação e Comunicação, que deixaram de figurar entre os critérios da área no documento que os atualiza, publicado em 2012. Entre todas as áreas de avaliação que compõem a grande área de Ciências Sociais Aplicadas destacou-se o uso das bases com cobertura internacional (Web of Science e Scopus) e regional (SciELO, LATINDEX e REDALYC). Outro aspecto importante foi o uso do Fator de Impacto para classificação dos periódicos pelas áreas de Economia e Administração, Ciências Contábeis e Turismo, a partir do triênio de 2004-2006. Por fim, observou-se que, do ponto de vista dos profissionais que atuam nas bases de dados, existe uma percepção mais aguçada dos quesitos sobre a qualidade esperada de um periódico científico. Por outro lado, quem está ligado ao meio editorial e às comissões das áreas não necessariamente percebe os detalhes fundamentais à efetividade da comunicação científica, quais sejam: existência de critérios de seleção de periódicos, presença de um conselho editorial atuante, diversidade geográfica dos autores, revisores ad hoc e membros do conselho editorial e informações sobre a lista de títulos dos periódicos indexados pela fonte de informação.

Palavras-Chave: Periódicos científicos; Avaliação; Base de dados; Critérios; Indexação; Política científica; Capes; Qualis. 


\section{ABSTRACT}

SALES, D. S. Criteria of evaluation of scientific production in applied social science: inquiring the databases. 2013. 115f. Master's Dissertation in Information Science - School of Communications and Arts, University of São Paulo, São Paulo.

The evaluation of graduation, by Capes, from 1970s, when it began a process that has been developed since then, resulting in the Qualis, whose goal is to assess thousands of postgraduate programs in Brazil. Specifically, there are trained committees, whose objective is to define and apply the criteria to ensure the scientific merit of the programs in terms of their proposal, its faculty, titration of new teachers and doctors, and the publication of research findings in recognized publishing vehicles. As a reflection of what is happening worldwide, the scientific journal stands in relation to other types of document, because of a historical process which culminated in the databases as the main source of information for evaluation of scientific production. This research aims to contribute to the process of evaluation of national scientific production, through the analysis of information sources that make up the criteria for classification of the scientific journals used in the areas of applied social sciences. The specific objectives were: 1) to identify the sources of information that can be classified effectively as a database, according to specific criteria that allow to test the scientific and/or editorial quality, 2) to identify which information sources have specific selection criteria that allow to test the scientific and/or publishing quality and if they are provided on their websites, and 3) to evaluate the use that has been made of these sources in different areas of assessment. Results showed that, from the 17 sources of information analyzed, only 7 were recognized as databases and were declaring to use criteria for selecting the scientific journals. All sources of information that were not mentioned a selection criteria were used for the area of Applied Social Sciences I in the triennium 2007-2009, consisting of thematic sources of Information Science and Communication, these sources are no longer available among the criteria in the area of the document that updates the criteria of the area, published in 2012. Among all evaluation areas that comprise the large area of applied social sciences, the use of bases with international coverage is the most important (Web of Science and Scopus) and regional (SciELO, LATINDEX and REDALYC) in most areas. Another important aspect was the use of the Impact Factor for the scientific journals classification, the areas of Economics and Business Administration, Accounting and Tourism, since the three-year period from 2004-2006. Finally, it was observed that, from the professional's point of view, there is a better perception regarding questions about the criteria that analyzes the expected quality of a scientific journal. On the other hand, who is linked to the editorial and area committees, cannot necessarily perceive the details that are critical to the effectiveness of scientific communication: the existence of periodic selection criteria, the presence of an active editorial board, the existence of a geographic diversity of the authors, ad hoc reviewers and editorial board members and information about the list of titles of the scientific journals indexed by the source of information.

Keywords: Scientific journals; Database; Evaluation; Criteria; Indexing; Scientific policy; Capes; Qualis. 


\section{LISTA DE ABREVIATURAS E SIGLAS}

ABC - Academia Brasileira de Ciências

ABE - Associação Brasileira de Educação

ABNT - Associação Brasileira de Normas Técnicas

APA - American Psychological Association

BIREME - Centro Latino-Americano e do Caribe de Informação em Ciências da

Saúde

BNDES - Banco Nacional de Desenvolvimento Econômico

Capes - Coordenação de Aperfeiçoamento de Pessoal de Nível Superior

$\mathrm{Cl}$ - Ciência da Informação

CLACSO - Consejo Latinoamericano de Ciencias Sociales

CLASE - Citas Latinoamericanas en Ciencias Sociales y Humanidades

CMMC - Communication \& Mass Media Complete

CNE - Conselho Nacional de Educação

CNPq - Conselho Nacional de Nível Superior

CNPq - Conselho Nacional de Desenvolvimento Científico e Tecnológico

CNRS - Centre National de la Recherche Scientifique

DOAJ - Directory of Open Access Journal

DSpace - Institutional Digital Repository System

ENANCIB - Encontro Nacional de Pesquisa em Ciência da Informação

FAPESP - Fundação de Amparo à Pesquisa do Estado de São Paulo

FESPSP - Fundação Escola de Sociologia e Política do Estado de São Paulo

Finep - Financiadora de Estudos e Projetos

HTML - HyperText Markup Language

IBICT - Instituto Brasileiro de Informação em Ciência e Tecnologia

INFOBILA - Base de Datos de Información y Bibliotecología Latinoamericana

INIST - Institut de l'Information Scientifique el Technique

IP - Internet Protocol

ISI - Information Sciences Institute

ISSN - International Standard Serial Number

JCR - Journal Citation Reports

LAPTOC - Latin American Periodicals Tables of Contents

LARRP - Latin Americanist Research Resources Project

Latindex - Sistema Regional de Información en Línea para Revistas Científicas de América Latina, el Caribe, España y Portugal

LISA - Library and Information Science Abstracts

MEC - Ministério da Educação

MIT - Massachusetts Institute of Technology

OAB - Ordem dos Advogados do Brasil

OMS - Organização Mundial da Saúde

OPAS - Organização Pan Americana da Saúde

PDF - Portable document format

Redalyc - Red de Revistas Científicas de América Latina, el Caribe, España y Portugal

SciELO - Scientific Electronic Library Online

UFMG - Universidade Federal de Minas Gerais

UFSC - Universidade Federal de Santa Catarina

UNAM - Universidade Nacional Autônoma do México 
UNESCO - United Nations Educational, Scientific and Cultural Organization URJ - Universidade do Rio de Janeiro

USP - Universidade de São Paulo

TIC - Tecnologia da informação e comunicação 


\section{LISTA DE ILUSTRAÇÕES}

Gráfico 1 - Número de revistas científicas correntes em relação à data...... 30

Quadro 1 - Cronologia das principais publicações periódicas. 31

Quadro 2 - Nível do Fator de Impacto exigido para definição de critérios de avaliação de periódicos do estrato $A 1$, segundo grande área do conhecimento e área de avaliação Qualis. .57

Quadro 3 - Fontes de informação: tipo, critérios de seleção e comitê consultivo. .86

Quadro 4: Fontes de informação utilizadas pelas áreas de avaliação das Ciências Sociais Aplicadas, segundo triênio de avaliação e estrato de classificação dos periódicos. 88 


\section{SUMÁRIO}

1. INTRODUÇÃO

2. PERIÓDICOS CIENTÍFICOS E FONTES DE INFORMAÇÃO:

RELEVÂNCIA PARA A COMUNICAÇÃO CIENTÍFICA ........................... 19

2.1 ORIGEM DOS PERIÓDICOS CIENTÍFICOS ……............................ 19

2.2 FUNÇÕES DOS PERIÓDICOS CIENTÍFICOS ….............................. 22

2.3 CARACTERIZAÇÃO DOS PERIÓDICOS CIENTÍFICOS …................... 25

2.4 CRITÉRIOS DE QUALIDADE DOS PERIÓDICOS CIENTÍFICOS......... 29

2.4.1 Tempo de Existência........................................................................ 33

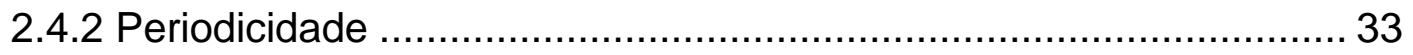

2.4.3 Regularidade ou Pontualidade .................................................. 34

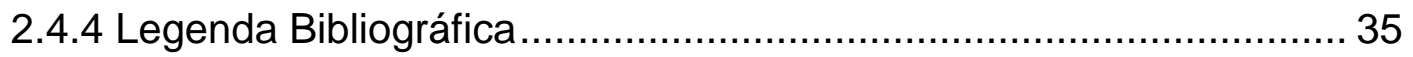

2.4.5 Data de Recebimento e Aprovação dos Artigos.............................. 35

2.4.6 Peer Review/Processo de Revisão por Pares.................................. 35

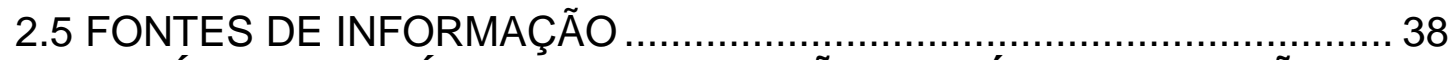

3. A POLÍTICA CIENTÍFICA E A AVALIAÇÃO DA PÓS-GRADUAÇÃO ..... 41

3.1 DA CRIAÇÃO DAS UNIVERSIDADES À PÓS-GRADUAÇÃO ............41

3.1.1 Marcos do Desenvolvimento Científico no Mundo ........................... 41

3.1.2 Histórico do Desenvolvimento Científico no Brasil ............................ 43

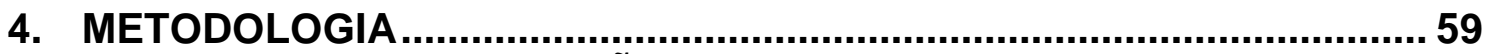

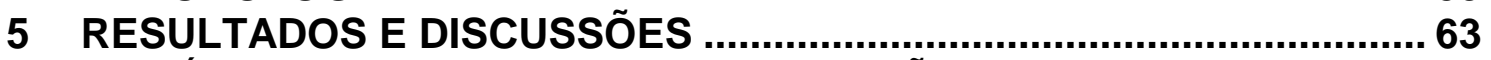

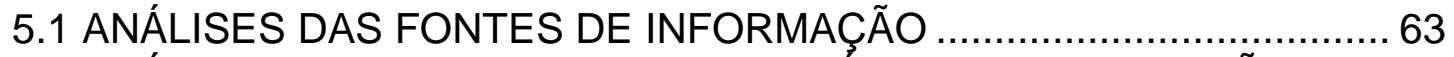

5.2 ANÁLISE DE USO DAS BASES PELAS AُREAS DE AVALIAÇÃO ......... 85

6 CONSIDERAÇÕES FINAIS............................................................. 90

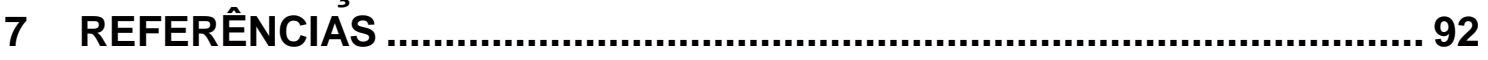

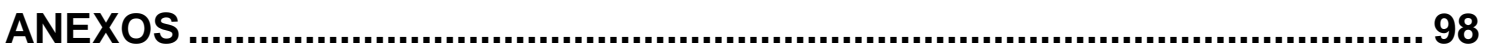

Anexo 1 - Modelo de protocolo utilizado para análise das bases de dados . 99 Anexo 2 - Lista de títulos de periódicos da base de dados ComABSTRACTS

Anexo 3 - Lista de membros da LARRP - LAPTOC .................................. 108 Anexo 4 - Critérios de classificação para periódicos impressos e eletrônicos

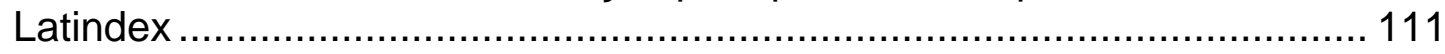
Anexo 5: Inexistência de documentos ou de critérios, segundo informações disponibilizadas pelas áreas. 


\section{INTRODUÇÃO}

O progresso do trabalho de um cientista é constantemente avaliado pela comunidade a que pertence, com base na produtividade das suas pesquisas. $\mathrm{E}$ sempre que ele conclui um estudo ou realiza uma nova descoberta, deve divulgar seus resultados e conclusões para essa comunidade. Para um cientista, seu progresso no local de trabalho e na comunidade científica é constantemente avaliado com base em sua produtividade na comunicação das pesquisas.

Tal divulgação pode ocorrer de diversas formas: oral, escrita, por meio de eventos etc. Mais antiga forma de comunicação humana, a oral é tida também como a mais importante no campo da ciência. Ela ocorre em reuniões e congressos, no contato direto dos cientistas com seus pares, para os quais submete seus resultados e ideias.

O crescimento da informação científica tem acompanhado o considerável aumento nos sistemas que armazenam, gerenciam e disponibilizam aos usuários essa produção, de maneira adequada e satisfatória. Para dar vazão ao maior volume de informações produzidas em decorrência do aumento das próprias comunidades científicas em diversas áreas do conhecimento, cresceu também o número de periódicos científicos.

Essas publicações dinamizam a divulgação dos achados científicos entre os pares, apesar de não serem os únicos instrumentos utilizados no processo de comunicação da ciência. Outros meios são as publicações resultantes de congressos e reuniões científicas, livros e teses. Esses produtos são utilizados com intensidades diferentes, de acordo com a área de pesquisa. Biojone (2001) afirma, contudo, que o periódico científico é indiscutivelmente o meio mais utilizado para a publicação dos resultados de pesquisa em várias áreas do conhecimento.

Para que o periódico seja considerado de qualidade e aceito pela comunidade científica alguns aspectos devem ser verificados, entre os quais a abrangência (nacional e internacional) e a indexação em bases de dados. Esses aspectos são levados em consideração no momento em que o 
pesquisador escolhe o veículo no qual quer que seus resultados sejam publicados. Os periódicos científicos têm peso e utilização diferentes nas várias áreas e disciplinas da ciência. Para as ciências sociais e humanas, por exemplo, essa não é a forma de comunicação mais relevante, sendo mais importante para os pesquisadores desses campos a publicação de seus estudos em livros. Já para outros ramos das ciências, como as naturais e as biológicas, os periódicos são essenciais. Mesmo assim, eles constituem formas bastante importantes de comunicação científica, de modo geral, uma vez que não são empregados exclusivamente na disseminação de informações, mas, também, na institucionalização do conhecimento, avaliação da produção científica e consagração e legitimação dessa produção.

Além disso, os periódicos vêm sendo objeto constante de avaliação por parte dos gestores e financiadores das atividades científicas nas organizações e em muitos países, como Estados Unidos, China, Alemanha, Japão e Inglaterra, bem colocados nos principais rankings de produção da ciência, em nível global. Esses países buscam obter, mediante a avaliação do Fator de Impacto das publicações, indicadores de produtividade e qualidade da ciência produzida por eles, de modo a obterem subsídios tanto para a tomada de decisão quanto de distribuição e alocação de recompensas e recursos (SANTOS; NORONHA, 2013).

Nessa perspectiva, a avaliação dos periódicos tornou-se, nos últimos anos, um instrumento bastante utilizado: 1) pelas agências de fomento para definição de apoio aos periódicos; e 2) pelos principais índices internacionais, visando a inclusão de títulos em suas bases de dados. Em função desses aspectos, há uma preocupação crescente com a formalização da comunicação científica, a fim de assegurar a legitimidade dos periódicos e garantir uma melhor circulação do conhecimento.

Assim, o processo de avaliação da pós-graduação no Brasil vem sendo desenvolvido, ao longo dos últimos 35 anos, pela Coordenação de Aperfeiçoamento de Pessoal de Nível Superior (Capes) por meio do sistema Qualis. Ele é responsável por validar a produção intelectual docente e discente em âmbito nacional, gerando uma classificação dos periódicos científicos 
utilizados pelos programas brasileiros de pós-graduação. Dentre os veículos avaliados estão os impressos e eletrônicos, nacionais e estrangeiros.

Tal como ocorre com os cursos, também os periódicos científicos são avaliados segundo critérios e parâmetros definidos pelas respectivas áreas do conhecimento. Os mais comumente utilizados para a classificação das publicações científicas são:

$\checkmark$ corpo editorial;

$\checkmark$ periodicidade;

$\checkmark$ regularidade;

$\checkmark$ distribuição;

$\checkmark$ sistema de arbitragem;

$\checkmark$ normalização;

$\checkmark$ tiragem; e

$\checkmark$ indexação.

Na prática, esses critérios costumam ser adotados em sua totalidade ou em partes. As áreas cujo conjunto de periódicos principais está presente nas mais importantes bases de dados internacionais acabam considerando o Fator de Impacto, índice usado para mensurar o impacto dos periódicos, como critério exclusivo de qualidade; outras consideram a indexação em bases de dados e a presença em fontes de informação. Há ainda áreas que estão consolidando seus primeiros periódicos científicos, tendo por isso o livro como principal veículo de comunicação.

Dessa forma, de acordo com Castro (2011), no caso da indexação em bases de dados, a comunidade científica reconhece os diferentes níveis de excelência, relevância e mérito de acordo com o rigor com que os processos de seleção são executados.

Contudo, são colocadas as seguintes questões: 1) Será que todas as bases de dados e/ou repositórios possuem critérios de avaliação? 2) Em uma mesma área do conhecimento, as diferenças entre os critérios adotados para a indexação de periódicos nas bases, em um mesmo estrato, apresentam divergências? Diante dessa perspectiva, este estudo se propõe a analisar as fontes de informação destacadas pelo documento de área da Capes. Isso 
porque, após avaliação preliminar, verificou-se que nem todas as fontes de informação que subsidiam os diferentes critérios de qualidade possuem característica de bases de dados. Outro ponto observado diz respeito ao fato de que algumas fontes sequer explicitam os critérios de seleção de periódicos que compõem suas coleções e, ainda, não apresentam informação de contato para esclarecimento de dúvidas.

Em razão dessa diversidade de critérios, em que cada base de dados possui padrões de seleção específicos e objetivos diferentes, os periódicos são classificados de maneiras próprias, não existindo um modelo de avaliação efetivo que cubra todos os aspectos relevantes de um processo avaliativo. Essa constatação torna-se de extrema relevância pelo fato de as áreas de avaliação tomarem determinadas fontes de informação como um atestado de qualidade dos periódicos que abarcam, quando nem sempre esses critérios de seleção podem ser observados. Com base nos documentos de classificação de periódicos do Qualis, das áreas de avaliação que compõem a grande área de ciências sociais aplicadas, aplicar mecanismos de análise que permitam caracterizar e pontuar cada uma das fontes citadas, gerando, assim, subsídios para o processo de avaliação das publicações científicas.

Nesse sentido, o objetivo geral desta pesquisa é contribuir com o processo de avaliação da produção científica nacional por meio de análise das fontes de informação que compõem os critérios de classificação dos periódicos utilizados nas áreas de ciências sociais aplicadas. Os objetivos específicos são: 1) identificar as fontes de informação que podem ser classificadas efetivamente como base de dados, segundo critérios específicos que permitam atestar a qualidade científica e/ou editorial; 2) identificar que fontes de informação possuem critérios de seleção específicos que permitam atestar a qualidade científica e/ou editorial e se os disponibilizam em seus sites; 3) avaliar o uso que tem sido feito dessas fontes nas diferentes áreas de avaliação.

Espera-se, assim, contribuir com o processo de avaliação da Capes e de outras agências de ciência e tecnologia (CASTRO, 2011), oferecendo subsídios que deem às fontes de informação maior transparência no processo 
de seleção de periódicos, uma vez que são importantes instrumentos qualificadores da produção científica nacional.

Com base no estudo de Castro (2011) percebeu-se uma lacuna em relação ao tema de pesquisa escolhido nesta dissertação, que se justifica pelos seguintes argumentos: 1) "[...] os parâmetros de avaliação do mérito das bases de dados não têm sido tão difundidos e discutidos quanto os das revistas científicas [...]" (p. 111); 2) a análise dos processos de seleção das bases de dados permitirá identificar os níveis de mérito de cada base ou repositório e, como consequência, o grau de validação que cada um deles confere aos periódicos que indexa; 3) “[...] conhecer os critérios e os graus de complexidade e restrições é fundamental para entender as diferenças entre as bases e para categorizá-las, de acordo com esses critérios, em níveis de qualidade do conteúdo indexado [...]" (p. 113).

O capítulo 2 desta dissertação trata dos periódicos científicos e das fontes de informação, por sua relevância para a comunicação científica, abordando pontos como os critérios de qualidade das publicações e o surgimento e caracterização das fontes de informação.

No capítulo 3 são tratadas a política científica e a forma de avaliação da pós-graduação, abordando aspectos da ciência e um histórico do desenvolvimento científico no mundo e no Brasil.

O capítulo 4 apresenta a metodologia desta pesquisa, enquanto o capítulo 5 apresenta os seus resultados, por meio da análise das bases de dados CLACSO; CLASE; CMMC ${ }^{\mathrm{TM}}$; ComABSTRACTS; Communication Abstracts; DOAJ; Index to Journals in Communication Studies (impresso); INFOBILA; Thomson Reuters (Web of Science e JCR); LAPTOC; Latindex; Library Literature \& Information Science Index; LISA; Pascal Thema; Redalyc; SciELO; e Scopus.

No capítulo 6 são apresentadas as considerações finais do estudo. 


\section{PERIÓDICOS CIENTÍFICOS E FONTES DE INFORMAÇÃO: RELEVÂNCIA PARA A COMUNICAÇÃO CIENTÍFICA}

\subsection{ORIGEM DOS PERIÓDICOS CIENTÍFICOS}

Para que seja possível realizar uma análise acerca do surgimento dos periódicos científicos como meios de comunicação da ciência, faz-se necessário retornar aos seus primórdios. Sua origem são os debates orais acadêmicos realizados pelos filósofos gregos, entre os séculos $V$ e IV a.C., e posteriormente registrados na forma escrita. Igualmente, a produção cultural e filosófica da civilização romana também foi preservada em manuscritos. Traduzida e preservada graças principalmente ao trabalho dos monges copistas, nos mosteiros medievais europeus, essa produção ancorou 0 Renascimento, entre os séculos XIV e XVI, sendo até hoje a base do pensamento filosófico ocidental (MEADOWS, 1999).

Não se sabe ao certo quando teve início a comunicação científica. Sabese que até meados do século XVII ela se restringia à troca de correspondência entre os pesquisadores, sendo esporádicas as publicações de panfletos e livros sobre ciência. No século XIX, com a produção de livros em escala industrial ${ }^{1}$, a comunicação escrita floresceu na Europa Ocidental, sendo multiplicado o número de exemplares de obras importantes para a ciência moderna, disseminando, ao mesmo tempo, todo tipo de conhecimento (MEADOWS, 1999).

Para Otlet (2007) é difícil distinguir o "nascimento" ou o início exato dos periódicos reconhecidos como científicos, uma vez que uma obra periódica era aquela que continha estratos de livros recém-impressos, detalhando as novas descobertas feitas nas artes e nas ciências. Durante um período, os catálogos de livros que incluíam notas e comentários sobre as obras também tinham

\footnotetext{
${ }^{1}$ Em 1442 foi impresso o primeiro exemplar em prensa tipográfica, criada pelo alemão Johann Gutenberg. Em 1448, em sociedade com Johann Fust, ele fundou a Fábrica de Livros (nome original Werk der Buchei), responsável, entre outras produções, pela Bíblia de Gutenberg, de 42 linhas. Disponível em: <http://www.usp.br/espacoaberto/arquivo/2002/espaco24out/vaipara.php?materia=0varia>. Acesso em: 17 ago. 2013.
} 
status científico. Os países que se destacaram nesse modelo foram França, Inglaterra e Alemanha (OTLET, 2007).

Acredita-se que essa fase foi o embrião do que viria a ser o periódico científico como conhecido hoje. Otlet (2007) enfatiza, ainda, que esses estratos de livros otimizavam a obtenção de informação e conhecimento de pessoas muito ocupadas ou "preguiçosas".

A ciência disseminou-se partir do século XIV graças à ampla aceitação do método científico. Com isso, começaram a se fortalecer as sociedades e academias de ciências. As primeiras a se tornarem conhecidas foram a Academia dei Lincei, em Roma (1600 a 1630), a Royal Society, fundada em 1622, em Londres, e a Académie Royal de Sciences, criada informalmente em 1666, na França, e mais tarde transformada em Académie des Sciences (BIOJONE, 2003). O objetivo dessas instituições era reunir pessoas interessadas em determinado campo de conhecimento, viabilizando a troca de experiências sobre suas pesquisas. Tais sociedades científicas eram:

associações que agrupavam pessoas interessadas em determinados temas, patrocinadas pelas universidades, mecenas ou figuras de destaque, e tinham como principal objetivo facilitar a comunicação e a discussão dos novos conhecimentos de uma forma mais direta do que permitiam os livros (SABATTINI, 1999 apud BIOJONE, 2003, p. 20).

Nesse contexto, a londrina Royal Society desempenhou um importante papel no desenvolvimento da comunicação científica, uma vez que se preocupava tanto da divulgação dos trabalhos de seus associados quanto de mantê-los atualizados, promovendo a troca de informações entre os pesquisadores locais e estrangeiros. A ampla correspondência com os pesquisadores de outros países favorecia a reprodução, compilação e distribuição do material resultante de tais cartas.

Esse sistema, mais tarde, deu origem ao Philosophical transctions of the Royal Society of Londres e ao Journal des Scavans, ambos publicados pela primeira vez em 1665 (BIOJONE, 2003). São, por isso, considerados os primeiros periódicos da história, definidos como: 
um marco da concepção cartesiana de mundo em oposição à concepção aristotélica e católica, expressando um novo paradigma da ciência, no período das revoluções científicas. Trata-se de uma instituição que reúne as condições para institucionalizar os procedimentos seculares visando ao estabelecimento de um sistema de comunicação da ciência, segundo os moldes sugeridos nos trabalhos de Francis Bacon (WEITZEL, 2005, p. 166).

Até por volta do século XVIII os meios oficiais aceitos para publicação de pesquisas científicas eram apenas os livros, sendo os artigos publicados em periódicos considerados formas provisórias de comunicação, por serem mais breves, resumidos e objetivos. Somente a partir de meados do século XVIII a visão de que cada artigo forma uma unidade por si só começou a ser aceita. Contudo, a aceitação tácita do periódico como meio de comunicação científica capaz de substituir os livros só ocorreu por volta do século XX (STUMPF, 1996).

As primeiras revistas que veicularam informação científica no Brasil foram: Miscelânia Scientífica, em 1835; Nictheroy, em 1836; e Minerva Braziliense, em 1843 (CARVALHO, 2011). Já Hayashi (2008) aponta como pioneiras a Gazeta Médica do Rio de Janeiro (1862), a Gazeta Médica da Bahia (1866) e a Academia de Ciências, que em 1917 começou a publicar regularmente os seus Anais, os quais receberam o nome de Revista da Sociedade Brasileira de Ciências.

Embora a preocupação com a comunicação da ciência seja localizada desde o século XVII, somente a partir de meados do século $X X$ ela foi sistematizada e disseminada, momento que ficou conhecido como o da "explosão da informação" (BIOJONE, 2003). Antes, no final do século XIX, foram criadas as revistas de maior vulto para a ciência, como, por exemplo, a Classical Review, lançada em 1887. Isso se deu porque a quantidade de cientistas aumentara consideravelmente, assim como aumentara a necessidade, a rapidez e a extensão (ou alcance) da comunicação (OTLET, 2007).

Já no início do século XX, segundo narrativa de Otlet (2007), em termos de formato os periódicos estavam mais parecidos com o que se conhece atualmente: 
La revista comprende tres elementos fundamentales: a) las rúbricas permanentes que permiten seguir la ciencia o el objeto de la publicación periódica, el movimiento bajo sus diversos aspectos; b) los estudios sobre puntos particulares (monografías); c) los estudios sintéticos que exponen un problema en toda su extensión y complejidad. Un buen periódico especializado se compone pues de rubricas, variables o permanentes. Eventualmente se compone de: $1^{\circ}$ una editorial que presenta algunos hechos, señalando su importancia; $2^{\circ}$ artículos de fondo; $3^{\circ}$ mezclas y variedades, documentos inéditos, notas, críticas, etc.; $4^{\circ}$ bibliografías metódicas (información crítica); $5^{\circ}$ una crónica que da precisiones sobre los trabajos emprendidos o en curso, el estado actual de una cuestión, detalles que interesan a las personas, etc. (p. 145).

\subsection{FUNÇÕES DOS PERIÓDICOS CIENTÍFICOS}

Existe atualmente um grande número de periódicos científicos cuja função vai muito além de apenas divulgar resultados de pesquisas. De acordo com a Royal Society of London, são quatro as suas principais funções:

- comunicação formal dos resultados da pesquisa original para a comunidade científica e demais interessados (finalidade primordial que permanece inalterada);

- preservação do conhecimento registrado: os periódicos constituem um arquivo das ideias dos pesquisadores, bem como dos resultados das suas pesquisas e observações, permitindo acesso a tais dados ao longo do tempo e impedindo que as informações se percam;

- estabelecimento da propriedade intelectual: ao publicar seus estudos em um periódico o autor registra formalmente a sua autoria, requerendo para si a descoberta científica; e

- manutenção do padrão de qualidade na ciência: os periódicos dispõem de um corpo de avaliadores respeitado, o que confere confiabilidade ao material a ser publicado (MUELLER, 2000).

Seguindo nessa mesma linha, Miranda (2012) compilou as visões de diversos autores sobre as funções dos periódicos científicos na atualidade, descrevendo da seguinte forma as suas funções: 
$\checkmark$ registrar o conhecimento;

$\checkmark$ constituir-se na memória da ciência;

$\checkmark$ disseminar o conhecimento;

$\checkmark$ salvaguardar a prioridade das descobertas e estabelecer a propriedade intelectual;

$\checkmark$ aprovar os novos conhecimentos produzidos, fortalecendo a geração de saberes;

$\checkmark$ conferir prestígio e recompensar autores, editores e membros do conselho editorial;

$\checkmark$ definir e legitimar novas disciplinas e campos de estudo;

$\checkmark$ servir como fonte de informação para novos estudos;

$\checkmark$ indicar a evolução de uma ciência;

$\checkmark$ indicar $o$ andamento de atividades científicas realizadas por pesquisadores, grupos de pesquisadores e instituições;

$\checkmark$ fomentar a integração entre autores, editores, revisores, pesquisadores, enfim, todos os envolvidos no processo de produção e disseminação do conhecimento científico;

$\checkmark$ manter o padrão da qualidade da ciência; e

$\checkmark$ ser um canal de comunicação que viabilize o desenvolvimento científico da área e do país onde é publicado.

De acordo com Mueller (2000), um dos mais relevantes aspectos da comunicação científica por meio dos periódicos, e também dos principais responsáveis pela grande aceitação e pelo sucesso desse método de comunicação, é a confiabilidade que ela proporciona. A confiabilidade é, portanto, uma das características mais importantes da ciência, pois a distingue do conhecimento popular, não científico. Além da utilização de uma rigorosa metodologia científica para geração do conhecimento, para obter confiabilidade é importante que os resultados obtidos pelas pesquisas de um cientista sejam divulgados e submetidos ao julgamento de outros cientistas, seus pares.

Quando um pesquisador não publica os resultados de suas pesquisas joga no limbo todo o seu trabalho, todo o investimento físico, humano e financeiro empregados em tal estudo. Considerando que toda pesquisa envolve 
mais do que o pesquisador, um estudioso que não compartilha suas descobertas com a comunidade acadêmica e com a sociedade em geral age egoistamente e não cumpre o seu papel social (WITTER, 2011). É nesse sentido que os periódicos se apresentam como importante fonte de divulgação e expansão do conhecimento científico, cumprindo, assim, também um papel social.

Atualmente, os periódicos são publicações seriadas, com características próprias, arbitrados por pares, reconhecidos e utilizados pela comunidade científica para divulgação de suas pesquisas. A publicação do estudo em um periódico permite a ascensão e o reconhecimento do cientista/pesquisador em seu meio, uma vez que publicar artigos é exigido como prova de atividade na pesquisa científica (MIRANDA; PEREIRA, 1996).

O progresso do pesquisador na comunidade a que pertence é constantemente avaliado com base em sua produtividade e publicação de seus estudos em periódicos especializados e de qualidade comprovada, provendo, assim, visibilidade e acessibilidade à sua produção científica. A publicação de artigos científicos também funciona como um indicador de performance acadêmica junto a instituições de fomento, além de proporcionar reconhecimento pessoal.

De acordo com Miranda e Pereira (1996), para que o periódico seja capaz de cumprir todas as suas funções é necessário que se estabeleça e se consolide. Tal consolidação só ocorre na presença da comunidade científica e com o fomento das atividades de pesquisa. Seu desenvolvimento vai depender de fatores como:

- estágio de desenvolvimento da área científica cujas ideias ele veicula;

- comunidade engajada na atividade de pesquisa e da afluência de artigos para publicação;

- existência de grupos e instituições que desempenhem funções típicas de edição, avaliação, publicação, disseminação e recuperação;

- existência de mercado representado por uma comunidade de usuários que o legitime; e

- infraestrutura para distribuição, recuperação e acesso às informações. 
Ainda segundo as autoras, as funções de disseminação do conhecimento científico e de recuperação de artigos são de grande importância para a visibilidade do periódico e também dos autores e editores.

O trabalho científico é um elemento universal e vital para o avanço da ciência, em que "nada se cria, nada se perde". Diante de toda a literatura disponível, cabe ao cientista explorá-la e conhecer as conquistas por ela já alçadas, para que possa dar continuidade ao desenvolvimento do objeto de sua área (MUGNAINI, 2006).

Finalmente, Ríos (2000 apud LÓPEZ ORNELAS; CORDERO ARROYO, 2005) afirma que o desempenho dessas funções faz com que o conhecimento seja construído e difundido, permitindo assim que as publicações se tornem um exemplo mais representativo da "[...] ciência que nutre a ciência [...]" (MUGNAINI, 2006, p. 4).

\title{
2.3 CARACTERIZAÇÃO DOS PERIÓDICOS CIENTÍFICOS
}

Paul Otlet, em seu Tratado de documentação, cuja primeira versão foi publicada em Bruxelas, em 1934, conceitua as publicações periódicas de forma geral:

\begin{abstract}
Por publicaciones periódicas se entiende en sentido amplio los periódicos políticos, literarios, científicos o profesionales, así como las publicaciones de mismo orden que aparecen periódicamente (periódicos de moda y publicaciones publicitarias). En sentido restringido una publicación periódica o "publicación en serie" es cualquier publicación que aparece a intervalos regulares o irregulares, con una numeración consecutiva y con un término no fijado con anterioridad. Salvo excepción, esta publicación se debe a una colaboración. En general está especializada en cuanto a un tema y en cuanto a los países, regiones o localidades (2007, p. 142-143).
\end{abstract}

Stumpf chama a atenção para as características próprias dos periódicos, revelando que são publicações:

feitas em partes ou fascículos, numeradas progressiva ou cronologicamente, reunidas sob um título comum, editadas em intervalos regulares, com a intenção de continuidade infinita, 
formadas por contribuições, na forma de artigos assinados, sob a direção de um editor, com um plano definido que indica a necessidade de um planejamento prévio (1998, p. 2).

Considerado como um arquivo oficial da comunidade cientifica, o periódico pode ser classificado de diversas maneiras. De acordo com os critérios da United Nations Educational, Scientific and Cultural Organization (Unesco), eles podem ser divididos em:

- de informação: periódicos que indicam programas científicos, técnicos, educativos ou econômicos, anunciam reuniões, informam a respeito de pessoas, principalmente em forma de artigos ou notas breves, que contêm informação geral ou detalhada;

- primários: também conhecidos como periódicos de investigação e desenvolvimento. Neles são publicados os resultados de pesquisas com todos os detalhes necessários para se comprovar a validade das argumentações do autor;

- de resumos ou secundários: que reúnem o conteúdo de periódicos primários, de forma resumida; e

- de progressos científicos ou tecnológicos: chamados por alguns autores de "periódicos terciários", publicam informes resumidos dos principais programas de investigação contidos nos periódicos primários, cobrindo períodos amplos.

De acordo com a Coordenação de Aperfeiçoamento de Pessoal de Nível Superior (Capes), os periódicos são definidos como publicação seriada, arbitrados e dirigidos prioritariamente à comunidade acadêmico-científica. Ainda segundo o órgão, para que uma publicação seja considerada um periódico científico alguns critérios devem ser rigorosamente apresentados. São eles:

$\checkmark$ ter um editor responsável;

$\checkmark$ contar com uma comissão editorial que auxilie o editor na tomada de decisões;

$\checkmark$ possuir o apoio de um conselho consultivo, formado por pesquisadores de diferentes instituições; 
$\checkmark$ ter registro de ISSN ${ }^{2}$;

$\checkmark$ contar com uma linha editorial definida: missão, foco temático, periodicidade e forma de avaliação/revisão;

$\checkmark$ ter periodicidade regular definida;

$\checkmark$ contar com avaliação dos artigos por membros do conselho consultivo ou pareceristas ad hoc;

$\checkmark$ publicar contribuições na forma de artigos assinados;

$\checkmark$ indicar a titulação e afiliação institucional dos autores;

$\checkmark$ indicar a titulação e afiliação institucional dos membros do conselho consultivo ou dos pareceristas ad hoc;

$\checkmark$ em se tratando de revista nacional, disponibilizar o título, o resumo e as palavras-chave no mínimo em dois idiomas, sendo um deles o português; e

$\checkmark$ informar datas de recebimento e aceitação de cada artigo.

Já para a Associação Brasileira de Normas Técnicas (ABNT), NBR 6023/2002, um periódico científico é definido como "[...] uma publicação em qualquer tipo de suporte, editada em unidades físicas sucessivas, com designação numérica e/ou cronológica e destinada a ser continuada indefinidamente [...]" (2002, p. 2). Ainda de acordo com a NBR/ABNT, os elementos essenciais para que um periódico seja considerado em conformidade com as normas para publicação de periódicos são:

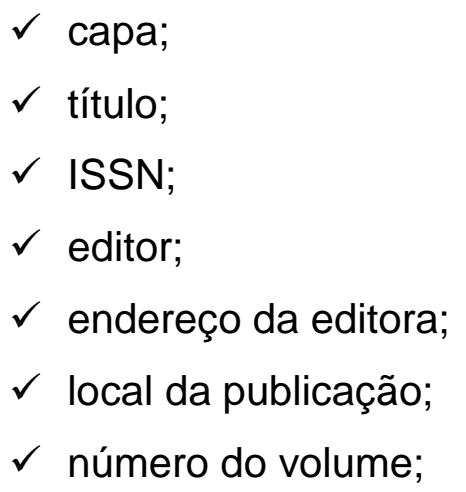

2 Código numérico que constitui um identificador unívoco para cada título de publicação em série, cujos componentes não têm um significado especial em si próprios. O sistema ISSN é definido pela norma ISSO 3297: 2007 - Information and Documentation. International Standard Serial Number ISSN, gerida pelo ISSN International $\quad$ Centre. <http://www.bnportugal.pt/index.php?option=com_content\&view=article\&id=154\&ltemid=191>. Acesso em: 17 ago. 2013. 
$\checkmark$ número do fascículo;

$\checkmark$ folha de rosto;

$\checkmark$ legenda bibliográfica da folha de rosto;

$\checkmark$ sumário;

$\checkmark$ título do artigo;

$\checkmark$ nome(s) do(s) autor(es);

$\checkmark$ classificação do artigo;

$\checkmark$ data da publicação;

$\checkmark$ resumo;

$\checkmark$ legenda bibliográfica das páginas do texto;

$\checkmark$ paginação;

$\checkmark$ periodicidade; $\mathrm{e}$

$\checkmark$ referências bibliográficas.

No que diz respeito à limitação geográfica e suas categorias, Barbalho (2005) observa que os periódicos podem ser internacionais, abrangendo as publicações que disseminam resultados de pesquisas de interesse da comunidade científica internacional; nacionais, referindo-se a títulos que divulgam resultados de pesquisa de interesse nacional e regional; e locais, que atendem e divulgam resultados de pesquisas de determinadas instituições ou comunidades científicas, objetivando assegurar a memória institucional.

Day (1998 apud LÓPEZ ORNELAS; CORDERO ARROYO, 2005) divide os periódicos em três níveis. O primeiro abrange as publicações sob responsabilidade de associações científicas reconhecidas pela comunidade internacional. Essas publicações normalmente contam com cotas de seus sócios, o que reduz os custos de produção e circulação (inclusive para assinaturas), tendo maior presença na área de interesse do estudo. O segundo nível envolve as publicações editadas e comercializas por grandes editores internacionais. Esse respaldo eleva seus custos, inclusive para submissão de artigos pelos autores, mas apresenta como principal vantagem grande circulação e, consequentemente, maior impacto. No terceiro nível encontramse os periódicos editados por instituições públicas, cujo maior exemplo são as publicações vinculadas às universidades. Em razão de sua dependência 
natural à estrutura administrativa das instituições a que pertencem, esses periódicos apresentam os maiores problemas de financiamento (dependência e restrições de verbas), recursos humanos (trocas de funcionários) e ineficácia na divulgação e distribuição, entre outras limitações que afetam principalmente a sua periodicidade.

Ao resumir as ideias de diversos autores, Barbalho (2005, p. 128) elaborou o seguinte conceito de periódico científico: "[...] canal de disseminação da ciência, publicado em períodos de tempo predefinidos, reunindo artigos de diversas autorias, e que apresentam rigor científico e metodológico". Com o propósito de validar os resultados da ciência e fomentar a utilização dos indicadores científicos, eles também auxiliam os pesquisadores na publicação de seus resultados de pesquisa, divulgando-os em um local considerado "nobre", neste caso, o periódico científico (OHIRA, et al., 2000).

Atualmente estão sendo desenvolvidos diversos periódicos científicos eletrônicos, também denominados digitais. Essas publicações surgiram em decorrência da introdução das TIC, que modificaram tanto o ambiente quanto o acesso às publicações, uma vez que possibilitaram a interatividade e o uso de hipertextos e multimídia (SILVA et al., 2011).

O periódico eletrônico é conceituado como "[...] um conjunto de artigos organizados, normatizados, e publicados sob a responsabilidade de uma instituição que pode ser comercial ou uma sociedade de caráter científico ou técnico; e cuja distribuição se faça exclusivamente por meio da rede eletrônica - Internet; fazendo o uso dos serviços e valores adjuntos que decorrem deste [sic] recursos eletrônico [...]" (BARRUECO; CORDÓN, 1997 apud SILVA et al., 2, p. 73).

\subsection{CRITÉRIOS DE QUALIDADE DOS PERIÓDICOS CIENTÍFICOS}

A partir da década de 1960 houve uma expressiva expansão no número de pesquisas científicas. Em consequência, a procura por meios de divulgação de tais pesquisas foi ampliada consideravelmente, conforme aponta o gráfico a seguir. 
Gráfico 1 - Número de revistas científicas correntes em relação à data.

Número

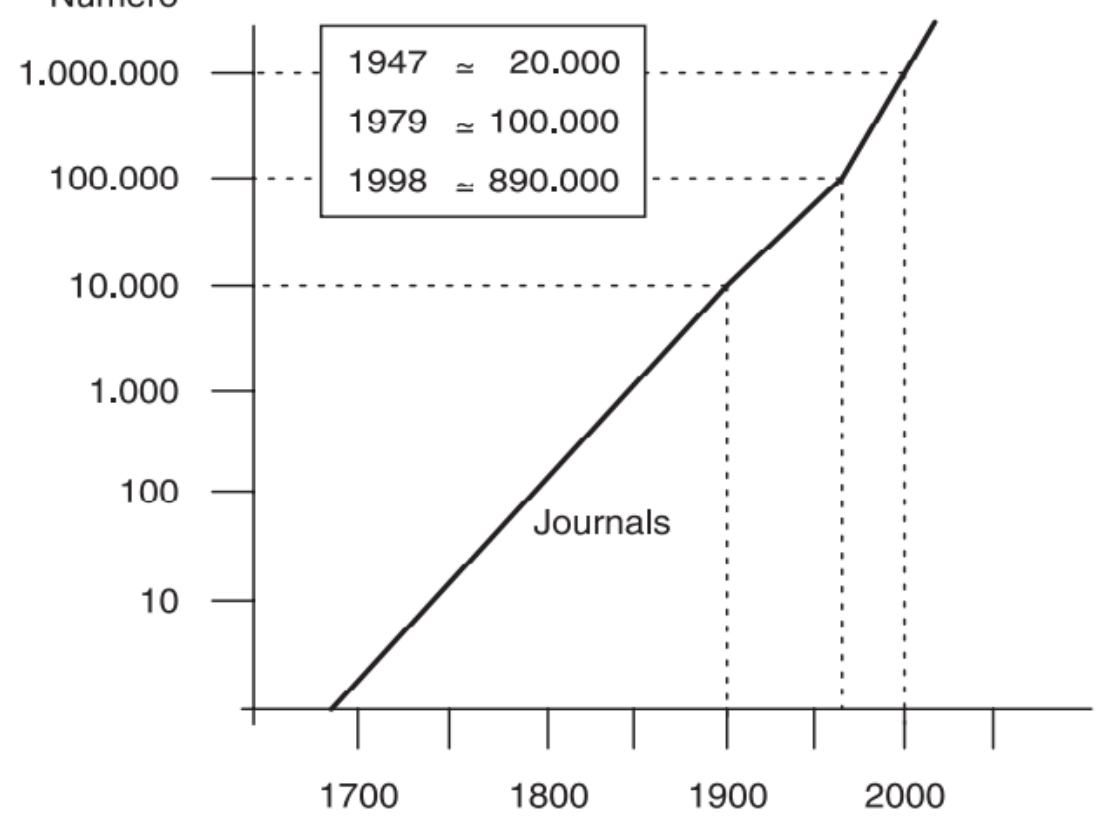

Fonte: WIEERS apud FERREIRA; KRZYZANOWSKI, 2003, p. 43

Com a crescente ampliação no número de publicações, aumentou também a preocupação com a qualidade de tais materiais. Afinal, apontam FERREIRA e KRZYZANOWSKI (2003), se uma das principais qualidades dos periódicos científicos é a confiabilidade, esse é um aspecto que não pode de modo algum ser negligenciado. Nessa perspectiva, os autores apresentam uma cronologia das principais publicações latino-americanas que visaram estabelecer parâmetros de qualidade para os periódicos científicos, conforme citado a seguir. 
Quadro 1 - Cronologia das principais publicações periódicas.

\begin{tabular}{|c|l|}
\hline Ano & Principais publicações \\
\hline 1964 & $\begin{array}{l}\text { É criado pela UNESCO um modelo de mensuração para avaliação das revistas } \\
\text { latino-americanas, que as classifica em categorias que variam entre deficientes e } \\
\text { excelentes. }\end{array}$ \\
\hline 1968 & $\begin{array}{l}\text { Com base no modelo da UNESCO, Arends estabelece critérios relacionados à } \\
\text { apresentação do material, sua regularidade, tempo de existência etc. }\end{array}$ \\
\hline 1982 & $\begin{array}{l}\text { Braga et al. apresentam um modelo de avaliação diferente do modelo da } \\
\text { Unesco, avaliando aspectos da forma dos periódicos, dentro de parâmetros } \\
\text { mensuráveis. }\end{array}$ \\
\hline 1985 & $\begin{array}{l}\text { Yahn, utilizando o modelo de Braga, introduz modificações ao modelo e sugere } \\
\text { que o resultado abranja a avaliação conjunta de mérito e desempenho. }\end{array}$ \\
\hline 1986 & $\begin{array}{l}\text { Martins avalia diversos títulos visando verificar itens referentes à normalização, } \\
\text { segundo as normas da ABNT. }\end{array}$ \\
\hline 1991 & $\begin{array}{l}\text { Krzyzanowski et al. dão sequência ao projeto de avaliação dos periódicos } \\
\text { científicos brasileiros com a intenção de refinar e atualizar o núcleo de revistas } \\
\text { científicas nacionais, tendo como princípio a avaliação de mérito pelos pares. }\end{array}$ \\
\hline 1996 & $\begin{array}{l}\text { Castro e Ferreira realizam a avaliação de diversos periódicos latino-americanos } \\
\text { com a intenção de verificar se as características formais e de divulgação eram } \\
\text { indicativas de qualidade. }\end{array}$ \\
\hline 1997 & $\begin{array}{l}\text { É realizada pela BIREME } \\
\text { privilegiando a coleta de dados acerca das instruções dos autores. }\end{array}$ \\
\hline 1998 & $\begin{array}{l}\text { Krzyzanowski e Ferreira realizam, a pedido das agências financiadoras, uma } \\
\text { avaliação de periódicos financiados pelas agências utilizando um método } \\
\text { baseado no método de Braga; concluem que a avaliação dos periódicos deve ser } \\
\text { feita tanto no quesito conteúdo quanto na apresentação. }\end{array}$ \\
\hline 1999 & Yamamoto realiza uma avaliação dos periódicos científicos em psicologia. \\
\hline
\end{tabular}

Fonte: FERREIRA; KRZYZANOWSKI, 2003

Por meio de todos esses estudos, que refletiram similarmente preocupação com a qualidade dos conteúdos publicados, os achados convergiram basicamente para as mesmas vertentes, destacando-se aquelas referentes ao conteúdo e à normalização.

Em relação ao conteúdo, de acordo com Krzyzanowski e Ferreira (2003), devem ser levados em consideração:

\footnotetext{
${ }^{3}$ O Centro Latino-Americano e do Caribe de Informação em Ciências da Saúde, também conhecido pelo seu nome original Biblioteca Regional de Medicina (BIREME), é um centro especializado da Organização Pan-Americana da Saúde/Organização Mundial da Saúde, orientado à cooperação técnica em informação científica em saúde. A sede da BIREME está localizada no Brasil, no campus central da Universidade Federal de São Paulo (Unifesp), desde a sua criação, em 1967, conforme acordo entre a OPAS e o governo brasileiro. Disponível em: <http://www.paho.org/bireme/index.php?option=com content\&view=article\&id=37\&ltemid=55\&lang=pt $>$.
} 
- qualidade dos artigos - nível científico, atualidade, identificação com a orientação temática da revista e percentual de artigos originais;

- qualidade do corpo editorial e dos consultores - participação de membros da comunidade científica nacional e internacional;

- critérios de arbitragem dos textos;

- natureza do órgão publicador - os periódicos devem ser editados de preferência por instituição de ensino, pesquisa e sociedade científica;

- abrangência quanto à origem dos trabalhos - abertura da revista para autores de nível institucional, nacional e internacional;

- difusão da revista - a distribuição e a divulgação devem ser as mais amplas possíveis; e

- indexação - a revista deve pleitear a inclusão em bases de dados nacionais e internacionais, de acordo com a área ou temática que abrange. Quanto maior o número de bases de dados nacionais e internacionais em que figurar, maior será a valorização de qualidade, produtividade e sua difusão indireta.

Já no que diz respeito à normalização, os autores apontam para a necessidade imprescindível de se seguir rigorosamente as normas adotadas, sejam elas as da ABNT, do grupo Vancouver, da American Psychological Association ou de outra qualquer.

Atualmente, os critérios propostos para avaliação dos periódicos baseiam-se, principalmente, na apreciação da qualidade dos artigos, apresentação do material, duração, periodicidade, aceitação de colaboradores de outras instituições, nível de especialização e indexação (SARMENTO; SOUZA, 2002).

No próximo item são expostos critérios mais comuns utilizados, hoje, por bases de dados nacionais e internacionais para avaliação e caracterização dos periódicos científicos. 


\subsubsection{Tempo de Existência}

O tempo de existência é um indicador de credibilidade e valorização da publicação, pois o periódico passa a ser considerado importante somente depois de ser disseminado e citado pela comunidade científica. É após esse período, também, que o Fator de Impacto passa a ser computado para cada publicação.

Normalmente, o tempo de existência é um critério muito importante para as bases de dados, no processo de avaliação. Pode-se confirmar esse fato nos critérios apresentados pela base de dados $\mathrm{SciELO}^{4}$, que somente considera em seu processo de avaliação periódicos que tenham publicado no mínimo quatro fascículos.

Esse é um critério que deve ser bastante observado pelos autores no momento da escolha do veículo para disseminação de suas pesquisas, pois, segundo Ferreira e Krzyzanowski (2003, p. 45), "[...] os periódicos que conseguem manter vida longa são bastante valorizados."

\subsubsection{Periodicidade}

A periodicidade é um dos indicadores mais importantes para a avaliação da qualidade efetiva dos periódicos científicos. Segundo Fachin (2002, p. 101) "[...] este critério [...] é responsável pelo reconhecimento da publicação como um periódico científico de qualidade, além de ser ponto referencial do mesmo para o reconhecimento das bibliografias da área."

$\mathrm{Na}$ década de 1960 foi criada uma metodologia para avaliação de periódicos por um grupo de trabalho da Unesco pautada nos critérios de qualidade extrínsecos (BRAGA; OBERHOFER, 1982). Alguns desses critérios são: a normalização, a periodicidade regular, o padrão gráfico, a tiragem e o tempo de existência. Entre os critérios intrínsecos estão a autoridade do corpo editorial e a qualidade científica dos manuscritos.

\footnotetext{
${ }^{4}$ A Scientific Electronic Library Online é uma biblioteca eletrônica que abrange uma coleção selecionada de periódicos científicos brasileiros. O projeto tem por objetivo o desenvolvimento de uma metodologia comum para a preparação, armazenamento, disseminação e avaliação da produção científica em formato eletrônico. Disponível em: <http://www.scielo.br/scielo.php?script=sci home\&lng=pt\&nrm=iso> .
} 
De acordo com Testa (1998), para medir a periodicidade adequadamente uma decisão sobre a abrangência jamais pode ser baseada em apenas um fascículo; geralmente é necessário analisar pelo menos três exemplares diferentes.

Sabe-se que algumas áreas, como a das ciências da saúde, precisam publicar seus resultados de forma rápida para que suas pesquisas não fiquem obsoletas; já as ciências humanas têm uma cultura voltada para a publicação de livros, o que permite que seus estudos sejam publicados em um tempo maior, sem que isso prejudique o pesquisador e/ou o periódico.

As publicações científicas podem ter periodicidade anual, semestral, quadrimestral, trimestral, bimestral ou mensal. A periodicidade regular é um dos critérios fundamentais para o processo de consolidação e credibilidade de um periódico, considerado como um "[...] indicador do fluxo da produção científica, é também um indicador relacionado com a oportunidade e velocidade da comunicação [...]" (SciELO, 2012).

\subsubsection{Regularidade ou Pontualidade}

A regularidade refere-se ao cumprimento da periodicidade determinada pela própria publicação. O fato de o editor não publicar pontualmente um periódico pode indicar problemas muito mais sérios do que somente um atraso na divulgação, estando, eventualmente, relacionado com a gestão.

Para que o periódico seja publicado de acordo com a sua regularidade é necessário que haja uma boa gestão editorial, pois "[...] a habilidade de publicar pontualmente um periódico implica um substancial estoque de manuscritos indispensáveis para sua viabilidade ininterrupta [...]" (GARFIELD apud TESTA, 1998, p. 234).

Os atrasos na publicação podem acarretar diversos problemas ao processo de comunicação científica, prejudicando tanto a divulgação imediata das descobertas à comunidade científica quanto gerar entraves na obtenção de financiamento. 


\subsubsection{Legenda Bibliográfica}

A legenda bibliográfica dos periódicos traz itens avaliados como importantes, de acordo com a norma utilizada. Nesse sentido, a ABNT descreve a legenda bibliográfica como um conjunto de elementos destinados à identificação de um fascículo e/ou volume da publicação e dos artigos nela contidos (ABNT, 2003).

É importante que o periódico apresente os dados da legenda bibliográfica de forma completa, contendo os elementos padronizados e título abreviado, seguindo o padrão cadastrado no ISSN. A partir daí, torna-se mais fácil e precisa a recuperação da informação e a seguridade de que o periódico seja citado, bem como sua bibliometria computada corretamente, beneficiando os autores e o próprio periódico.

\subsubsection{Data de Recebimento e Aprovação dos Artigos}

A citação das datas de recebimento e aceitação reflete o anseio da comunidade científica em poder tomar uma decisão quanto à alegação de prioridade intelectual. Dessa forma, a revista científica contribui para esclarecer a questão de pioneirismo em determinado tópico (SARMENTO; SOUZA, 2002).

Além disso, a divulgação dessas informações pode ser considerada como um identificador importantíssimo no momento da avaliação do periódico, pois, através da publicação das datas de recebimento e aceitação, é possível saber quanto tempo se levou para avaliar tal artigo e também possíveis falhas no processo de avaliação e gestão editorial do periódico. Essa análise pode ser realizada quando levamos em consideração a data em que o documento deu entrada e o tempo que o periódico levou para avaliá-lo e publicá-lo.

\subsubsection{Peer Review/Processo de Revisão por Pares}

O processo de avaliação de artigos a serem publicados teve origem em 1665, quando a Académie des Sciences, de Paris, e a Royal Society, de Londres, instituíram um grupo de referees para a revisão de manuscritos 
submetidos a seus periódicos, o Journal des Sçavans e o Philisophical Transactions, respectivamente (DAVYT; VELHO, 2000). Contudo, a disseminação dessa prática ocorreu somente após a Segunda Guerra Mundial, impulsionada pelo "[...] crescimento exponencial do número de pesquisadores, à fragmentação da ciência em subdisciplinas e ao desenvolvimento de vocabulários específicos [...]" (PESSANHA, 1998, p. 226).

O autor ainda destaca que o início oficial do sistema de revisão por pares ocorreu em 1753, quando a Royal Society of London passou a responsabilizar-se formalmente pela avaliação dos textos publicados. A necessidade de organizar e selecionar o material a ser publicado fez surgir os dois principais atores no processo de avaliação: o editor científico, então representado pelo secretário da sociedade e encarregado da organização da revista, e os avaliadores, representados pelo seu conselho (PESSANHA, 1998).

No campo científico, a publicação de artigos acadêmicos constitui-se uma poderosa ferramenta do cientista para a comunicação da sua pesquisa à comunidade de sua área: "Os cientistas se esforçam para convencer seus pares da validade de suas descobertas dentro de um contexto persuasivo, tornando o artigo científico um processo retórico [...]" (GROSS apud FERREIRA et al., 2009, p.13).

O processo de peer review envolve o uso sistemático de árbitros para assessorar na aceitação de manuscritos submetidos à publicação, geralmente executado por revisores externos. Ou seja, revisores que não pertencem ao corpo editorial do periódico, pois,

com a especialização e o aumento do número de trabalhos, os editores se viram impossibilitados de executar, sem auxílio externo, esta função. Considera-se que cabe ao editor, ao receber um original, decidir se é compatível ou não com a política editorial do periódico. Em caso positivo, o editor ou editor associado geralmente escolhe o revisor, cabendo-lhe ainda, na maior parte das vezes, a decisão final quanto à publicação de um manuscrito, mesmo após sua revisão (DANCIK, 1991 apud CASTRO et al., 1996).

De acordo com Zuckerman e Merton (apud PESSANHA, 1998, p. 226), esse sistema não surgiu de forma pronta e acabada e, da mesma forma que a 
instituição social da ciência, "[...] evoluiu em resposta aos 'problemas concretos' com que se defrontaram os cientistas no processo de desenvolvimento da pesquisa... [e] ...como subproduto da emergente organização social dos cientistas."

Apesar de apresentar grandes vantagens e ser aceito pela comunidade científica, Pessanha (1998, p. 227) destaca que o "[...] sistema de revisão por pares sofreu uma série de críticas motivadas pelas distorções do seu uso [...]", acrescentando que, além de problemas éticos, "[...] a avaliação dos artigos pode, simplesmente, conter erro de julgamento ou avaliação. Para fazer face às distorções apontadas nesse sistema, vários mecanismos e procedimentos foram introduzidos, a fim de evitá-las ou minimizá-las."

\subsubsection{Endogenia}

Entende-se por endogenia a concentração institucional ou geográfica, por meio da afiliação declarada do conselho editorial, dos revisores e dos autores, com membros oriundos de uma mesma instituição, cidade ou região.

Um fator importante para disseminação de um periódico é que ele seja amplamente divulgado e acessado por pessoas de todas as regiões do país e internacionalmente. Com esse intuito é cobrado que um periódico não seja endógeno, isto é, que apresente uma distribuição de autores, revisores ou membros do conselho editorial por diferentes Estados ou instituições. O editor do periódico é responsável por divulgá-lo, e, portanto, deve cuidar para que não haja concentração, o que pode restringir o acesso à informação para uma determinada área ou região.

Os cientistas que fazem parte dos conselhos editoriais de alta qualidade de periódicos internacionais têm a responsabilidade de orientar, direcionar e definir os padrões da pesquisa científica. Ao decidir o que publicar, eles definem a qualidade das investigações, promovem áreas emergentes e estabelecem os critérios por meio dos quais a pesquisa é avaliada (MENEGHINI, 2012). 


\subsection{FONTES DE INFORMAÇÃO}

Antes de tratarmos da questão da indexação em bases de dados, veremos que para que um periódico possa ser inserido em uma base ou diretório, usufruindo corretamente, a partir daí, dos serviços oferecidos por eles, julga-se necessário conceituar os termos e apresentar as funções de cada uma dessas ferramentas, tão importantes para melhor divulgação da produção científica.

A literatura define diretórios de diferentes modos, mas nesta pesquisa utilizamos a classificação empregada pelo portal de revistas Univerciencia.org, descrita a seguir.

Diretórios: comparáveis às páginas amarelas ${ }^{5}$, podem ser de âmbito nacional, temático, regional e internacional.

Índices (index): elaboram referências bibliográficas especializadas para periódicos parceiros. Com o intuito de facilitar o levantamento bibliográfico da produção científica em áreas e subáreas diversas, registram e fornecem as referências bibliográficas dos artigos, disponibilizando busca por autor, título, palavras-chave e resumo. Além disso, podem ter abrangência institucional, nacional, regional e internacional.

Índices de citação: indexam as referências bibliográficas citadas em cada artigo componente de periódicos científicos parceiros, constituindo-se assim maneira alternativa de recuperação de informação, que posteriormente passam a ser contabilizadas, originando indicadores de citação (MUGNAINI; STREHL, 2008). Atualmente, os índices de citação mais populares são o Fator de Impacto e o índice $\mathrm{H}$, apresentando significativa utilidade na avaliação da

5 Em inglês, yellow pages; em alemão, gelbe seiten; e em francês, pages jaunes, as páginas amarelas são uma lista telefônica de empresas e serviços. Internacionalmente conhecidas pela cor amarela do diretório comercial, existem em vários países. O nome e o conceito yellow pages surgiu em 1883. Em 1886 o norte-americano Reuben $\mathrm{H}$. Donnelley publicou oficialmente as primeiras páginas amarelas. Disponível em: <http://pt.wikipedia.org/wiki/P\%C3\%A1ginas_Amarelas>. 
produção científica brasileira (MUGNAINI; SALES, 2011). Eles podem ter abrangência nacional, regional e internacional.

Repositórios digitais: são conjuntos de serviços oferecidos por uma instituição aos membros de sua comunidade para gestão e disseminação da sua produção técnico-científica em meio digital. Dentre as principais funções do repositório digital, destacamos a contribuição para o aumento do impacto da investigação desenvolvida nas instituições de fomento à pesquisa, ampliando assim sua visibilidade e acessibilidade. Esse serviço pode ser considerado uma ferramenta de gestão documental que permite a preservação da memória intelectual e sua criação, tratamento, transmissão e acesso.

No Brasil um dos softwares mais conhecidos para implantação de repositório é o DSpace Institutional Digital Repository System ${ }^{6}$ (projeto colaborativo da MIT Libraries e a Hewlett-Packard Co.). Por ser um software livre, transfere para as organizações a responsabilidade pela gestão da informação técnico-científica, garantido que o acesso seja definitivo. A iniciativa de distribuição do DSpace no Brasil é do Instituto Brasileiro de Informação em Ciência e Tecnologia.

Bases de dados: coleção de registros de documentos ou de registros similares e que contém determinadas relações entre si. Para Lancaster (1993, p. 305) base de dados pode ser definida por:

uma coleção de itens sobre os quais podem ser realizadas buscas com a finalidade de revelar aquelas que tratam de um determinado assunto. A base de dados consiste em artefatos, como livros (o acervo de uma biblioteca é uma base de dados com certeza), ou registros que apresentam artefatos, como, por exemplo, registros bibliográficos constantes de páginas impressas, de fichas ou de meios eletrônicos.

Tudo isso, com o objetivo de realizar o controle bibliográfico das áreas, disseminar a informação e gerar indicadores estatísticos e bibliométricos.

\footnotetext{
6 DIGITAL repositories: helping universities and colleges. JISC Briefing Paper, [S.I.], 2005. <http://www.jisc.ac.uk/uploaded_documents/JISC-BP-Repository(HE)-v1-final.pdf>. Acesso em: 14 ago. 2013.
} 
As bases de dados são consideradas uma evolução dos índices bibliográficos ${ }^{7}$, sendo o seu acesso facilitado pelo uso de computadores para a recuperação de informação. Dessa forma, várias bases foram criadas em muitas áreas do conhecimento, cada uma delas com seus critérios de seleção do material a ser indexado, cobertura temática e abrangência geográfica (CASTRO, 2011).

Durante o processo de comunicação científica, lembra Castro (2011), toda a produção de documentos passa por vários crivos ou filtros, que têm tanto o objetivo de selecionar quanto o de validar o caráter científico de tudo o que é publicado. No caso dos periódicos, o primeiro filtro é o que convencionou-se chamar de revisão por pares; o segundo, o crivo das bases de dados; e o último é a citação pela comunidade da área de pesquisa.

\footnotetext{
7 Índices bibliográficos: criados em meados do século XIX para registrar e divulgar o maior número possível de artigos publicados em revistas científicas sobre determinado assunto (CASTRO, 2011).
} 


\section{A POLÍTICA CIENTÍFICA E A AVALIAÇÃO DA PÓS- GRADUAÇÃO}

\subsection{DA CRIAÇÃO DAS UNIVERSIDADES À PÓS-GRADUAÇÃO}

Quando se fala em ciência, logo se pensa na resolução de um problema. Essa busca por soluções, de forma geral, se dá pela própria natureza humana, que está sempre tentando moldar o mundo ao seu redor.

Gil (1979, p. 174) afirma que "[...] o objeto da ciência é um intermundo situado entre a teoria, o instrumentário científico e a percepção." Para Lopes (1999) a ciência tem como tarefa principal a construção de modelos que objetivem a experiência a partir de um ideal de formalização completa, tendo ainda a característica de não ser estagnada por promover revisões contínuas.

De acordo com Mattelart (2002), o que confere à ciência a qualidade de "sagrada" é a forma da atividade científica, que é imparcial, universalista, desvinculada de ideologias e busca da verdade acima de tudo. Por outro lado, Gil (1979) ressalta que o sucesso social da ciência reside no fato de que ela se desdobrou em técnicas que acabaram gerando mudanças tanto na natureza como na vida social.

Lakatos e Marconi (1985) resumem bem alguns aspectos que tornam a ciência tão importante para a humanidade: a) criatividade: qualidade dos homens para contornar situações complexas; b) linguagem: capacidade de exposição de ideias, por meio de narrativas, formulando situações ou descrevendo os métodos adotados para mudá-las; c) métodos: atividades sistemáticas e racionais que possibilitam o alcance dos objetivos propostos; d) publicação: exposição dos achados de pesquisa em meios consagrados pela área do conhecimento e reconhecidos por seus pares.

\subsubsection{Marcos do Desenvolvimento Científico no Mundo}

Retomamos aqui alguns dos marcos que contribuíram substancialmente para o desenvolvimento científico, já citados nesta dissertação: 1) a iniciativa do homem de registrar seu pensamento nos mais variados suportes, desde 
blocos de argila ao ambiente virtual; 2) a invenção da prensa de tipos móveis, por instituir o livro, suporte que viabilizou a expansão da produção de textos/obras; e 3) o desenvolvimento das universidades como espaços de pesquisa.

A criação das universidades foi impulsionada pelos interesses da igreja e do Estado. A primeira, porque não conseguia suprir o corpo de secretários, chanceleres e notários necessário para atender aos reis e príncipes; o segundo, para instruir a burguesia, que precisava obter mais conhecimentos para realizar atividades comerciais, que cresciam a passos largos no final do século XII (JANOTTI, 1992).

Assim, de acordo com esse autor, nesse período foram criadas as primeiras universidades nas cidades de Bolonha, Paris e Oxford, enquanto no século XIII foram fundadas as de Siena (Itália), Toulouse (França), Cambridge (Inglaterra), Salamanca (Espanha) e Lisboa e Coimbra (Portugal). Entre os avanços proporcionados pela atuação das universidades Janotti (1992) ressalta os seguintes:

1) desenvolvimento de um espírito de curiosidade;

2) maior vigor da língua latina e interesse pela língua grega;

3) retomada do interesse pela antiguidade clássica;

4) renascimento do direito romano;

5) interesse pelas ciências médicas e da natureza;

6) sistematização da filosofia e da teologia; e

7) desenvolvimento dos idiomas e literatura.

Conforme já citado, em meados do século XV, após a criação, no final dos anos 1430, da prensa de tipos móveis por Gutenberg, ampliou-se ainda mais a circulação de informação registrada no suporte impresso na Europa (CARVALHO, 2011).

Chartier (2009), analisando os fatores que influenciaram a Revolução Francesa, acrescenta que na França, em meados de 1600, o número alfabetizados havia aumentado de forma considerável, com crescente expansão da circulação de material impresso nos meios sociais. Concomitantemente, cresceu também a população que passou a consumir o 
material impresso e o tamanho das bibliotecas. Segundo o mesmo autor, houve uma transformação, inclusive, nas práticas de leitura, quando o livro passou a concorrer com peças impressas, como os panfletos e os libelos, de caráter efêmero.

Barreto (2009) lembra que, no mesmo período, as sociedades científicas eram espaços onde surgiam ideias e novos tópicos de estudo, ao mesmo tempo em que proporcionavam o livre fluxo de informação, com a intenção de gerar conhecimento. Eram, por isso, segundo o autor, reconhecidas como verdadeiras redes de saber.

A partir daí, ganhou relevância a troca de informações entre os estudiosos. Em um primeiro momento utilizando cartas ou discussões em cafés e, depois, por meio dos primeiros periódicos científicos, ponto abordado no capítulo anterior.

\subsubsection{Histórico do Desenvolvimento Científico no Brasil}

Nos três primeiros séculos da história brasileira a organização social estava assentada no sistema colonial, que pode ser entendido a partir de dois elementos básicos: "[...] toda atividade econômica se orienta segundo os interesses da burguesia comercial da Europa, e as colônias se constituem em instrumentos de poder das respectivas metrópoles" (NOVAIS apud MOREL, 1979, p. 25).

Nesse contexto, a educação no Brasil foi delegada aos jesuítas religiosos católicos pertencentes à Ordem de Jesus. Eles ensinavam a catequese distanciando-se completamente do movimento científico que se espalhava pela Europa, à época. Tal ordem fundava-se na crença de que Deus era a única verdade, e que a fé deveria ser pregada pela igreja, única a representá-lo na Terra:

Essa visão de mundo também significou a união da Igreja (clero) e do Estado (nobreza) em interesses comuns de manutenção de uma estrutura social tripartite e hierarquizada (defesa/luta, espiritualidade/reza e manutenção/trabalho), na sustentação de seus privilégios e nas restrições à acumulação 
de capital e a livre produção e contratação de força de trabalho praticada pela burguesia (LEDESMA, 2010, p. 9).

Considerando que a educação brasileira seguiu por essa linha, as pesquisas científicas restringiam-se ao campo das ciências naturais, no sentido da exploração das riquezas que o país oferecia. Em geral, eram pontuais, específicas e de curta duração (MOREL, 1979, p. 27). As poucas iniciativas tomadas no sentido de desenvolver pesquisas científicas não obtiveram êxito:

As condições da colônia eram adversas ao desenvolvimento científico: imprensa proibida, sistema escolar deficiente, ausência de universidades, nenhum intercambio com os centros mais avançados, poucos brasileiros tinham condições de completar seus estudos na Europa (MOREL, 1979, p. 26).

Esse quadro começou a sofrer leve modificação a partir de 1759, quando, por iniciativa de Marquês de Pombal, os jesuítas foram expulsos do Brasil, de modo que o sistema de ensino então vigente foi desmantelado, sendo levado a cabo por "[...] padres seculares, frades franciscanos e carmelitas, mantendo a característica de ser todo voltado para as elites das áreas rurais e urbanas" (MOREL, 1979, p. 28).

A partir daí, a primeira tentativa de criação de uma universidade brasileira foi liderada por Tiradentes, no movimento da Inconfidência Mineira. A classe chegou a funcionar na Bahia, mas não perdurou por muito tempo, transformando-se em mais uma tentativa frustrada.

Já em 1808, com a instalação da família real portuguesa no Brasil e no intuito de adequar o país ao papel de centro administrativo do império português, o governo colonial tomou diversas iniciativas nesse sentido.

A primeira medida, tomada em 22 de janeiro de 1808, a abertura dos portos brasileiros às nações amigas, facilitaria nossas relações intelectuais com os países europeus. As obras estrangeiras passaram a entrar livremente no país, e se inicia então a fase das grandes expedições científicas, abrindo novos horizontes, sobretudo no campo da História natural (MOREL, 1979, p. 29). 
Barreto (2009) também destaca a chegada da família real portuguesa como um marco do grande incentivo ao desenvolvimento da ciência brasileira. Isso foi possível a partir das seguintes providências: a) a abertura de portos e estradas; b) a concessão da liberdade de comércio; c) a criação do primeiro jornal impresso brasileiro, chamado de Gazeta do Rio de Janeiro; e d) a introdução do ensino leigo superior a partir da instalção, por D. João VI, de:

1) uma escola superior de medicina;

2) uma escola de técnicas agrícolas;

3) um laboratório de estudos e análises químicas;

4) da Academia Real Militar, que cobria o ensino de engenharia civil e mineração;

5) da Biblioteca Nacional; e

6) dos jardins botânicos reais.

De acordo com Morel (1979), os objetivos de tais medidas eram suprir as necessidades imediatas que se impunham ao governo, uma vez que o Brasil configurara-se como o centro econômico do império. Fazia-se necessário, naquele momento, formar cirurgiões, engenheiros e indivíduos ligados à defesa militar, entre outras prioridades.

Com o advento da Independência e do Primeiro Império, já no século $\mathrm{XIX}$, as características do sistema científico brasileiro não sofreram grandes mudanças.

O reconhecimento do trabalho científico surgiu as universidades. As primeiras tentativas de criação de instituições universitárias datam de 1810 e 1889, porém, somente em 1915, já sob o regime republicano, por meio do Decreto $\mathrm{n}^{0}$ 11.530, que ficou conhecido como Lei Maximiliano ${ }^{8}$, o governo federal reuniu como universidade as escolas Politécnica e de Medicina do Rio de Janeiro (FÁVERO, 2006).

Para Teixeira (1989) o sistema educacional superior brasileiro, apesar de ter se constituído como estatal sob a influência (mas não sob a gestão) da

\footnotetext{
${ }^{8}$ Em 18 de março de 1915 foi sancionado o Decreto Federal $n^{\circ} 11.530$, que dispunha sobre a reforma do ensino superior, proposta por Carlos Maximiliano Pereira dos Santos. Conhecida como Lei Maximiliano, exigia que as instituições de ensino superior fossem equiparadas a estabelecimentos oficiais e tivessem cinco anos de funcionamento, em localidade com população superior a 100 mil habitantes. Disponível em: <http://www.ufpr.br/portalufpr/a-mais-antiga-do-brasil/>. Acesso em: 29 ago. 2013.
} 
igreja católica - segundo a tradição portuguesa -, em um primeiro momento não teve início com a criação de universidades, mas, sim, com as escolas autônomas para a formação de profissionais liberais. Essas escolas foram criadas por iniciativa exclusiva da coroa portuguesa. O modelo adotado, de inspiração napoleônica, tinha como base o pragmatismo que havia orientado o projeto de modernização de Portugal, no final do século XVIII. Nele, a expressão mais significativa no campo educacional foi a reforma da Universidade de Coimbra.

Já a partir do Segundo Império, com a ascensão de Visconde do Rio Branco (o baiano José Maria da Silva Paranhos) ao poder, em 1871, algumas iniciativas, ligadas às transformações socioeconômicas que a sociedade brasileira estava passando, teve papel decisivo no desenvolvimento da educação e da ciência brasileiras (MOREL, 1979). As medidas adotadas por ele criaram a infraestrutura educacional necessária para a ascensão da burguesia: a reorganização da escola central, em 1874, dividida em escola politécnica e escola militar, que se configuraram como importantes centros de educação profissional superior, conferindo, no mesmo ano, pela primeira vez no país, o grau de bacharel em ciências.

Outras iniciativas importantes dos últimos anos do século XIX merecem ser lembradas. A pesquisa científica brasileira foi alavancada pelas instituições criadas por D. João VI, como:

[...] o Museu Paraense, fundado em 1885 pelo suíço Emílio Goeldi, passando a ter esse nome em 1900; o Museu Paulista, fundado em 1893 pelo alemão Hermann Von Lhering; o Instituto Agronômico, criado em 1887, em Campinas, transferido no período republicano para o governo de São Paulo (MOREL, 1979, p. 35).

Com a Proclamação da República, no final do século XIX, o ensino praticado no Brasil tinha um caráter puramente tecnicista. Nessa perspectiva, as escolas superiores deveriam formar apenas "[...] um letrado com aptidões gerais e um mínimo de informações técnico-profissionais, habilitado para preencher certos papéis específicos na burocracia, na estrutura de poder político e na esfera das profissões liberais" (FERNANDES apud MOREL 1979, p. 34). De acordo com Teixeira (1989, p. 107), “[...] a única real mutação 
operada no ensino superior no século XIX foi a introdução da ciência experimental na universidade."

Segundo Schwartzman (2001), as instituições científicas do início da República visavam os resultados da ciência para as necessidades de saneamento do país. Ao mesmo tempo, a pesquisa acadêmica era escassa e realizada por poucos professores autoditadas. Nesse período a ciência era vista pela elite intelectual brasileira como cultura importada da Europa, para obter reconhecimento social aqui.

Até aquele momento o trabalho científico como profissão ainda não existia, sendo a cidade do Rio de Janeiro a precursora da atividade científica na universidade, com a criação do Instituto de Patologia Experimental de Manguinhos. Foi a primeira instituição a possibilitar a realização de uma carreira científica. O seu financiamento provinha da patente de uma vacina desenvolvida por dois cientistas, doada para o sustento do instituto (SCHWARTZMAN, 1979).

Já a partir do início do século XX esse cenário começou a sofrer uma alteração. O nível da ciência começou a se elevar como resultado de uma relação mais intensa com países da Europa - principalmente a França -, o que permitiu a cooperação dos pesquisadores brasileiros com os estrangeiros. Da década de 1920 em diante, aconteceu uma grande modificação no campo das ciências que resultou na criação de diversas universidades. Para Durham (2003) isso se deu em razão do grande movimento de modernização do Brasil, com a urbanização e as transformações econômicas derivadas da industrialização, o que acarretou uma verdadeira renovação cultural.

O período de 1920 a 1930 foi de extrema efervescência cultural e científica, quando os intelectuais, liderados pela Associação Brasileira de Educação (ABE), criaram um movimento por uma educação mais abrangente e moderna, com fomentos à ciência e à tecnologia. A Revolução Constitucionalista de 1932 também foi um essencial para alavancar esse processo. A criação de uma universidade em São Paulo supriria a falta de dirigentes capacitados para gerir o Estado, contribuindo para a transformação do Brasil em um mais moderno e industrial (MOREL, 1979). 
Antes, em 1920, a primeira universidade brasileira fora criada oficialmente pelo presidente Epitácio Pessoa, que instituiu a Universidade do Rio de Janeiro (URJ) como marco histórico na educação nacional (FÁVERO, 2006).

Durham (2003) destaca duas características importantes que marcaram o nascimento do ensino superior brasileiro: 1) seu caráter tardio, pois as primeiras instituições de educação superior apareceram por volta de 1808, enquanto as primeiras universidades propriamente ditas são da década de 1930; e 2) o desenvolvimento precoce de um poderoso sistema de ensino privado paralelo ao setor público. Esse segundo aspecto é muito importante porque o sistema de ensino privado acabou por subverter a concepção dominante de ensino superior centrado na associação entre ensino e pesquisa, na liberdade acadêmica e no interesse público.

$\mathrm{Na}$ linha do tempo de criação das universidades brasileiras, após a fundação da URJ, foi criada a Universidade de Minas Gerais (UMG), em 1927, nos mesmos padrões da instituição carioca. A partir desses modelos, surgiram mais universidades e escolas visando fomentar a formação das elites sociais do país (TEIXEIRA, 1989).

Na década de 1930 foram criadas normas legais para regulamentar as instituições de ensino superior. É exemplo a lei que ficou conhecida como Reforma Francisco Campos, de 1931, que "[...] instituiu o sistema universitário como regra de organização do ensino superior" (MOREL, 1979 p. 38).

Em 1933, foi criada a Escola de Sociologia e Política de São Paulo por iniciativa de um grupo da sociedade paulistana. Nele se destacaram os dirigentes das principais entidades de ensino instaladas na capital, como a Faculdade de Direito, a Escola Politécnica, a Faculdade de Medicina, a Escola de Comércio "Álvares Penteado" e a Escola de Belas Artes, além de representantes da Ordem dos Advogados do Brasil, do Instituto de Engenharia, da Federação das Indústrias, dentre outros (FESPSP, [1995?]). Até então, no Estado, não havia universidades e sim escolas superiores, como a própria Escola de Sociologia e Política e a Faculdade de Direito, criada em 1827.

Em 1933, Armando de Sales Oliveira foi nomeado interventor do estado de São Paulo pelo presidente Getúlio Vargas. No ano seguinte, 1934, Sales 
criou a Universidade de São Paulo, a partir da reunião das faculdades e dos institutos de ensino existentes. Foi instituída a Faculdade de Filosofia, Ciências e Letras, que oferecia matérias básicas para todos os cursos (MOREL, 1979). Desde sua criação a USP teve uma estreita relação com outras universidades e pesquisadores de todo mundo. Idealizada como um instrumento para posicionar o estado de São Paulo no cenário nacional, à época de sua criação recebeu missões francesas para formação de seu corpo docente. Foi orientada, desde o início, para o estudo da sociedade brasileira e para a formação de quadros técnicos e dirigentes atuantes no quadro de modernização social. O nascimento da Universidade de São Paulo se deu, nesse período, como uma tentativa de fortalecer a autonomia paulista.

Em 1935 foi criada, por Anísio Teixeira, a Universidade do Distrito Federal do Rio (MOREL, 1979).

Em 1936, nasceu a Fundação Escola de Sociologia e Política do Estado de São Paulo (FESPSP), que, em 1940, incorporou tanto a Escola de Sociologia e Política de São Paulo quanto o curso de Biblioteconomia e Documentação, mantido pelo governo municipal de São Paulo. Em 1941, foi fundada a Divisão de Estudos Pós-Graduados, atual Escola Pós-Graduada de Ciências Sociais, responsável pela formação da primeira geração de pesquisadores nas áreas da sociologia, política e administração pública no país (FESPSP, [1995?]).

A década de 1950 foi marcada pela consolidação do capitalismo industrial brasileiro, contexto em que se dá a institucionalização da política científica do país. O processo de regulamentação da pós-graduação brasileira teve uma forte orientação nacionalista, tendo ocorrido durante o regime militar. Nesse sentido, para Balbachevsky (2002) a iniciativa de regulamentação desse nível de ensino superior se deveu à percepção dos militares quanto às potencialidades estratégicas dessa etapa avançada de formação. Além disso, havia a necessidade de qualificação dos professores das universidades federais, que se expandiam fortemente. 
A pós-graduação brasileira foi baseada nas cátedras ${ }^{9}$, modelo adotado pelas primeiras universidades brasileiras, em meados de 1930. As experiências realizadas pelos pós-graduandos, no período, quase não tiveram impacto na pós-graduação. Ele viria somente em 1965, quando "[...] o Ministério da Educação regulamentou essas experiências, reconhecendo-as como um novo nível de ensino, além do bacharelado" (BALBACHEVSKY, 2002, p. 277).

O fato curioso é que, até então, a pós-graduação brasileira não enxergava o mestrado e o doutorado como um processo contínuo. As características da pós-graduação no Brasil foram fixadas pelo parecer nº 977 , conhecido como Parecer Sucupira, que:

estabeleceu pela primeira vez, o formato institucional básico da pós-graduação brasileira, diferenciando dois níveis de formação, o mestrado e o doutorado, e estabelecendo uma linha de continuidade entre os dois, consagrando o mestrado como um pré-requisito para o doutorado (BALBACHEVSKY, 2002, p. 277).

A pós-graduação também contou com o apoio de importantes órgãos que impulsionaram a ciência brasileira, pois a pesquisa e a produção científicas, como se sabe, são os quesitos que mais influenciam na determinação do padrão de qualidade dos cursos.

Nessa perspectiva, em 1951 foi criado o Conselho Nacional de Desenvolvimento Científico e Tecnológico (CNPq) e a Coordenação de Aperfeiçoamento de Pessoal de Nível Superior (Capes). O CNPq nasceu com a missão de promover o desenvolvimento científico e tecnológico e executar as pesquisas necessárias ao progresso social, econômico e cultural do país (CNPq, [1995?]). O órgão começou a ser idealizado, em meados dos anos 1920, por integrantes da Academia Brasileira de Ciências (ABC); porém, somente se consolidou em 15 de janeiro de 1951. Após inúmeros debates em diversas comissões na Câmara dos Deputados, o presidente Eurico Gaspar Dutra finalmente sancionou a lei que criou o CNPq, então chamada de "Lei

\footnotetext{
9 "A organização da universidade de cátedras se distingue do modelo departamental adotado no Brasil a partir da reforma de 1968. Nesse sistema, de origem europeia, as responsabilidades estão nas mãos de um único professor (professor catedrático), que responde pelas atividades ligadas à sua disciplina, contando com o auxílio de um número variável de assistentes por ele nomeados" (BALBACHEVSKY, 2002, p. 276).
} 
Áurea da Pesquisa no Brasil". Com esse ato, Dutra consolidou seu legado antes de passar a faixa presidencial a Getúlio Vargas.

Já a Capes, vinculada ao Ministério da Educação (MEC), entre outras ações, teve por objetivo formar recursos humanos altamente qualificados, promover a cooperação internacional, classificar a produção científica nacional e aprimorar os indicadores da produção científica brasileira. Com a reforma de $1968^{10}$, a pós-graduação mudou e os estudos pós-graduados passaram a ter uma nova característica, que preservou parte do modelo antigo de ensino (relação entre estudante e seu orientador). Foram criados os conselhos para avaliação dos alunos, passando-se a exigir do candidato a conclusão de um número mínimo de disciplinas, sua qualificação junto a uma banca de professores e a defesa pública da tese diante de uma banca constituída por pelo menos um professor de fora do departamento de vínculo do candidato ao título (MOREL, 1979).

Interessante ressaltar que esse modelo perdura até hoje - ou com a entrega da dissertação ou tese; ou, dependendo da área, com a entrega de dois ou três artigos publicados reunidos num único documento, contendo uma introdução e uma conclusão.

A somatória desses fatores resultou na construção de um robusto sistema de ciência e, consequentemente, na formação de milhares de mestres e doutores. Isso permitiu que a pós-graduação brasileira permanecesse em evidência, mostrando sua qualidade e contribuindo para o desenvolvimento do país.

Balbachevsky (2002) lembra que o sucesso alcançado pelo Brasil na pós-graduação foi motivo de orgulho tanto para a academia quanto para as autoridades públicas brasileiras, pois "[...] o salto de qualidade se deu quando esses programas de pós-graduação foram definidos como foco privilegiado das políticas de apoio ao desenvolvimento científico e tecnológico, no início dos anos 1970" (SCHWARTZMAN, 1991 apud BALBACHEVSKY, 2002, p. 278).

\footnotetext{
10 Visando tornar o ensino superior mais eficiente, em 1968 o governo federal promoveu a reforma universitária, instituindo uma diferenciação interna no sistema universitário, estabelecendo estudos de curta e longa duração, nível de graduação, subdivisão da pós-graduação em mestrado e doutorado, cabendo a cada nível um valor acadêmico diverso (MOREL, 1979).
} 
Importante salientar que os motivos que impulsionaram esse salto de qualidade estavam ligados a interesses de dois setores da elite nacional, bastante influentes naquele período: 1 ) as lideranças científicas nacionais (com forte orientação política de esquerda); e 2) o setor nacionalista das forças armadas (BALBACHEVSKY, 2002). Para eles, a ciência básica se mostrava como um instrumento importante de desenvolvimento econômico do Brasil.

Para a elite científica a oferta de conhecimento e de incentivos adequados transformaria os investidores privados de consumidores a produtores de tecnologia. Na visão das forças armadas o desenvolvimento da capacidade científica seria uma forma de garantir o acesso do Brasil ao que se convencionou chamar, à época, de "tecnologias sensíveis" - a informática, a tecnologia aeroespacial e a energia nuclear (BALBACHEVSKY, 2002).

A partir daí, conta a autora, o governo brasileiro lançou um ambicioso projeto de capacitação de pesquisadores no exterior, por meio da concessão de bolsas de pós-graduação. Essa nova geração de cientistas, com toda essa bagagem, foi responsável tanto por aumentar o conteúdo acadêmico quanto por imprimir maior dinamismo ao sistema da pós-graduação.

Passou-se a contar com apoio do Banco Nacional de Desenvolvimento Econômico (BNDES), por meio do estabelecimento de um fundo de suporte ao desenvolvimento tecnológico. Em 1971, foi criada a Financiadora de Estudos e Projetos (Finep) e o fundo nacional passou a ser um item permanente do orçamento público federal (BALBACHEVSKY, 2002).

A autora indica o crescimento da pós-graduação brasileira em três momentos: 1) em 1965 o Conselho Nacional de Educação identificou 38 programas de pós, sendo 27 de mestrado e 11 de doutorado; 2) em 1975 os números passaram para 429 programas de mestrado e 149 de doutorado; e 3) em 2002, os programas ativos contavam 1.506 de mestrado e 841 de doutorado.

\subsubsection{A Avaliação da Pós-Graduação}

O processo de Avaliação da Pós-Graduação no Brasil vem sendo desenvolvido, ao longo dos últimos 35 anos, pela Capes (MOREIRA, 
HORTALE, HARTZ, 2004; SPAGNOLO, SOUZA, 2004). Porém, uma reformulação significativa se evidenciou entre os anos de 1996 e 1997, estabelecendo-se, em 1998, um novo ciclo trienal de avaliação. Dentre os diversos aspectos avaliados pelo órgão, a pesquisa e a produção científica são "[...] os quesitos que mais influem na determinação do padrão de qualidade dos cursos" (SOUZA; PAULA, 2002, p. 7).

Como instituição responsável por avaliar e atestar a qualidade das publicações nacionais, a Capes possui um método próprio de avaliação e classificação de periódicos, que é dividida em estratos, dentro das respectivas áreas do conhecimento. Nesse processo, são avaliados: pontualidade, periodicidade, caráter científico, presença de editor chefe, corpo editorial, porcentagem de autores doutores e presença em fontes de informação ou indexadores.

Os periódicos são classificados de forma horizontal como 'A' e 'B', além do nível 'C', que caracteriza as publicações em desacordo com o perfil de um periódico científico. O documento de avaliação abrange três campos do conhecimento dentro da grande área de ciência sociais aplicadas: comunicação, ciência da informação e museologia.

Com vistas a minimizar as discrepâncias de critérios entre elas, os coordenadores da grande área de humanidades da Capes fixaram parâmetros mínimos comuns para a elaboração do Qualis Periódicos.

De acordo com os critérios do Qualis ${ }^{11}$, para que o periódico obtenha uma boa classificação junto ao sistema é necessário que ele cumpra e atenda alguns requisitos mínimos. Assim, para que uma publicação seja avaliada como periódico científico é essencial que possua: a) editor responsável; b) comissão editorial; c) conselho consultivo; d) ISSN; e) linha editorial definida; f) normas; g) periodicidade; h) processo de revisão por pares; i) titulação e afiliação dos autores, dos membros do conselho consultivo e dos pareceristas ad hoc; j) título, resumo e palavras-chave no mínimo em dois idiomas, sendo um deles o português; e k) data de recebimento e aceitação de cada artigo.

11 Avaliação Trienal 2010 (triênio $2007 \quad$ - 2009 ). Disponível em: <http://www.capes.gov.br/avaliacao/documentos-de-area->. Acesso em 01 ago. 2011. 
A classificação dos periódicos se dá a partir desses parâmetros mínimos, respeitando-se as discrepâncias e segundo a realidade de cada área de avaliação, como, por exemplo, as Ciências Sociais Aplicadas I, que reúnem as áreas acima citadas. Os estratos são os que seguem:

- Estrato C: periódicos impróprios.

- Estrato B5: periódicos que atendem aos critérios mínimos de publicação científica.

- Estrato B4: critérios de periódicos, autores doutores e $20 \%$ de artigos de três instituições diferentes.

- Estrato B3: ser publicado por instituição com pós-graduação stricto sensu, 40\% autores doutores e 30\% de artigos de três instituições diferentes daquela que edita o periódico, por volume.

- Estrato B2: ser publicado por instituição com pós-graduação stricto sensu, 60\% de autores doutores; $50 \%$ de artigos de autores de três instituições; presença em duas bases de dados ou indexadores (LATINDEX; REDALYC; DOAJ; CLACSO; Pascal Thema; INFOBILA; Library Literature \& Information Science Index; LISA; Scopus; ComAbstracts; Index to Journals in Communication Studies; LAPTOC; Comunication Abstracts).

- Estrato B1: ser publicado por instituição com pós-graduação strictu sensu, 70\% autores doutores; $60 \%$ de artigos de autores de três instituições; 10\% coautores filiados a instituições estrangeiras; presença em três bases de dados ou indexadores (LATINDEX; REDALYC; DOAJ; CLACSO; Pascal Thema; INFOBILA; Library Literature \& Information Science Index; LISA; Scopus; ComAbstracts; Index to Journals in Communication Studies; LAPTOC; Comunication Abstracts).

- Estrato A2: ser publicado por instituição com pós-graduação strictu sensu, $80 \%$ de autores doutores; $70 \%$ de artigos de autores de quatro instituições; $20 \%$ coautores filiados a instituições estrangeiras; presença em quatro bases de dados ou indexadores (LATINDEX; REDALYC; DOAJ; CLACSO; Pascal Thema; INFOBILA; Library Literature \& Information Science Index; 
LISA; Scopus; ComAbstracts; Index to Journals in Communication Studies; LAPTOC; Comunication Abstracts).

- Estrato A1: qualidade na publicação, demonstrada em relatório pelos avaliadores e necessariamente superiores a todas as exigências estabelecidas para o Estrato 6; títulos do JCR de 2008.

Conforme descrito nos estratos acima, para que o periódico obtenha uma boa classificação junto à Capes é importante que ele atenda requisitos como abrangência, qualidade e presença em algumas fontes de informação ou indexadores.

Percebe-se que a política científica nacional tenta fazer com que todas as áreas tenham uma mesma estrutura de publicação. Porém, as que compõem as ciências humanas e as sociais aplicadas são diferentes, mantendo processos de comunicação científica com características próprias.

Nesse sentido, Velho (1997) destaca que alguns pesquisadores já levantaram evidências e tendências que permitem conhecer um pouco mais sobre os diversos canais de publicação. Assim, ressalte-se que as ciências puras preferem canais regionais ou locais. Além disso, os pesquisadores dessa área publicam muito em inglês e em periódicos internacionais.

Já as ciências humanas e sociais publicam e fazem mais uso de livros para divulgação de suas pesquisas, o que se dá porque esse tipo de publicação ainda é muito forte e significativa para essa área. Nesse sentido, esses pesquisadores "[...] não apenas publicam em livros, mas referem-se preferencialmente a eles" (VELHO, 2008, p. 14).

As ciências da saúde tendem a escolher documentos novos; as ciências agrárias e biológicas dão preferência a documentos com mais de 15 anos de idade; as áreas de linguística, letras e artes dão ênfase aos ainda mais antigos (MUGNAINI, 2011).

Entende-se que, de forma geral, a maioria das áreas tem tentado se enquadrar nos critérios ditados pelas principais fontes de informação (MUGNAINI; SALES, 2011) visando obter uma melhor avaliação. Entretanto essa pressão pode ter um desdobramento negativo para certos campos de 
pesquisa, podendo ocasionar danos de identidade, tanto por descaracterizá-los em sua dinâmica de redação, quanto por bloquear a forma de divulgação de seus resultados.

Mugnaini (2011) corrobora a ideia considerando que o próprio panorama da política de C\&T na América Latina evidencia uma dependência em relação aos países desenvolvidos. Isso reforça a necessidade de se concentrar em pesquisas que sejam focadas a contextos nacionais para alinhar o sistema de C\&T às realidades locais.

Outro aspecto ressaltado diz respeito ao fato de que parte dos editores parece ter aderido ao "jogo" do Fator de Impacto, pois muitos autores dos artigos são obrigados a valorizar o processo baseado em dados quantitativos. Além disso, há casos em que editores "sugerem" que seus autores citem artigos da própria revista.

Questionamentos sobre o uso muitas vezes inadequado do Fator de Impacto têm suscitado muitas críticas, e a adoção exclusiva desse indicador denota grande limitação. Para avaliar o uso que tem sido feito do FI na política científica nacional, Mugnaini e Sales (2011) analisaram os documentos de área e observaram que a maior parte utiliza o $\mathrm{Fl}$ para definição do critério de avaliação dos periódicos A1 (Quadro 2). A maioria das áreas de avaliação de ciências sociais aplicadas e humanas apenas exige que o periódico esteja indexado no Journal Citation Reports. Mas o triênio de 2007 a 2009 revelou exceções: as áreas de administração, ciências contábeis e turismo (sociais aplicadas) e geografia (humanas) exigem um Fator de Impacto mínimo de 0,5; enquanto economia (sociais aplicadas) compôs um ranking de citação específico. 
Quadro 2 - Nível do Fator de Impacto exigido para definição de critérios de avaliação de periódicos do estrato A1, segundo grande área do conhecimento e área de avaliação Qualis.

\begin{tabular}{|c|c|c|c|c|c|c|c|c|c|c|}
\hline $\begin{array}{c}\text { Critério para classificação A1 } \\
\text { baseado no Fator de Ímpacto (JCR) }\end{array}$ & Área de Avaliação Qualis & \multicolumn{9}{|c|}{ Grande Área } \\
\hline 6 & ASTRONOMIA / FÍSICA & & & & EX\&T & & & & & \\
\hline 4,95 (baseado na mediana) & BIOTECNOLOGIA & & & & & & & MULT & & \\
\hline 4,89 & CIËNCIAS BIOLÓGICAS III & & $\mathrm{BIO}$ & & & & & & & \\
\hline 4,7 & CIÊNCIAS BIOLÓGICAS II & & $\mathrm{BIO}$ & & & & & & & \\
\hline $4,1(\mathrm{GBG}) ; 2,1(\mathrm{BOZ})$ & CIËNCIAS BIOLÓGICAS I & & $\mathrm{BIO}$ & & & & & & & \\
\hline . & QUÍMICA & & & & EX\&T & & & & & \\
\hline 4 & SAÚDE COLETIVA & & & & & & & & SAU & \\
\hline & MEDICINA I & & & & & & & & SAU & \\
\hline 3,8 & MEDICINA II & & & & & & & & SAU & \\
\hline 3,08 & ODONTOLOGIA & & & & & & & & SAU & \\
\hline & ECOLOGIA E MEIO AMBIENTE & & $\mathrm{BIO}$ & & & & & & & \\
\hline 3 & FARMÁCIA & & & & & & & & SAU & \\
\hline 2,96 & MEDICINA III & & & & & & & & SAU & \\
\hline 2,75 & GEOCIËNCIAS & & & & EX\&T & & & & & \\
\hline 2,6 & CIÊNCIA DE ALIMENTOS & AGR & & & & & & & & \\
\hline 2,57 & MEDICINA VETERINÁRIA & AGR & & & & & & & & \\
\hline & CIËNCIAS AGRÁRIAS I & AGR & & & & & & & & \\
\hline 2 & ZOOTECNIA / RECURSOS PESQUEIROS & AGR & & & & & & & & \\
\hline 1,85 (própria área); 4,0 (outras) & EDUCAÇÃO FÍSICA & & & & & & & & SAU & \\
\hline 1,42 (para compor indicador especifico & CIËNCIA DA COMPUTAÇÄO & & & & EX\&T & & & & & \\
\hline & ENGENHARIAS II & & & ENG & & & & & & \\
\hline 1 & MATERIAIS & & & & & & & MULT & & \\
\hline 0,95 (e meia-vida > 9) & MATEMÁTICA / PROBAB. E ESTATÍSTICA & & & & EX\&T & & & & & \\
\hline 0,95 (própria área); 5,0 (outras) & ENGENHARIAS IV & & & ENG & & & & & & \\
\hline 0,8 & ENGENHARIAS I & & & ENG & & & & & & \\
\hline 0,8 (própria área); 2,4 (outras) & ENFERMAGEM & & & & & & & & SAU & \\
\hline & ADMINIST., C. CONTÁBEIS E TURISMO & & & & & & & & & SOC \\
\hline 0,5 & GEOGRAFIA & & & & & HUM & & & & \\
\hline & ECONOMIA & & & & & & & & & SOC \\
\hline Propõe indicador especifico & INTERDISCIPLINAR & & & & & & & MULT & & \\
\hline & ENGENHARIAS III & & & ENG & & & & & & \\
\hline & CIËNCIA POLÍTICA E RELS. INTERNACS. & & & & & HUM & & & & \\
\hline & CIËNCIAS SOCIAIS APLICADAS I & & & & & & & & & SOC \\
\hline & DIREITO & & & & & & & & & SOC \\
\hline Exige indexaçao & HISTÓRIA & & & & & HUM & & & & \\
\hline & PSICOLOGIA & & & & & HUM & & & & \\
\hline & SERVIÇO SOCIAL & & & & & & & & & SOC \\
\hline & ANTROPOLOGIA / ARQUEOLOGIA & & & & & HUM & & & & \\
\hline & EDUCAÇÃO & & & & & HUM & & & & \\
\hline & ENSINO DE CIËNCIAS E MATEMATICA & & & & & & & MULT & & \\
\hline & FILOSOFIA / TEOLOGIA & & & & & HUM & & & & \\
\hline não & SOCIOLOGIA & & & & & HUM & & & & \\
\hline & ARQUITETURA E URBANISMO & & & & & & & & & SOC \\
\hline & PLAN. URB. E REG. / DEMOGRAFIA & & & & & & & & & SOC \\
\hline & ARTES / MÚSICA & & & & & & LING & & & \\
\hline & LETRAS / LINGUÍSTICA & & & & & & LING & & & \\
\hline
\end{tabular}

Fonte: Mugnaini; Sales (2011)

Quanto ao nível do Fator de Impacto, 6,0 é o valor mais alto (astronomia/física) e 0,5 o mínimo (áreas supracitadas). Analisando as grandes áreas do Quadro 2 pode-se notar uma concentração de áreas de ciências biológicas, seguidas de ciências da saúde, agrárias e engenharias. Já as áreas de ciências exatas e da terra apresentam valores bem diversificados, assim como as da grande área multidisciplinar (com destaque para biotecnologia, na segunda posição). 
Diante desse cenário, percebe-se que as bases de dados e os indicadores de citação vêm sendo utilizados crescentemente, apontando uma tendência de compartilhamento de critérios que resulta na adoção, pelas áreas de ciências sociais e humanidades, de práticas características das ciências biológicas e exatas.

Evidencia-se a necessidade de investigação mais cuidadosa do conjunto de fontes de informação que vem servindo a esse propósito, no intuito de avaliar o papel que as instituições mantenedoras desses serviços vêm desenvolvendo, dada a importância que tem sido dada às fontes de informação no âmbito do sistema brasileiro de ciência e tecnologia. 


\section{METODOLOGIA}

O material utilizado é constituído dos documentos propostos pelas comissões das 46 áreas de avaliação do Qualis (triênio 2007-2009), mais especificamente a seção "III. Considerações gerais sobre o Qualis Periódicos. Roteiro para a classificação de livros e os critérios da área para a estratificação e uso dos mesmos na avaliação", na qual são definidos os critérios de classificação de periódicos.

A fim de mapear a utilização que a Capes faz das fontes de informação, os documentos foram descarregados do sítio web da Capes ${ }^{12}$, entre os meses de maio e julho de 2011. Foi elaborada uma planilha em Microsoft ${ }^{\circledR}$ Excel 2007 para coleta, registro e armazenamento dos dados de cada uma das áreas de avaliação.

A análise restringiu-se aos critérios de classificação das áreas de avaliação compreendidas na grande área de Ciências Sociais Aplicadas, que compreende as seguintes áreas de avaliação:

1. Administração, Ciências Contábeis e Turismo;

2. Arquitetura e Urbanismo;

3. Ciências Sociais Aplicadas I (Ciência da Informação, Comunicação e Museologia);

4. Direito;

5. Economia;

6. Planejamento Urbano e Regional e Serviço Social.

As informações de interesse foram:

$\checkmark$ área de avaliação Qualis;

$\checkmark$ grande área;

$\checkmark$ fontes de informação utilizadas para definição de critério de classificação dos periódicos, e

$\checkmark$ estrato de classificação (A1, A2, B1, B2, B3, B4, B5 e C, sendo A1 o mais alto).

12 Avaliação Trienal 2010 (triênio 2007-2009). Disponível em: 
Buscou-se avaliar o tipo de uso da fonte de informação para definição do critério, cujo impacto para a comunidade científica de cada área de avaliação é proporcional ao nível do estrato de classificação.

O presente estudo se caracteriza como uma pesquisa exploratória, cujos procedimentos para seu desenvolvimento são listados a seguir.

- Seleção das fontes de informação a serem analisadas: a partir dos documentos de área do Qualis da Capes, grande área de Ciências Sociais Aplicadas, foram identificadas as fontes de informação utilizadas para definição de critérios de classificação, resultando em um total de 17 fontes:

1. CLACSO - Consejo Latinoamericano de Ciencias Sociales

2. CLASE - Citas Latinoamericanas en Ciencias Sociales y Humanidades

3. $\mathrm{CMMC}-$ Communication \& Mass Media Complete ${ }^{\mathrm{TM}}$

4. ComAbstracts - Communication Institute for Online Scholarship

5. Communication Abstracts

6. DOAJ - Directory of Open Access Journal

7. Index to Journals in Communication Studies (índice impresso)

8. INFOBILA - Base de Datos de Información y Bibliotecología Latinoamericana

9. Web of Science e JCR

10. LAPTOC - Latin American Periodicals Tables of Contents

11. LATINDEX - Sistema Regional de Información en Línea para Revistas Científicas de América Latina, el Caribe, España y Portugal

12. Library Literature \& Information Science

13. LISA - Library and Information Science Abstracts

14. Pascal Thema - Science de L'Information Documentation

15. REDALYC - Red de Revistas Científicas de América Latina, el Caribe, España y Portugal

16. SciELO - Scientific Electronic Library Online

17. Scopus e SCImago 
- Levantamento e análise de critérios de seleção de periódicos, pelas fontes selecionadas: foram consultados os sites de cada fonte de informação para descobrir quais deixavam ou não explícitos os seus critérios de avaliação; em alguns casos buscouse contato com os responsáveis. Foi utilizado um protocolo de avaliação que permitiu identificar as fontes de informação que possuem critérios de seleção, confrontando-os com aqueles observados na revisão de literatura desta pesquisa.

O protocolo utilizado foi elaborado como objeto de estudo de um grupo de pesquisa científica, realizado em 2007, na BIREME/OPAS/OMS, cuja proposta era analisar fontes de informação consideradas importantes para a área da saúde (Anexo 1).

Destacam-se a seguir os aspectos julgados mais importantes a esse estudo:

$\checkmark$ conteúdo;

$\checkmark$ abrangência;

$\checkmark$ área temática/cobertura: assunto e tipo de material adequado, abrangência duplicidade e outros serviços;

$\checkmark$ tipo de fonte de informação: referencial, bibliográfica;

$\checkmark$ tipo de documento que indexa;

$\checkmark$ oferece acesso ao documento;

$\checkmark$ atualidade: período coberto pela fonte e/ou desde quando está disponível, frequência de atualizações das referências, qualidade dos resumos, forma (ficha, microforma, papel), em linha ou fora de linha, extensão da saída;

$\checkmark$ linguagem de indexação: variedade de pontos de acesso ou campos pesquisáveis, em termos de desempenho de recuperação almejado;

$\checkmark$ acesso: pago ou gratuito;

$\checkmark$ documentação e instrumentos auxiliares de busca: manuais, help, informações sobre sistemas de classificação, tesauro, manuais de treinamento etc.; 
$\checkmark$ hospedeiro: onde a fonte se encontra disponível;

$\checkmark$ meio de armazenamento e possibilidades de acesso;

$\checkmark$ formato de registro e estrutura da fonte de informação;

$\checkmark$ políticas de seleção;

$\checkmark$ existência de um comitê de seleção;

$\checkmark$ frequência das reuniões;

$\checkmark$ procedimentos para seleção;

$\checkmark$ navegabilidade/acessibilidade; e

$\checkmark$ metadados.

Fundamentados na literatura, são listados a seguir os itens que o periódico deve apresentar para ser selecionado pela fonte:

$\checkmark$ caráter científico;

$\checkmark$ existência de processo de revisão por pares;

$\checkmark$ composição do corpo editorial e de revisores ad hoc;

$\checkmark$ regularidade de publicação;

$\checkmark$ indexação em bases de dados; e

$\checkmark$ periodicidade. 


\section{RESULTADOS E DISCUSSÕES}

\subsection{ANÁLISES DAS FONTES DE INFORMAÇÃO}

Uma descrição detalhada das fontes de informação que compõem os critérios de avaliação de periódicos da grande área Ciências Sociais Aplicadas I se faz necessária, devido ao impacto da classificação de periódicos para a comunidade científica de sete áreas de avaliação.

Para se ter um parâmetro da sua magnitude, é importante mencionar que se trata de 414 programas de pós-graduação, equivalendo a $12,4 \%$ dos programas em funcionamento no país. Um total de 6.659 docentes está credenciado nele, correspondendo a $10,2 \%$ de todo o sistema de pósgraduação, segundo dados da Capes para o ano de 2012.

Os critérios de classificação definem o rumo da produção científica dessas comunidades, justificando o grande esforço que a Capes empreende constantemente ao estratificar os periódicos.

A seguir, são listadas as características das fontes de informação e os aspectos relativos à avaliação de qualidade empreendida pelas mesmas para composição do conjunto de periódicos que abarcam.

Deve-se esclarecer que tais informações estão publicadas nos respectivos sites. Sabe-se, porém, da limitação dessa abordagem metodológica, pois a ausência de informações pode resultar de uma falta de efetividade na simples divulgação, e não necessariamente na ausência de algum procedimento. Por outro lado, o que deve ser evidenciado é a não observação de procedimentos que permitam tomar uma fonte de informação parâmetro confiável para avaliação. 


\subsubsection{CLACSO - Consejo Latinoamericano de Ciencias Sociales}

\section{Sobre o repositório}

O $\mathrm{CLACSO}^{13}$ é um repositório digital formado por 324 centros cooperantes e está presente em 25 países da América Latina e do Caribe. 0 repositório existe desde 1998 e oferece acesso livre, estando as informações disponíveis em HTML e texto completo.

O repositório disponibiliza mais de 30 mil artigos com texto completo, além de documentos e livros que são publicados pela Rede CLASO. As informações aparecem em três blocos: Sala de leitura - que disponibiliza textos completos, livros e documentos; Portal de revistas - que consiste num projeto em conjunto com o Redalyc; e o Portal multimídia - que permite acesso à documentos audiovisuais, arquivos de áudio e coleções fotográficas. A CLACSO também disponibiliza todo e qualquer documento que os centros colaborativos necessitam.

\section{Sobre os títulos}

O repositório não disponibiliza uma listagem com os títulos de sua coleção. Para ter acesso a ela é necessário ir diretamente ao link no site do Redalyc. Por esse portal, é possível acessar 61 títulos.

A busca no portal é realizada por meio de pesquisa de termos e utiliza operadores booleanos; a maioria dos artigos foi publicada/atualizada até 2012. Em uma amostra de 10, somente 2 títulos disponibilizam artigos de 2013.

No momento em que o periódico é submetido ao processo de avaliação por pares, o editor ou membro do centro cooperante da CLACSO deve encaminhá-lo ao Redalyc e adequar-se a seus critérios.

\section{Critérios}

Assim como a lista de títulos, o link para acesso aos critérios também não está acessível pelo portal da CLACSO. Somente é possível acessá-los através do link de critérios em Redalyc.

\footnotetext{
${ }^{13}$ http://www.biblioteca.clacso.edu.ar/
} 
Percorrendo esse caminho, foi possível identificar que o repositório possui 39 critérios que são considerados como mais importantes, e, para que o periódico faça parte da rede, é necessário cumprir ao menos 82\% deles.

Os mais importantes e de maior peso são:

$\checkmark$ tempo de existência;

$\checkmark 75 \%$ de artigos originais;

$\checkmark$ revisão por pares;

$\checkmark$ artigos inéditos;

$\checkmark$ periodicidade; e

$\checkmark$ data de recebimento e aceitação

\section{Comitê}

Os periódicos passam pela avaliação de um comitê assessor constituído por 13 membros.

\section{Observação}

O conteúdo da base é duplicado na página da Redalyc.

\subsubsection{CLASE - Citas Latinoamericanas en Ciencias Sociales y Humanidades}

\section{Sobre a base}

$\mathrm{CLASE}^{14}$ é uma base de dados bibliográfica internacional, que abrange a área de ciências sociais aplicadas e humanidades, disponibilizando informações da América Latina e do Caribe. Criada em 1975 na Universidade Nacional Autônoma do México (UNAM), tem como objetivo indexar periódicos científicos e técnicos profissionais (de divulgação científica).

Possui 1.500 títulos de periódicos e 330 mil registros bibliográficos diversos, como, por exemplo, resenhas, editoriais, entrevistas etc. A pesquisa pode ser realizada através de uma lista de títulos disponibilizada pela base. A amostra recupera a relação dos títulos de acordo com o termo pesquisado ou

\footnotetext{
${ }^{14}$ Disponível em: <http://132.248.9.1:8991/F/IF3K6HMIQKCAPG79SJPKNPND5AIC5R9E6T4DQVLYGAFQ1K6FH718451 ?func $=$ file\&file_name $=$ base-info $>$.
} 
nome da revista/autor. A base de dados não disponibiliza uma lista contendo todos os títulos em ordem alfabética ou dividida por áreas de atuação.

Atualmente as informações estão disponíveis on-line, mas nem sempre foi assim. Durante os anos de 1975-1997, as informações foram publicadas como índice impresso; de 1989-1994 e 2003-2004, a divulgação foi disponibilizada em CD-ROM.

\section{Comitê}

Os periódicos que se submetem à avaliação passam pelo crivo de um comitê consultivo.

\section{Critérios}

Os critérios utilizados pela base para avaliação dos periódicos são:

$\checkmark$ normalização editorial;

$\checkmark$ adoção de normas técnicas;

$\checkmark$ ISSN;

$\checkmark$ informação confiável;

$\checkmark$ visibilidade;

$\checkmark$ periodicidade;

$\checkmark$ gestão e visibilidade;

$\checkmark$ conselho editorial heterogênio;

$\checkmark$ datas de recebimento e aceitação;

$\checkmark$ cobertura;

$\checkmark$ processo de peer review;

$\checkmark$ conteúdo com fins de indexação;

$\checkmark$ resumos;

$\checkmark$ palavras-chave;

$\checkmark$ referências;

$\checkmark$ artigos originais;

$\checkmark$ artigos de revisão; e

$\checkmark$ ensaios 
Para submeter os periódicos ao processo de avaliação é necessário que sejam encaminhados à base de dados os três últimos fascículos e uma carta de apresentação.

\section{Observações}

É importante ressaltar que a CLASE possui todos os dados completos de contato: email, telefone e endereço.

O acesso às informações é gratuito e dispensa o IP de universidade. Além da CLASE, outras três bases de dados estão sob os cuidados da Universidad Nacional Autónoma de México: 1) PERIÓDICA - Índice de Revistas Latinoamericanas en Ciencias $^{15}$; 2) IRESIE - Base de Datos sobre Educación Iberoamericana ${ }^{16}$; e 3) Recursos electrónicos libres ${ }^{17}$.

Na página da base consta que as atualizações dos dados são realizadas diariamente.

\subsubsection{CMMC - Communication \& Mass Media Complete ${ }^{\mathrm{TM}}$}

\section{Sobre a base}

$\mathrm{CMMC}^{18}$ é uma base de dados da área de comunicação que disponibiliza informações de cerca de 350 títulos de periódicos, com textos completos. Além disso, traz documentos datados de 1915 e indexa também outros tipos de documentos e resumos.

As informações são padronizadas e podem ser pesquisadas através de termos baseados em um Thesaurus da área de comunicação.

Possui uma lista de títulos atualizada em 2013, que é disponibilizada por assunto, nos formatos PDF, HTML ou Excel. Porém, por ser paga, não permite acesso ao texto completo dos artigos. Como a base de dados é um produto da EBSCO, para acessar o conteúdo o usuário deve pagar e ser ligado a uma instituição (representante autorizado da mesma).

\footnotetext{
${ }^{15} \mathrm{http}: / / 132.248 .9 .1: 8991 / F / T 8 D T 51 N H 2 P Q S 7 X 3 X 9 N N V 4 H J 453 G H 51 R I V H X T E A D 8 E S E A U 3 A L 6 D-$ 01432 ?func=file\&file_name=base-info

${ }^{16}$ http://132.248.9.1:8991/F/T8DT51NH2PQS7X3X9NNV4HJ453GH51RIVHXTEAD8ESEAU3AL6D01824 ?func=file \&file_name=base-info

${ }^{17}$ http://132.248.9.1:8991/F/T8DT51NH2PQS7X3X9NNV4HJ453GH51RIVHXTEAD8ESEAU3AL6D02066 ?func $=$ file \&file name=base-info

18 http://www.ebscohost.com/academic/communication-mass-media-complete
} 


\section{Comitê}

Não informa muito sobre seu comitê assessor, se sua composição é formada por pesquisadores, professores, nomes etc. Porém, é possível saber que seu comitê é composto por dois grupos: bibliotecários e profissionais da mídia e da comunicação.

\section{Observação}

Existe uma página comum da $\mathrm{EBSCO}^{19}$ (disponível para todas as suas bases) que contém um "painel" no qual são disponibilizadas capas de alguns periódicos. É possível clicar nelas e acessar o conteúdo, porém, só um artigo é acessível, como uma "amostra" do que é disponibilizado pela base.

\subsubsection{ComABSTRACTS - Communication Institute for Online Scholarship}

\section{Sobre a base}

Como uma base de dados da área de comunicação, a ComAbstracts ${ }^{20}$ pode ser acessada por meio da home page da CIOS Service ${ }^{21}$. A base disponibiliza registros bibliográficos, resumos dos artigos (com palavras-chave), livros etc., mas seu acesso só é permitido através de assinatura.

Apesar dessa restrição, foi possível identificar que a busca por informações é realizada com o auxílio de operadores booleanos and, or, note. De acordo com o termo pesquisado, as informações são recuperadas através das citações, resumos, autor, afiliação institucional, palavras-chave e metatermos.

A base informa que os links para acesso aos textos completos são fornecidos por periódicos que fazem parte de uma rede de bibliotecas universitárias. $\mathrm{O}$ acesso é permitido desde que a biblioteca contenha um servidor registrado no CIOS.

\section{Critérios}

\footnotetext{
19 http://www.ebsco.com/about

${ }^{20} \mathrm{http}: / /$ www.cios.org/www/aboutcomabstracts.htm

${ }^{21}$ Organização acadêmica, sem fins lucrativos, cujo objetivo é apoiar a investigação e a educação em disciplinas de comunicação. Presta serviços e fornece informações para pesquisadores, professores e alunos da área da comunicação.
} 
Não diz nada sobre critérios de avaliação.

\section{Comitê}

Não trás informações sobre a existência de um comitê científico.

As informações aqui disponíveis só foram encontradas por meio de uma página que traz dados genéricos sobre a base.

Não foi possível realizar uma busca, nem acessar nada além de uma relação contendo uma média de 132 títulos e seus respectivos números de ISSN, conforme mostrado no Anexo 2

\section{Observação}

O CIOS é a editora do periódico The Electronic Journal of Communication, primeira revista acadêmica on-line com processo de peer review da área de ciências sociais.

\section{Outras informações}

Também é o criador de outros índices e bases de dados, conforme descrito abaixo:

$\checkmark$ ComIndex, primeiro índice de bibliográfica eletrônica para a literatura do campo da comunicação;

$\checkmark$ Visual Concept Explorer, ferramenta de pesquisas visuais de última geração para os estudantes e estudiosos que trabalham em bancos de dados CIOS;

$\checkmark$ ComVista, banco de dados que identifica os principais centros de pesquisa da área de comunicação;

$\checkmark$ ComAnalytics, banco de dados para análise de pares de produtividade de estudiosos individuais e departamentos acadêmicos de comunicação;

$\checkmark$ ComContents, fornece tabelas interativas de conteúdo para milhares de questões de periódicos acadêmicos de comunicação; e 
ComUpdate, sistema exclusivo que permite aos estudiosos e estudantes de comunicação atualizarem-se sobre novos desenvolvimentos no campo.

\subsubsection{Communication Abstracts}

\section{Sobre a base}

Produto da EBSCO, a Communication Abstracts ${ }^{22}$ é apresentada como uma base de dados da área de comunicação. A fonte de informação possui 254 mil registros e 330 títulos com acesso ao texto completo, cobertura de capa a capa, porém, como outros produtos da EBSCO, o acesso ao conteúdo é pago.

Disponibiliza a lista de títulos nos formatos PDF, HTML e Excel.

Apesar de também ser uma base EBSCO, as informações não seguem o mesmo padrão das outras disponibilizadas pelo publisher. A home page da Communication Abstracts não disponibiliza informações sobre a utilização de Thesaurus.

\section{Critérios}

Não diz nada sobre critérios de avaliação.

\section{Comitê}

Não trás informações sobre a existência de um comitê científico.

\section{Observação}

Existe uma página comum da EBSCO ${ }^{23}$ (disponível para todas as suas bases) que contém um "painel" que apresenta capas de alguns periódicos. É possível clicar nelas e acessar o conteúdo; porém, mostra o conteúdo de um artigo somente, como uma "amostra" do conjunto disponibilizado pela base.

\subsubsection{DOAJ - Directory of Open Access Journal}

\footnotetext{
${ }^{22}$ http://www.ebscohost.com/academic/communication-abstracts

23 http://www.ebsco.com/about
} 


\section{Sobre o diretório}

Com o objetivo de aumentar a visibilidade e facilitar o acesso aos periódicos através de um endereço único, o diretório DOAJ foi fundado em 2003, fornecendo metadados e acesso aos periódicos com cobertura internacional.

Abrangendo todas as áreas do conhecimento, ao longo dos seus dez anos o portal disponibiliza mais de 9.900 periódicos e possui lista que permite realizar uma pesquisa por: ordem alfabética, país e área. Quando clicamos no título do periódico que desejamos consultar, o link remete para a página da base de dados em que a publicação está indexada - por exemplo, ABCD, site SCIELO.

Para estar presente no diretório é exigido dos periódicos que façam uso de uma licença de Creative Commons dos tipos: BY/BY NC. A título de curiosidade, a maioria dos periódicos disponíveis nesse diretório adota a licença BY.

\section{Critérios}

Para ser incluso no portal é necessário que o periódico: 1) preencha um formulário de avaliação ${ }^{24}$ contendo informações detalhadas sobre os fascículos; 2) faça uso de um processo de peer review ou controle editorial (corpo editorial e/ou sistema de peer review); 3) seja open access e 4) apresente número de ISSN.

\section{Comitê}

O comitê consultor é formado por uma equipe de 14 membros, divididos em:

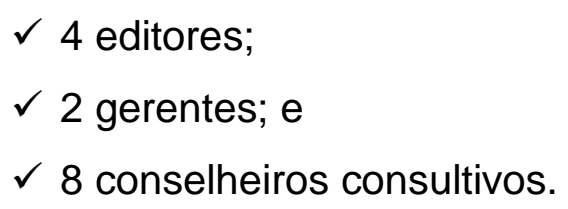

\footnotetext{
${ }^{24}$ Formulário de avaliação DOAJ disponível em: $<$ https://docs.google.com/spreadsheet/ccc?key=0AIFw8p9XB3C6dHE3ZC1Hd2FMMjAweE96czRQb3NDb nc\#gid=0>.
} 
O comitê também conta com uma parceria com publisher e outros, como Spring e Redalyc.

\section{Objetivo}

O link para as instruções aos autores possui um diferencial: tem atalhos diretos para divulgação automática do conteúdo acessado em blogs, Facebook, Twitter e email.

\section{Observação}

O DOAJ publicou novos critérios ${ }^{25}$ em 12 de junho de 2013. São eles:

$\checkmark$ fornecer informações sobre o ISSN;

$\checkmark$ fornecer informações sobre as políticas do periódico;

$\checkmark$ ter um conselho editorial cujos membros apresentem a afiliação institucional;

$\checkmark$ publicar no mínimo cinco artigos por ano;

$\checkmark$ o texto completo, metadados e citações de artigos podem ser rastreados e acessados com permissão (Máquina Readability Nível 4);

$\checkmark$ reutilização sujeita a certas restrições, sem remixagem (Reuse Direitos Nível 3);

$\checkmark$ permitir que os autores mantenham os direitos autorais em seu artigo, sem restrições (Copyrights Nível 1);

$\checkmark$ autor pode postar a versão manuscrito peer-reviewed final e postprint em qualquer repositório ou website.

\subsubsection{Index to Journals in Communication Studies (Índice} Impresso)

\section{Sobre a base}

Não foi encontrado nenhum tipo de informação sobre esse índice. Percebe-se que não é uma base de dados, porém, não foi possível comprovar sem a realização de uma análise mais profunda das informações acerca dele.

\footnotetext{
${ }^{25}$ Nova versão dos critérios: <http://www.doaj.org/doaj?func=news\&nld=303\&uiLanguage=en>.
} 
5.1.8 INFOBILA - Base de Datos de Información y Bibliotecología Latinoamericana

\section{Sobre a base}

Assim como a base de dados CLASE, a INFOBILA foi criada no México, a partir de um projeto de cooperação entre vários países, com o objetivo de reunir, organizar e facilitar o acesso à literatura da biblioteconomia e estudos da informação da América Latina e Caribe, num total de 29 países.

A base de dados disponibiliza diversos tipos de documentos, tais como artigos, capítulos de livros, teses e documentos audiovisuais. São mais de 17.000 registros de artigos de periódicos.

\section{Pesquisa}

A pesquisa pelo termo "biblioteconomia" recuperou uma página com 19 registros, o mais atual datado de 2003. Os periódicos e artigos pesquisados e recuperados através da INFOBILA possuem uma defasagem de dez anos. A título de exemplo, o periódico Perspectiva em Ciência da Informação apresentou como último número publicado na base, um fascículo de 2006.

\section{Critérios}

Não diz nada sobre critérios de avaliação.

\section{Comitê}

Não trás informações sobre a existência de um comitê científico.

Faz falta a apresentação de uma listagem em ordem alfabética de todos os títulos e também a data de atualização dos dados da base.

\section{Contato}

Para entrar em contato com os seus mantenedores é necessário encaminhar as dúvidas através de um formulário. A base não disponibiliza um número de telefone ou endereço de email. Todas as perguntas devem ser encaminhadas por esse formulário ${ }^{26}$, que é disponibilizado em sua home page.

\footnotetext{
${ }^{26}$ Formulário de avaliação da INFOBILA: <http://132.248.242.3/ ibt/formareg.htm>.
} 


\subsubsection{Web of Science (WOS) e Journal Citation Reports (JCR)}

\section{Sobre o índice WoS}

Como um produto da Thomson Reuters (antigo Institute for Scientific Information - ISI), a base de dados Web of Science é um índice de citação tido como o mais popular do mundo. Com o objetivo de facilitar o acesso rápido ao banco de citações, pesquisadores, administradores, professores e estudantes estão diante de um banco de dados que abrange mais de 12 mil dos principais periódicos internacionais e regionais de todas as áreas das ciências naturais, sociais, artes e humanidades. Deriva do Science Citation Index, criado na década de 1960 por Eugene Garfield.

\section{Critérios}

Cada periódico incluso no Web of Science passa por um processo de avaliação objetiva. Muitos fatores são levados em conta no processo de avaliação dos periódicos:

$\checkmark$ padrões básicos de uma publicação;

$\checkmark$ conteúdo editorial;

$\checkmark$ diversidade internacional dos autores;

$\checkmark$ dados de citação;

$\checkmark$ Fator de Impacto combinado com pontos fortes e pontos fracos dos periódicos;

$\checkmark$ pontualidade;

$\checkmark$ texto completo em inglês;

$\checkmark$ processo de peer review;

$\checkmark$ conteúdo editorial;

$\checkmark$ diversidade institucional dos autores; editores e membros do corpo editorial; e

$\checkmark$ análise de citação.

O editor deve encaminhar três fascículos atuais e consecutivos. Os periódicos são avaliados em seu suporte impresso e on-line. 


\section{Comitê consultivo}

A equipe executiva da Thomson Reuters é composta por 11 membros.

\section{Sobre o relatório de citação de periódicos JCR}

Criada em 1976, essa base tem o objetivo de oferecer indicadores de citação dos principais periódicos do mundo. O JCR oferece o Fator de Impacto, sendo uma marca registrada da empresa cujo uso se propagou em todo mundo.

\subsubsection{LAPTOC - Latin American Periodicals Tables of Contents}

\section{Sobre a base}

A LAPTOC ${ }^{27}$ disponibiliza acesso a 975 periódicos acadêmicos e de pesquisa, incluindo referências bibliográficas para 340 mil artigos. De acesso aberto, abrange principalmente a área de ciências humanas e sociais. Envolvendo 29 países da região, os periódicos e referências bibliográficas são disponibilizados em formato eletrônico para periódicos da América Latina e do Caribe.

A base de dados está hospedada na Universidade de Vanderbilt e faz parte de um projeto de consórcio de bibliotecas Latin Americanist Research Resources Project (LARRP) ${ }^{28}$, que visa aumentar o acesso livre e aberto à informação.

A busca pelas informações pode ser realizada por: título do periódico; palavras-chave; títulos dos artigos; e país de publicação.

\section{Critérios}

Não foi possível identificar os critérios de seleção dessa base.

\section{Comitê}

Possui um comitê consultivo formado por 55 pessoas, pertencentes à LARRP (Anexo 3).

\footnotetext{
${ }^{27}<$ http://laptoc.library.vanderbilt.edu/query/about.jsp $>$. Acesso em: 04 ago. 2013

28 http://www.crl.edu/grn/larrp
} 
As informações na página da LARRP dizem que existe um grupo de trabalho denominado Serials. Ele é responsável pela supervisão dos periódicos Mesa-de-Conteúdo da América Latina ${ }^{29}$ (LAPTOC), e coordena a introdução da tabela de conteúdo por parte de membros.

No site consta que mais informações sobre esse grupo de trabalho podem ser encontradas nas "Serials Grupo de Trabalho Workspac" ${ }^{30}$; porém, ao se clicar no link é solicitado login e senha. Ao clicar em "cadastrar" e inserir o email, surge uma mensagem dizendo que o mesmo não existe.

5.1.11 LATINDEX - Sistema Regional de Información en Línea para Revistas Científicas de América Latina, el Caribe, España y Portugal

\section{Sobre o sistema}

O objetivo do Latindex é divulgar as informações de periódicos científicos, técnicos profissionais e de divulgação científica editados nos países da América Latina, Caribe, Espanha e Portugal.

É produto de cooperação de uma rede de instituições que funcionam de maneira coordenada para reunir e disseminar informações bibliográficas sobre as publicações científicas produzidas na região.

A ideia da criação do portal surgiu em 1995, na Universidade Autônoma do México (UNAM), tendo se transformado, a partir de 1997, em uma rede de cooperação regional, oferecendo acesso aos dados de três bases de dados:

1) Diretório: disponibiliza toda e qualquer revista acadêmica, desde que seja um periódico registrado (com numero de ISSN);

2) Catálogo: inclui unicamente periódicos impressos ou eletrônicos que cumprem os critérios impostos pelo sistema do Latindex; e

3) Link para periódicos eletrônicos: para acessar a página on-line no próprio site do periódico.

Com a missão de elevar a qualidade dos periódicos científicos, seus objetivos específicos visam estabelecer políticas e ações que conduzam os

\footnotetext{
${ }^{29}$ http://laptoc.library.vanderbilt.edu/query/basic_search.jsp

${ }^{30} \mathrm{http}: / /$ workspace.crl.edu/login.action?os_destination=\%2Fpages\%2Fviewpage.action\%3FspaceKey\%3DI arrpswg\%26title\%3DHome
} 
periódicos disponibilizados pelo Latindex a uma maior visibilidade e cobertura internacional, aproveitando as informações para elaborar novos conhecimentos.

\section{Critérios}

Para que um periódico seja incluído no Latindex é necessário fazer um primeiro contato com o representante do sistema em seu país de origem. No caso do Brasil, o contato é realizado através do IBICT ${ }^{31}$.

O sistema disponibiliza uma relação com 36 itens relacionados a características editoriais dos periódicos. Para ingressar no catálogo é necessário que o periódico cumpra no mínimo 25 características, das quais 8 são classificadas como obrigatórias. Em resumo, os aspectos levados em conta no momento da avaliação dos periódicos são:

$\checkmark$ existência de um corpo editorial;

$\checkmark$ 40\% dos artigos originais;

$\checkmark$ tempo de existência de no mínimo 1 ano ou 3 fascículos;

$\checkmark$ demonstrar a geração de novos conteúdos;

$\checkmark$ identificação dos autores;

$\checkmark$ local de edição;

$\checkmark$ navegação e funcionalidade;

$\checkmark$ mencionar a periodicidade;

$\checkmark$ publicar o nome dos membros do corpo editorial com suas afiliações;

$\checkmark$ afiliação dos autores

$\checkmark$ publicação das datas de recebimento e aprovação dos artigos;

$\checkmark$ sistema de arbitragem;

$\checkmark$ avaliadores externos;

$\checkmark$ abrangência dos autores (mínimo 50\% de autores externos);

$\checkmark$ palavras-chave; e

$\checkmark \quad$ resumo em duas línguas.

${ }^{31}$ Elza Maria Ferraz Barboza - Brasil - IBICT - latindex@ibict.br. 
Esses critérios são aplicados ao grupo do Catálogo ${ }^{32}$, e estão detalhados no Anexo 4.

Não foram localizadas informações sobre a existência de um comitê consultivo e reuniões para avaliação dos periódicos.

\subsubsection{Library Literature \& Information Science Index}

\section{Sobre a base}

Desenvolvida por bibliotecários, a base de dados Library Literature \& Information Science Index indexa de forma completa (capa a capa) cerca de 400 periódicos da área de biblioteconomia e ciência da informação.

Oferecendo documentos que datam de 1980 e com ampla cobertura, a base serve como importante ferramenta para os estudos de biblioteconomia, abrangendo temas como automação, catalogação, ajuda do governo, censura, direitos autorais, indexação, livros raros, relações públicas etc.

Como a base de dados é um produto da EBSCO, para ter acesso ao seu conteúdo é necessário pagar e também ser ligado a uma instituição (e ser um representante autorizado da mesma).

\section{Critérios}

Não faz qualquer referência a critérios de avaliação.

\section{Comitê}

Não traz informações sobre a existência de um comitê científico.

\section{Observação}

Existe uma página comum da $\mathrm{EBSCO}^{33}$ (disponível para todas as suas bases) que contém um "painel" no qual são disponibilizadas as capas de alguns periódicos. É possível clicar nelas e acessar o seu conteúdo; porém, oferece o conteúdo de somente um artigo, tipo uma "amostra" do que é disponibilizado pela base.

\footnotetext{
${ }^{32}$ O catálogo inclui unicamente revistas impressas ou eletrônicas que cumprem os critérios impostos pelo sistema do LATINDEX.

${ }^{33}<$ http://www.ebsco.com/about>.
} 


\subsubsection{LISA - Library and Information Science Abstracts}

\section{Sobre a base}

A LISA é uma base de dados da área de biblioteconomia que indexa atualmente mais de 440 periódicos de quase 70 países, em mais de 20 idiomas. A cobertura de assuntos inclui todos os aspectos da biblioteconomia, usuários de biblioteca, recuperação de informações, tecnologia da informação, gestão do conhecimento, uso da biblioteca e recuperação de informações online, entre outros.

\section{Critérios}

Como a base de dados é pertencente ao ProQuest, os critérios para inclusão da também trazem este nome: "critérios para inclusão de produtos na ProQuest".

A avaliação é baseada em extensa pesquisa de mercado entre bibliotecários e educadores, rankings de publicação de especialistas de disciplinas externas e exame aprofundado de indexação atual das publicações.

De qualquer maneira, não está claro se existe um critério somente para a base LISA ou se este é utilizado por ela e todas as outras disponibilizadas através do ProQuest.

\section{Comitê}

Não informa se existe um comitê consultivo. Em sua página traz a seguinte informação: equipes avaliam a melhor forma de pesquisa de conteúdo da fonte do seu site, por exemplo, cópia, alimentação eletrônica etc.

Caso haja interesse, os responsáveis pela publicação devem entrar em contato com os mantenedores da base por telefone ou email; então, um representante da parceria entrará em contato para solicitação as informações.

\section{Observação}

As informações somente podem ser acessadas através de instituições. Não é possível acessá-las sem o IP de uma universidade. 
5.1.14 PASCAL THEMA - Science de L'information Documentation

\section{Sobre a base}

Acessível através do Dialog, a Pascal Thema é uma base de dados multidisciplinar, produzida pelo Institut de I'Information Scientifique el Technique (INIST) do Conselho Nacional de Pesquisa Francês (CNRS).

Os registros do Dialog ${ }^{34}$ informam que a base foi criada em 1973 e está ativa até o presente momento. Fornece acesso à literatura científica e técnica do mundo e inclui cerca de 450 mil novas citações por ano (DIALOG, 2013).

$A$ base de dados possui cobertura internacional, abrangendo as áreas da física, ciências da vida; ciências sociais aplicadas, ciências da terra e ciência da informação. Além disso, indexa os seguintes tipos de documento:

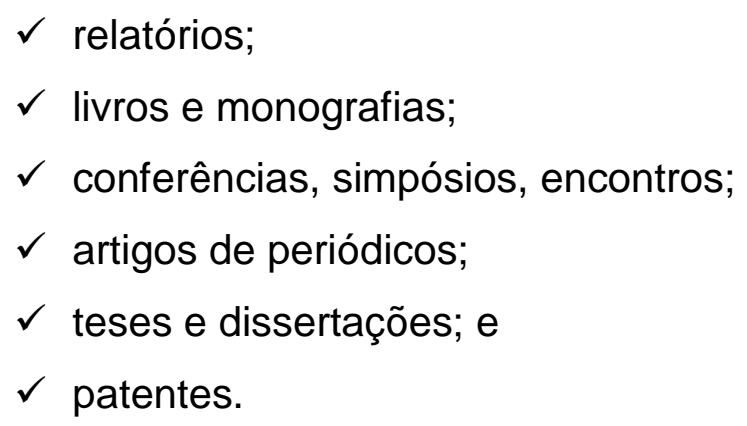

Utiliza descritores controlados a partir de um vocabulário com mais de 80 mil termos, cadastrados em inglês, francês e, em alguns casos, espanhol e alemão.

\section{Critérios}

Não diz nada sobre critérios de avaliação.

\section{Comitê}

Não traz informações sobre a existência de um comitê científico.

Possui informações de contato (endereço, telefone e email); porém, tentamos contatar a base sem êxito, não recebendo nenhum retorno.

\section{Observação}

\footnotetext{
${ }^{34}$ http://library.dialog.com/bluesheets/html/bl0144.html\#GC
} 
Não foi possível acessar as informações da base de dados pelo site. As mesmas foram localizadas pelo Dialog.

5.1.15 REDALYC - Red de Revistas Científicas de América Latina, el Caribe, España y Portugal

\section{Sobre a base}

Redalyc é uma base de dados internacional que disponibiliza cerca de 700 títulos de periódicos, artigos com texto completo e em formato eletrônico.

O acesso à base é gratuito, não precisando de IP de universidade. Sua interface é amigável e as buscas podem ser realizadas por países, instituições, autores, disciplinas artigos e periódicos.

Uma curiosidade: o Brasil é a terceira maior coleção da Redalyc, porém, fica em primeiro lugar de produção científica dentre os países constantes na base.

\section{Critérios}

Possui 60 critérios, dos quais 39 deles são considerados mais importantes. Para que uma coleção seja disponibilizada na base, é necessário que o periódico cumpra $82 \%$ dos critérios. Os mais importantes são:

$\checkmark$ tempo de existência;

$\checkmark$ 75\% de artigos originais;

$\checkmark$ revisão por pares;

$\checkmark$ artigos inéditos;

$\checkmark$ periodicidade;

$\checkmark$ título;

$\checkmark$ ISSN; e

$\checkmark$ data de recebimento e aceitação.

Por fim, os periódicos são avaliados por um comitê composto por 13 membros.

\section{Observação}

A base disponibiliza email para contato. 


\subsubsection{SciELO - Scientific Electronic Library Online}

\section{Sobre a base}

SciELO é uma base de dados regional, que indexa e disponibiliza periódicos científicos de todas as áreas do conhecimento. Com o objetivo de contribuir para disseminação do conhecimento científico na América Latina, Portugal e Caribe, surgiu de uma parceria da FAPESP e do CNPq, com um projeto piloto de dez periódicos científicos. Hoje, somente a Coleção SciELO Brasil conta com 320 títulos. Desses, 279 são títulos correntes. A base indexa e disponibiliza documentos on-line e com acesso aberto, textos completos de todas as áreas do conhecimento. Além disso, possui metadados e por meio deles é possível extrair relatórios diversos, tais como: acesso aos periódicos, acesso aos idiomas publicados na base e artigos mais visitados por mês.

Possui interface amigável e a pesquisa pode ser realizada por: lista alfabética; lista por assunto; pesquisa por títulos; autores; assuntos; e artigos.

\section{Comitê}

As reuniões são realizadas de 4 a 6 vezes por ano e conta com a presença de um comitê consultivo formado por membros representantes das cinco áreas do conhecimento: ciências agrárias, ciências biológicas, ciências exatas, ciências humanas e linguística, letras e artes. Possui ainda representantes da FAPESP, CNPq, ABEC, Capes e também o coordenador operacional do programa SciELO, que atua como membro coordenador do Comitê Consultivo.

\section{Critérios}

Diversos aspectos dos periódicos são levados em conta no momento da avaliação. Para ser incluído na Coleção SciELO Brasil o periódico passa por um processo de avaliação baseado em critérios adotados internacionalmente pelas bases de dados. Dessa forma, é avaliado não somente por seu conteúdo, mas também por aspectos como:

$\checkmark$ publicação predominante de contribuições originais; 
$\checkmark$ revisão e aprovação por pares das contribuições publicadas;

$\checkmark$ composição pública e heterogênea do conselho editorial;

$\checkmark$ periodicidade regular;

$\checkmark$ tempo de existência do periódico;

$\checkmark$ pontualidade na publicação;

$\checkmark$ resumos, título e palavras-chave em inglês, quando esse não é o idioma do artigo;

$\checkmark$ adoção e especificação das normas utilizada no periódico;

$\checkmark$ identificação das afiliações dos autores; e

$\checkmark$ citações recebidas dos periódicos da Coleção.

Para fazer parte da Coleção SciELO é necessário que o editor preencha um formulário contendo os dados dos três últimos fascículos publicados e o envie por email juntamente com o formulário que o periódico utiliza para análise dos artigos (peer review). No caso da opção pela análise do fascículo impresso, o editor deve encaminhar três exemplares correspondentes à documentação preenchida.

\section{Observação}

A base avalia os periódicos tanto no suporte impresso como no suporte on-line, aplicando em ambos os mesmos critérios.

\subsubsection{SCOPUS}

\section{Sobre a base}

É uma base de dados de resumo e citação. Possui ferramentas inteligentes para acompanhar, analisar e visualizar a pesquisa. Oferece uma visão mais abrangente dos resultados da investigação do mundo nas áreas de ciência, tecnologia, medicina, ciências sociais, artes e humanidades.

Abrange 50 milhões de registros e cerca de 18 mil títulos de mais de 5 mil publishers internacionais, com cobertura de 16.500 periódicos pertencentes à área de ciências médicas e ciências sociais. 
É hoje a melhor ferramenta para estudos bibliométricos e avaliações de produção científica, não apenas por seu incomparável conteúdo, mas também por ser a única base que reúne as ferramentas adequadas, tais como: perfil de autor, perfil de instituição, rastreador de citações, índice $\mathrm{h}$ e analisador de periódicos. (SCOPUS, 2012).

\section{Critérios}

$\checkmark$ Política editorial: possuir processo de peer review; diversidade geográfica dos autores e editores;

$\checkmark$ ter um número de ISSN;

$\checkmark$ conteúdo: deve ser relevante e legível para um público internacional, apresentando clareza nos resumos e conteúdo em acordo com o escopo;

$\checkmark$ a publicação deve seguir os princípios éticos;

$\checkmark$ regularidade: publicar sem atrasos no cronograma de publicação;

$\checkmark$ disponibilidade on-line; e

$\checkmark$ resumo em inglês e no idioma do artigo.

\section{Comitê consultivo}

O comitê de seleção de conteúdo é formado por um grupo internacional de cientistas, pesquisadores e bibliotecários representantes de todas as áreas do conhecimento. Os conselheiros são responsáveis por analisar todos os títulos que são sugeridos para serem indexados no Scopus.

\section{Observações}

De propriedade da Elsevier, seu acesso é pago; para ter acesso aos dados da base é necessário fazer assinatura.

A base aceita indicação de títulos para serem indexados. Para tanto, é necessário preencher um formulário com dados detalhados do título a ser indicado.

Ranking de periódicos e países (SCIMAGO JOURNAL \& COUNTRY RANK) 
Portal que disponibiliza diversos indicadores dos periódicos científicos, especialmente o SCImago Journal Ranking (SJR). Os dados dos periódicos são extraídos a partir das informações disponibilizadas na base de dados Scopus.

\subsection{ANÁLISE DE USO DAS BASES PELAS ÁREAS DE AVALIAÇÃO}

A análise dos dados contemplou os itens considerados mais relevantes, tais como: ter ou não critérios de seleção; utilizar ou não processo de peer review; tempo de existência do periódico; e diversidade geográfica.

Considerando que a indexação em fontes de informação é um dos critérios que garantem aos periódicos científicos uma melhor classificação no Qualis Capes, é importante identificar as fontes de informação que realmente aferem a qualidade e o mérito científico dos periódicos.

De acordo com Castro (2011), da mesma forma que as revistas científicas são avaliadas, as fontes também devem ser, segundo critérios específicos que estabeleçam um processo de seleção que privilegie os aspectos de qualidade dos periódicos.

Analisando as 17 fontes de informação consideradas nos documentos da área de Ciências Sociais Aplicadas foi possível identificar que: nove fontes (ou 53\%) possuem critérios de seleção e os disponibilizam em seus sites. Dessas, sete são bases de dados, um é repositório e o último, diretório.

Apoiando-se em Castro (2011), que considera que os critérios e processos de seleção adotados pelas fontes garantem o nível de autoridade e mérito científico nas suas áreas de cobertura, é possível inferir que as bases (e/ou diretórios e/ou índices) que não os disponibilizam não deveriam servir como parâmetro de avaliação.

A autora afirma ainda que as fontes de informação que não declaram explicitamente os critérios de seleção que adotam, ou aquelas que têm padrões muito abrangentes para a cobertura em sua área de conhecimento, podem ser comparadas com periódicos que não descrevem seu processo de revisão por pares. 
É o caso das oito fontes de informação (ou 47\%) restantes, que não disponibilizam seus critérios de seleção em seus sites, suscitando a indagação se esses critérios realmente existem. Dessa constatação questiona-se a adoção de tais fontes para composição de critérios. De acordo com o Quadro 3 , todas essas bases eram adotadas pela área de Ciências Sociais Aplicadas I, no triênio de 2007-2009. No entanto, deixaram de ser utilizadas no triênio seguinte.

Quadro 3 - Fontes de informação: tipo, critérios de seleção e comitê consultivo.

\begin{tabular}{|c|c|c|c|c|c|c|c|c|c|}
\hline \multirow[b]{2}{*}{$\begin{array}{l}\text { Fontes de } \\
\text { Informação }\end{array}$} & \multicolumn{5}{|c|}{ Tipo } & \multicolumn{3}{|c|}{ Critérios } & \multirow[b]{2}{*}{$\begin{array}{c}\text { Possui } \\
\text { comitê } \\
\text { consultivo }\end{array}$} \\
\hline & $\begin{array}{l}\text { Base de } \\
\text { Dados }\end{array}$ & Repositório & Diretório & Índice & $\begin{array}{l}\text { Sistema de } \\
\text { Informaçăo }\end{array}$ & $\begin{array}{l}\text { Possui critérios } \\
\text { de seleçấo }\end{array}$ & $\begin{array}{c}\text { Peer } \\
\text { reviem }\end{array}$ & $\begin{array}{l}\text { Diversidade } \\
\text { geográfica/ } \\
\text { endogenia }\end{array}$ & \\
\hline \multicolumn{10}{|l|}{ CLASE } \\
\hline \multicolumn{10}{|l|}{ WOS/JCR } \\
\hline \multicolumn{10}{|l|}{ LATINDEX } \\
\hline \multicolumn{10}{|l|}{ LISA } \\
\hline \multicolumn{10}{|l|}{ REDALYC } \\
\hline \multicolumn{10}{|l|}{ SCiELO } \\
\hline \multicolumn{10}{|l|}{ ScOPUS / ScIMago } \\
\hline \multicolumn{10}{|l|}{ CLACSO } \\
\hline \multicolumn{10}{|l|}{ DOAJ } \\
\hline \multicolumn{10}{|l|}{ CMMC } \\
\hline \multicolumn{10}{|l|}{ ComAbstracts } \\
\hline \multicolumn{10}{|l|}{\begin{tabular}{|l} 
Communication \\
Abstracts
\end{tabular}} \\
\hline \multicolumn{10}{|l|}{ INFOBILA } \\
\hline \multicolumn{10}{|l|}{ LAPTOC } \\
\hline \multicolumn{10}{|l|}{$\begin{array}{|lr|}\text { Library } & \text { Literature \& } \\
\text { Information } & \text { Science } \\
\end{array}$} \\
\hline \multicolumn{10}{|l|}{ Pascal } \\
\hline $\begin{array}{l}\text { Index to Journals in } \\
\text { Communication }\end{array}$ & & & & & & & & & \\
\hline
\end{tabular}

Outro aspecto relevante em relação à maioria das fontes utilizadas pela área de Ciências Sociais Aplicas I é a não existência informações sobre comitê consultivo, também descritas no Quadro 3.

Mais uma vez considerando a pesquisa de Castro (2011, p. 121), entendemos que "[...] a existência de critérios e de Comitês de Seleção idôneos e a rigorosidade com que os critérios são aplicados constituem os elementos mais decisivos na diferenciação das bases de dados". Deve-se destacar ser 
necessário que tais comitês atuem de maneira a garantir que o processo de seleção se efetive segundo os critérios de avaliação.

O processo de avaliação pelos pares (peer review), cuja função é aferir o mérito científico dos periódicos, tem papel essencial na seleção, o que se confirma pelo fato de que, de todas as fontes que definem critérios de seleção, apenas LISA não divulga a adoção desse tipo de iniciativa.

Outro aspecto levado em consideração quando da avaliação de periódicos, a diversidade geográfica dos membros do conselho editorial, autores e revisores é um aspecto destacado na literatura. Dentre as fontes de informação analisadas, apenas as bases de dados de maior escopo declaram explicitamente a utilização desse critério de seleção: WoS e Scopus, com abrangência mundial; e SciELO e CLASE, com abrangência regional.

Foi observado que SciELO e CLASE são as únicas fontes que exigem do periódico: 1) que publique as data de recebimento e aceite e 2) considere a questão da diversidade institucional e geográfica dos membros do corpo editorial, autores e revisores.

Antes do triênio 2007-2009 poucas áreas estudadas utilizavam bases de dados como critério para classificação dos periódicos (quadro abaixo). No triênio 2001-2003, várias delas não tinham um documento de área definido, ou o documento era demasiadamente simplificado (ver Anexo 5).

A área de Administração, que considerava Redalyc, SciELO, Scopus e Wos/JCR, passou a considerar também as fontes DOAJ, GALE, CLASE, HAPI, ICAP e IBSS para classificação dos periódicos da área, o que pode significar a adoção de critérios utilizados por outras áreas de avaliação (por exemplo as Ciências Sociais Aplicadas I) em triênios anteriores.

Já a área de Arquitetura e Urbanismo, que no triênio de 2007-2009 não considerava indexação em bases de dados para classificar seus periódicos, passou a basear-se em indicadores de impacto (Fator de Impacto JCR e SCImago Journal Ranking) e presença em bases de dados como Latindex e SciELO no triênio atual.

A área de Economia, que não utiliza o Fator de Impacto isoladamente no triênio de 2007-2009, menciona que o fazia no triênio de 2001-2003, passando a compor um índice de citação próprio, sugerindo que este índice foi sendo 
aprimorado até o último triênio (ainda que não apresente detalhes de como o mesmo é calculado, limitando-se a citar um estudo realizado por um pesquisador estrangeiro da área).

Quadro 4: Fontes de informação utilizadas pelas áreas de avaliação das Ciências Sociais Aplicadas, segundo triênio de avaliação e estrato de classificação dos periódicos.

\begin{tabular}{|c|c|c|c|c|c|c|c|}
\hline \multirow[b]{2}{*}{$\begin{array}{c}\text { Fontes de } \\
\text { Informação }\end{array}$} & \multicolumn{7}{|c|}{ Áreas de avaliação: grande área Ciências Sociais Aplicadas } \\
\hline & $\begin{array}{l}\text { Administração, } \\
\text { Ciências } \\
\text { Contábeis e } \\
\text { Turismo }\end{array}$ & $\begin{array}{l}\text { Arquitetura } \\
\text { e Urbanismo }\end{array}$ & $\begin{array}{l}\text { Ciências Sociais } \\
\text { Aplicadas I }\end{array}$ & Direito & Economia & $\begin{array}{c}\text { Planejamento Urbano } \\
\text { e Regional / } \\
\text { Demografia }\end{array}$ & Serviço Social \\
\hline CLACSO & - & - & 2007-2009: B2 & - & - & - & - \\
\hline CLASE & - & - & 2007-2009: B2 & - & - & - & - \\
\hline CMMC & - & - & 2007-2009: A2;B1;B2 & - & - & - & - \\
\hline ComAbstracts & - & - & 2007-2009: A2;B1;B2 & - & - & - & - \\
\hline $\begin{array}{l}\text { Communication } \\
\text { Abstracts }\end{array}$ & - & - & 2007-2009: A2;B1;B2 & - & - & - & - \\
\hline DOAJ & - & - & 2007-2009: A2;B1;B2 & - & - & - & - \\
\hline $\begin{array}{l}\text { Index to Journals in } \\
\text { Communication }\end{array}$ & - & - & 2007-2009: A2;B1;B2 & - & - & - & - \\
\hline INFOBILA & - & - & 2007-2009: A2;B1;B2 & - & - & - & - \\
\hline LAPTOC & - & - & 2007-2009: A2;B1;B2 & - & - & - & - \\
\hline LATINDEX & - & - & 2007-2009: A2;B1;B2 & - & - & 2007-2009: A1;A2;B1;B2 & - \\
\hline $\begin{array}{l}\text { Library Literature } \\
\text { \& Information }\end{array}$ & - & - & 2007-2009: A2;B1;B2 & - & - & - & - \\
\hline LISA & - & - & 2007-2009: A2;B1;B2 & - & - & - & - \\
\hline Pascal & - & - & 2007-2009: A2;B1;B2 & - & - & - & - \\
\hline REDALYC & 2007-2009: B1 & - & 2007-2009: A2;B1;B2 & - & - & - & - \\
\hline SCIELO & 2007-2009: B1 & - & 2007-2009: A2;B1 & 2007-2009: A1;A2 & - & 2007-2009: A1;A2;B1;B2 & 2007-2009: A1;A2;B1;B2;B3 \\
\hline SCOPUS / SCIMago & 2007-2009: A1;A2 & - & 2007-2009: A2;B1;B2 & 2007-2009: A1;A2 & - & - & 2007-2009: A1;A2;B1;B2;B3 \\
\hline WoS / JCR & \begin{tabular}{|l} 
2004-2006: A;B \\
2007-2009: A1;A2
\end{tabular} & - & 2007-2009: A1;A2;B1;B2 & 2007-2009: A1;A2 & 2001-2003 & - & 2007-2009: A1;A2;B1;B2;B3 \\
\hline
\end{tabular}

A utilização de fontes de informação que não publicam critérios de seleção de periódicos, pela área de Ciências Sociais Aplicadas I, conforme identificado no documento de áreas do triênio 2007-2009, foi alterada no triênio atual $^{35}$ (2010-2012). A área passou a considerar a indexação no JCR para classificar seus periódicos como A1; já para o estrato $A 2$, a exigência é que os mesmos estejam indexados nas bases Scopus e/ou SciELO. Para indexação no estrato B1, é exigida indexação em uma das seguintes bases: CLACSO, CLASE, DOAJ, LATINDEX e REDALYC; e das bases temáticas foram mantidas apenas as de Ciência da Informação e Museologia, INFOBILA e

${ }^{35}$ Os documentos de área do triênio atual não estavam disponíveis no momento de coleta dos dados, mas era possível acessar as comunicações que algumas comissões de área publicavam, quando da atualização do Qualis da área. 
LISA. Deve-se destacar no sítio da base INFOBILA não foram encontradas informações sobre critérios de seleção de periódicos, o que sugere ainda a necessidade de se questionar os mantenedores da base.

As áreas de Direito e Serviço Social utilizavam apenas os índices de citação (SciELO, Scopus e WoS) no triênio de 2007-2009. No documento de atualização dos critérios da área de Direito para o triênio de 2010-2012, já menciona utilização do Fator de Impacto.

E a área de Planejamento Urbano e Reginal / Demografia, que utilizava as bases LATINDEX e SciELO no triênio de 2007-2009, anuncia a adoção de outras fontes para o triênio seguinte: Library of the US Congress, Scopus, WoS (entre outras que não mencionam).

Como se pôde verificar, as fontes de informação são utilizadas pelas áreas de ciências sociais aplicadas para classificação dos periódicos de mais alto estrato, evidenciando a importância das mesmas para a definição dos rumos da comunicação científica de milhares de pesquisadores brasileiros. $\mathrm{O}$ rumo está traçado, cabendo a indagação sobre que adequações serão necessárias. Por essa razão diz-se que um projeto de pesquisa nunca termina. 


\section{CONSIDERAÇÕES FINAIS}

A realização desta pesquisa permitiu lançar luz sobre um aspecto da avaliação de produção científica nas Ciências Sociais Aplicadas, relacionado ao uso que vem sendo feito das fontes de informação para classificação de periódicos.

Em um primeiro momento percebeu-se que nem todas as fontes de informação analisadas configuraram-se como bases de dados, e, ainda, que as informações sobre os critérios de seleção adotados puderam ser verificadas em algumas das fontes, que consideradas como as mais importantes: CLASE, Latindex, LISA, Redalyc, SciELO, Scopus/SCImago e WoS/JCR.

Por outro lado, foi possível observar que tanto as bases com abrangência e popularidade mundial (Scopus/SCImago e WoS/JCR) quanto a SciELO, mantida com verba pública, apresentam uma prática de transparência no anúncio dos critérios utilizados no processo de seleção. Tal prática pode ter sido estimulada em virtude do esforço constante de editores, que por muitos anos lutaram e continuam lutando para conseguir a indexação.

Além da importância decorrente do uso dessas fontes de informação, soma-se o montante investido pela Capes para provimento de acesso a bases como WoS e Scopus. Tal esforço trouxe significativo avanço na produção científica nacional, mas parece ser necessário também um esforço político a fim de se conseguir maior transparência por parte de cada fonte de informação, no que diz respeito ao anúncio de sua política de seleção de periódicos. Ao mesmo tempo, o desenvolvimento de massa crítica quanto a esta questão permitirá que os critérios de bases nacionais ou regionais sejam consolidados, com vistas ao aprimoramento dos periódicos da região.

Entre as áreas de avaliação analisadas, pôde-se constatar que a situação mais problemática se evidenciou na área de Ciências Sociais Aplicadas I, que considerava uma maior diversidade de fontes de informação, porém todas as que não declaram seus critérios de seleção. Tratava-se de fontes com características diversas, porém tendo em comum o fato de serem 
fontes temáticas, associadas às áreas de ciência da informação ou comunicação.

Nas outras áreas esse aspecto não se mostrou tão problemático, pois o que se notou foi a utilização das bases internacionais mais conhecidas: Scopus/SCImago e WoS/JCR; e as bases regionais, cuja abrangência se atém ao contexto latino-americano: Latindex, Redalyc e SciELO. Por outro lado, nota-se o caso de áreas como Economia e Administração, Ciências Contábeis e Turismo, que vem utilizando o Fator de Impacto - destacando-se ainda o recente anúncio da Direito.

É importante considerar que, do ponto de vista dos profissionais que atuam nas bases de dados, existe uma percepção mais aguçada quanto aos quesitos sobre a qualidade esperada de um periódico científico. E do outro lado, quem está ligado ao meio editorial e às comissões das áreas não necessariamente percebe os detalhes que são fundamentais à efetividade da comunicação científica: a existência de critérios de seleção de periódicos, presença de um conselho editorial atuante, diversidade geográfica dos autores, revisores ad hoc e membros do conselho editorial e informações sobre a lista de títulos dos periódicos indexados pela fonte de informação.

O caminho já foi aberto por fontes de informação como WoS, SciELO, Redalyc e Scopus, que podem servir de modelo às demais áreas de avaliação - fora da grande área de Ciências Sociais Aplicadas I - o que denota a necessidade de estender esta pesquisa para as demais áreas. Tal iniciativa beneficiaria não apenas as comissões de área, e, por conseguinte a avaliação da produção científica nacional, mas também os editores dos periódicos, e certamente, os milhares de pesquisadores que estão inseridos no sistema. 


\section{REFERÊNCIAS}

ASSOCIAÇÃO BRASILEIRA DE NORMAS TÉCNICAS. NBR 6023/2002. Informação e documentação - referências - elaboração. Rio de Janeiro, 2002.

AXT, M. O pesquisador frente à avaliação na pós-graduação: em pauta novos modos de subjetivação. Psicologia \& Sociedade, Belo Horizonte, v. 16, n. 1, p. 69-85, 2004.2 Disponível em: <http://www.scielo.br/scielo.php?script=sci_arttext\&pid=S0102-

71822004000100006\&lng=pt\&nrm=iso>. Acesso em: 10 fev. 2010.

BARBALHO, C. R. S. Periódico científico: parâmetros para avaliação de qualidade. In: FERREIRA, S. M. S. P.; TARGINO, M. G. (Org.). Preparação de revistas científicas: teoria e prática. São Paulo: Reichmann \& Autores, 2005. p. 123-158.

BARRETO, A. A. Olhar sobre os 20 anos da Associação Nacional de Pesquisa e Pós-Graduação em Ciência da Informação (Ancib). Pesquisa Brasileira em Ciência da Informação, Brasília, v. 2, n. 1, p. 3-28, jan./dez. 2009. Disponível em: <http://inseer.ibict.br/ancib/index.php/tpbci/article/view/13/35>. Acesso em: 20 nov. 2012.

BIOJONE, M. R. Os periódicos científicos na comunicação da ciência. São Paulo: FAPESP, 2003.

COORDENAÇÃO DE APERFEIÇOAMENTO DE PESSOAL DE NÍVEL SUPERIOR. Diretoria de Avaliação. Documento de área. Brasília, 2010. Disponível em: <http://www.capes.gov.br/images/stories/download/avaliacao/SOC_APLIC_07 mai10.pdf>. Acesso em: 25 Ago. 2012.

CARVALHO, K. Revista científica e pesquisa: perspectiva histórica. In: POBLACIÓN, D. A. et al. (Org.). Revistas científicas: dos processos tradicionais às perspectivas alternativas de comunicação. Cotia: Ateliê Editorial, 2011. p. 23-42.

CASTRO, R. Indexação de revistas científicas em bases de dados. In: POBLACIÓN, D. A. et al. (Org.). Revistas científicas: dos processos tradicionais às perspectivas alternativas de comunicação. Cotia: Ateliê Editorial, 2011. p. 109-126.

CASTRO, R. C. F., FERREIRA, M. C. G. Periódicos latino-americanos: avaliação das características formais e sua relação com a qualidade científica. Ciência da Informação, Brasília, v. 25, n. 3, p. 357-67, set./dez. 1996.

CHARTIER, R. Origens culturais da Revolução Francesa. São Paulo: Ed. Unesp, 2009. 316p. 
Lynch C. A; Lippincott J. K. Institutional repository deployment in the United States as of early 2005. D-Lib Magazine, Reston, VA, US, v. 11, n. 9, September 2005. Disponível em: <http://www.dlib.org/dlib/september05/lynch/09lynch.html>. Acesso em: 28 ago. 2013.

CONSELHO NACIONAL DE DESENVOLVIMENTO CIENTÍFICO E TECNOLÓGICO. A criação. Brasília, [1995?]. Disponível em: <http://www.cnpq.br/web/guest/a-criacao>. Acesso em: 22 abr. 2013.

FACHIN, G. R. B. e HILLESHEIM, A. I. A. Periódico científico: padronização e organização. Florianópolis: Ed. da UFSC, 2006.

FÁVERO, M. L. A. A universidade no Brasil: das origens à Reforma Universitária de 1968. Educar em Revista, Curitiba, n. 28, p. 17-36, jul./dez. 2006. Disponível em: <http://www.scielo.br/pdf/er/n28/a03n28.pdf>. Acesso em: 6 ago. 2013.

FERREIRA, A. A. et al. Avaliação de periódicos científicos online na área do direito. CRB-8 Digital, São Paulo, v. 2, n. 2, p. 12-26, set. 2009.

FERREIRA, M. C. G, KRZYZANOWSKI, R. F. Periódicos científicos: critérios de qualidade. Pesquisa Odontológica Brasileira, São Paulo, v. 17; p. 43-8, 2003. Suplemento.

FONSECA, C. Avaliação dos programas de pós-graduação: do ponto de vista de um nativo. Horizontes Antropológicos, Porto Alegre, v. 7, n. 16, p. 261275, $2001 . \quad$ Disponível em: <http://www.scielo.br/scielo.php?script=sci_arttext\&pid=S010471832001000200014\&lng=pt\&nrm=iso>. Acesso em: 10 fev. 2012.

FUNDAÇÃO ESCOLA DE SOCIOLOGIA E POLÍTICA DO ESTADO DE SÃO PAULO. Histórico. São Paulo, [1995?]. Disponível em: <http://www.fespsp.org.br/sobre-a-fespsp>. Acesso em: 22 jul. 2013.

GIL, F. O plano da ciência. In: DEUS, J. D. (Org.). A crítica da ciência: sociologia e ideologia da ciência. 2. ed. Rio de Janeiro: Zahar, 1979. p. 158186.

JANOTTI, A. Origens da universidade: a singularidade do caso português. São Paulo: Edusp, 1992. 226p.

HAYASHI, M. C. P. I. Avaliação de periódicos científicos no contexto dos estudos. In: Hoffmann, W. A. M.; Furnival, A. C. M. Olhar: ciência, tecnologia e sociedade. São Carlos, SP: Pedro \& João Editores/CECH-UFSCar, 2008. p. 22.

KRZYZANOWSKI, R. F.; FERREIRA, M. C. G. Avaliação de periódicos científicos e técnicos brasileiros. Ciência da Informação, Brasília, v. 27, n. 2, p. 165-175, maio/ago. 1998. 
LAKATOS, E. M.; MARCONI, M. A. Fundamentos de metodologia científica. São Paulo: Atlas, 1985. 238 p.

LEDESMA, M. R. K. Evolução histórica da educação brasileira. Guarapuava: Ed. da Unicentro, 2010.

LOPES, M. I. V. Pesquisa em comunicação: formulação de um modelo metodológico. 4. ed. São Paulo: Loyola, 1999. 148p.

MATTELART, A. História da sociedade da informação. São Paulo: Loyola, 2002. 197p.

MATOSO, M. C. Aspectos simbólicos da produção científica: uma análise de periódicos da área de nutrição. 2004. 163f. Dissertação (Mestrado em Biblioteconomia e Ciência da Informação) - Pontifícia Universidade Católica de Campinas, Campinas.

MEADOWS, A. J. A comunicação científica. Brasília, DF: Briquet de Lemos, 1999.

MENEGHINI, R. Emerging journals: the benefits of and challenges for publishing scientific journals in and by emerging countries. EMBOreports, [S.I.], v. 13, n. 2, 2012.

MIRANDA, D. B.; PEREIRA, M. N. F. O periódico científico como veículo de comunicação: uma revisão de literatura. Ciência da Informação, Brasília, v. 25, n. 3, p. 375-382, 1996.

MOREIRA, M. L., VELHO, L. Pós-graduação no Brasil: da concepção "ofertista linear" para "novos modos de produção do conhecimento" implicações para a avaliação. AVALIAÇÃO, Campinas; Sorocaba, SP, v. 13, n. 3, p. 625-645, nov. 2008.

MOREL, R.L.M. Ciência e Estado, a política científica no Brasil. Queiroz. Editor: São Paulo, 1979.

MUELLER, S. P. M. O periódico científico. In: CAMPELO, B. S; CENDÓN, B. V; KREMER, J. M (Org.). Fontes de informação para pesquisadores e profissionais. Belo Horizonte: UFMG, 2000.

MUGNAINI, R. Caminhos para adequação da avaliação da produção científica brasileira: impacto nacional versus internacional. São Paulo, 2006. 253 p. Tese (Doutorado em Ciência da Informação) - Escola de Comunicações e Artes, Universidade de São Paulo, São Paulo. Disponível em: <http://www.teses.usp.br/teses/disponiveis/27/27151/tde-11052007091052/publico/TESE_mugnaini_r.pdf>. Acesso em: 12 ago. 2013. 
MUGNAINI, R. Avaliação da produção científica nacional: contextualização e indicadores. In: POBLACIÓN, D. A. et al. (Org.). Revistas científicas: dos processos tradicionais às perspectivas alternativas de comunicação. Cotia: Ateliê Editorial, 2011. p. 43-68.

Indicadores bibliométricos da base de dados pascal como fonte de informação da produção científica e tecnológica do Brasil. 2003. Dissertação (Mestrado em Biblioteconomia e Ciência da Informação). Pontifícia Universidade Católica de Campinas, Campinas.

MUGNAINI, R.; STREHL, L. Recuperação e impacto da produção científica na era Google: uma análise comparativa entre o Google Acadêmico e a Web of Science. Encontros Bibli, [s.I.], v. 13, p. 92-105, 2008.

MUGNAINI, R.; SALES, D. P. Mapeamento do uso de índices de citação e indicadores bibliométricos na avaliação da produção científica brasileira. In: ENCONTRO NACIONAL DE PESQUISA EM CIÊNCIA DA INFORMAÇÃO, 12., Brasília, 2011. Anais... Brasília: Thesaurus, 2011. v. 12. p. 2361-2372.

OHIRA, M. L. B., SOMBRIO, M. L. L. N., PRADO, N. S. Periódicos brasileiros especializados em biblioteconomia e ciência da informação: evolução. Encontros Bibli: Revista Eletrônica de Biblioteconomia e Ciência da Informação, Brasília, n. 10, p. 26-20, 2000.

OTLET, P. El tratado de documentación: el libro sobre el libro: teoría y práctica. Traducción M. D. A García. 2. ed. Murcia: Universidad de Murcia, 2007. 445p.

PESSANHA, C. Critérios editoriais de avaliação científica: notas para discussão. Ciência da Informação, Brasília, v. 27, n. 2, p. 226-229, 1998.

SANTOS, M. S. Perfil dos periódicos científicos de ciências sociais e humanidades: mapeamento das características extrínsecas. 2010. $174 \mathrm{f}$. Dissertação (Mestrado em Ciência da Informação) - Escola de Comunicação e Artes, Universidade de São Paulo, São Paulo.

SARMENTO e SOUZA, M. F. Periódicos científicos eletrônicos: apresentação de modelo para análise de estrutura. 2002. 133f. Dissertação (Mestrado em Informação e Tecnologia) - Faculdade de Filosofia e Ciências, Universidade Estadual Paulista, Marília. Disponível em: <http://www.athena.biblioteca.unesp.br/exlibris/bd/bma/33004110043P4/2002/s armentoesouza_mfs_me_mar.pdf>. Acesso em: 26 jan. 2013.

SCHWARTZMAN, S. Formação da comunidade científica no Brasil. São Paulo: Ed. Nacional; Rio de Janeiro: Financiadora de Estudos e Projetos, 1979.

SCHWARTZMAN, S. Um espaço para a ciência: a formação da comunidade científica no Brasil. Reedição. Brasília: MCT/CNPq/CEE, 2001. 
SCIENTIFIC ELECTRONIC LIBRARY ONLINE. Critérios SciELO Brasil: critérios, política e procedimentos para a admissão e a permanência de periódicos científicos na coleção SciELO Brasil. São Paulo, 2009. Disponível em: <http://www.scielo.br/avaliacao/criterio/scielo_brasil_pt.htm>. Acesso em: 05 dez. 2012.

SILVA, J. F. M.; SANTOS, M.; PRAZERES, A. P. P. Incubadora de revistas científicas. In: POBLACIÓN, D. A. et al. (Org.). Revistas científicas: dos processos tradicionais às perspectivas alternativas de comunicação. Cotia: Ateliê Editorial, 2011. p. 69-90.

SOUZA E. P.; PAULA M. C. S. QUALIS: a base de qualificação dos periódicos científicos utilizada na avaliação CAPES. INFOCAPES - Boletim Informativo da CAPES, São Paulo, v. 10, n. 2, p. 7-25, 2002. Disponível em: <http://www.capes.gov.br/images/stories/download/bolsas/Infocapes10_2_2002 .pdf>. Acesso em: 10 fev. 2010.

SPAGNOLO, F.; CALHAU, M. G. Observadores internacionais avaliam a avaliação da CAPES. INFOCAPES - Boletim Informativo da CAPES, Brasília, v. 10, n. 1, p. 7-34, 2002 . Disponível em: <http://www.capes.gov.br/images/stories/download/bolsas/Infocapes10_1_2002 .pdf>. Acesso em: 10 fev. 2010.

SPAGNOLO, F.; SOUZA, V. C. O que mudar na avaliação da Capes? Revista Brasileira de Pós-graduação, Brasília, v. 1, n. 2, p. 8-34, 2004. Disponível em: <http://www2.capes.gov.br/rbpg/images/stories/downloads/RBPG/Vol.1_2_nov2 004_/08_34_o_que_mudar_na_avaliacao_capes.pdf $>$. Acesso em: $10 \mathrm{fev}$. $201 \overline{0}$.

STUMPF, I. R.C. Reflexões sobre as revistas brasileiras. Intexto, Porto Alegre, v. 1, n. 3, 1998.

STUMPF, I.R.C. Passado e futuro das revistas científicas. Ciência da Informação, Brasília, v. 25, n. 3, 1996.

TEIXEIRA, A. Ensino superior no Brasil: análise e interpretação de sua evolução até 1969. Rio de Janeiro: Editora FGV, 1989. Disponível em: $<$ http://www.bvanisioteixeira.ufba.br/livros/chama_cap8.htm>. Acesso em: 20 ago. 2013

TESTA, J. A base de dados ISI e seu processo de seleção de revistas. Ciência da Informação, Brasília, v. 27, n. 2, p. 233-235, 1998.

TRIGUEIRO, M. G. S. A comunidade científica, o Estado e as universidades, no atual estágio de desenvolvimento científico tecnológico. Sociologias, Porto Alegre, $\quad \mathrm{n}$. 6, p. 30-50, 2001. Disponível em: <http://www.scielo.br/scielo.php?script=sci_arttext\&pid=S151745222001000200003\&lng=pt\&nrm=iso>. Acesso em: 10 fev. 2010. 
WEITZEL, S. R. E-PRINTS: modelo da comunicação científica de transição. In: FERREIRA, S. M. S.; TARGINO, M. G. (Org.). Preparação de revistas científicas. São Paulo: Reichmannn \& Autores, 2005.

WITTER, G. P. Revistas científicas: da incubação à visibilidade. In: POBLACIÓN, D. A. et al. Revistas científicas: dos processos tradicionais ás perspectivas alternativas de comunicação. Cotia, SP: Ateliê editorial, 2011. Disponível em:

<http://www.revistas.univerciencia.org/index.php/noticia/pages/view/indexacao> . Acesso em: 10 mai. 2013. 
ANEXOS 


\section{Anexo 1 - Modelo de protocolo utilizado para análise das bases de dados}

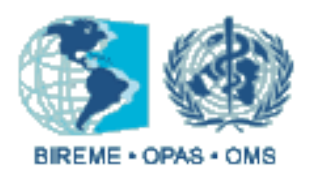

\section{BIREME/OPASIOMS}

Centro Latino-Americano e do Caribe de Informação em Ciências da Saúde Organização Pan-Americana da Saúde

Organização Mundial da Saúde

\section{Grupo de Trabalho sobre Literatura Científica em Saúde}

Protocolo para Avaliação de Bases de Dados

Versão para pré-teste (revisada durante a $1^{\mathrm{a}}$ reunião)

Março de 2008

\section{Identificação}

\section{BASE DE DADOS（） REPOSITÓRIO（） DIRETÓRIO（）}

1. Nome da base:

2. URL:

3. Instituição responsável:

4. Tipo de instituição: a) Pública ( ） b) Privada ( )

\section{Conteúdo}

5. Área temática da base:

6. Abrangência:
a) Internacional ( ) Especificar:
b) Regional ( ) Especificar:
c) Nacional ( ) Especificar:

Distribuição geográfica das revistas indexadas:
a) total de países ( )
b) total de títulos em 2013: informação não localizada

7. Tipos de documentos indexados:
a) Artigos de revistas ( )
b) Livros ( )
c) Capítulos de livros ( )
d) Dissertações e Teses ( )
e) Trabalhos de congressos ( )
f) Outros documentos ( ) Especificar:

8. Existência de lista de títulos indexados:
a) impressa ( )b) online ( ) c) não existe ( )
URL:

9. Duplicidade de conteúdo com outras bases de dados:
Explícita ( )
Não explícita ( )
Não há ( )
Especificar: 
10. Vocabulário para indexação:

Adota ( )

Especificar:

Não especifica ( ) Não adota ( )

Políticas de seleção

11. Existência de critérios de seleção

a) Explícitos no site ( )

URL:

b) Disponíveis em documento eletrônico ( )

URL:

c) Não disponíveis ( )

12. Existência de Comitê de Seleção

a) Existe Comitê e há informação explícita sobre os membros ( ) URL:

b) Existe Comitê, mas não há informação sobre os membros ( )

c) Não existe Comitê de Seleção ( )

13. Frequência de reuniões de avaliação:

14. Procedimentos para seleção

a) Instruções e formulário online para submissão de revistas ( )

URL:

b) Instruções online, mas não há formulário específico ( )

URL:

c) Não informa sobre os procedimentos de seleção ( )

\section{Visibilidade - navegabilidade - usabilidade}

15. Frequência de atualização dos registros (na interface pública)
a) Frequência:
Diária ( ) Semanal ( ) Mensal ( ) Outra ( ) Especificar:
b) Total de registros:
c) Total de registros ingressados em 2013:
d) Se possível, indicar total documentos publicados em 2013:

16. Acessibilidade
a) Acesso gratuito ( )
URL
b) Acesso por assinatura ( )

URL 

c) Disponível no Portal da Capes ( )
d) Disponível através de IP de Universidades ( )
e) Disponível em CD-ROM ( )

17. Acesso aos documentos indexados
a) Oferece acesso ao texto completo ( )
b) Oferece serviço de acesso ao documento ( )
c) Não oferece acesso aos documentos indexados ( )

18. Formatos de saída de acordo com normas nacionais ou internacionais $\operatorname{Sim}($ )

Não ( )

Quais normas?

19. Presença de tutoriais e manuais de orientação sobre conteúdo e uso da base de dados $\operatorname{Sim}($ )

Não ( )

20. Interface de busca: facilidade de operação

$\operatorname{Sim}($ )

Não ( )

21. Opção de contato com os produtores da base (Fale conosco, contact us etc.)

$\operatorname{Sim}($ )

Não ( )

22. A base fornece metadados?

$\operatorname{Sim}($ )

Não ( ) 


\section{Anexo 2 - Lista de títulos de periódicos da base de dados ComABSTRACTS}

\begin{tabular}{|c|c|c|c|}
\hline \#\# & Títulos & Fascículos & $\begin{array}{l}\text { Status de } \\
\text { publicação }\end{array}$ \\
\hline 1 & Avanços nos processos discursivos & 19771 & anual \\
\hline 2 & A revisão da Comunicação (1535-8593) & $3,2003(1)$ & contínuo \\
\hline 3 & American Journalism (0882-1127) & $19831(1)$ & contínuo \\
\hline 4 & Análise Retórica (0735-0198) & $19821(1)$ & contínuo \\
\hline 5 & Anuário Free Speech & 19621 & contínuo \\
\hline 6 & $\begin{array}{l}\text { Argumentação e Advocacy / Journal of the American } \\
\text { Association Forense (1051-1431) }\end{array}$ & $19641(1)$ & contínuo \\
\hline 7 & Asian Journal of Communication (0129-2986) & $19901(1)$ & contínuo \\
\hline 8 & Australian Journal of Communication (0811-6202) & $19821(1)$ & contínuo \\
\hline 9 & Avanços em Telemática & 19911 & anual \\
\hline 10 & Avanços na História da Retórica (1536-2426) & $19961(1)$ & contínuo \\
\hline 11 & Britânico Journalism Review (0956-4748) & $200516(1)$ & contínuo \\
\hline 12 & Canadian Journal of Communication (0705-3657) & $19785(1)$ & contínuo \\
\hline 13 & Canadian Journal of Studies retóricas (07.709-03.398) & $19944(1)$ & cessado \\
\hline 14 & $\begin{array}{l}\text { Catalão Jornal de Comunicação e Estudos Culturais (1757- } \\
\text { 1898) }\end{array}$ & $20091(1)$ & contínuo \\
\hline 15 & Ciências da Comunicação (1075-5470) & $199820(1)$ & contínuo \\
\hline 16 & Communicatie (0771-7342) & $199726(1)$ & cessado \\
\hline 17 & $\begin{array}{l}\text { Communicatio: Sul-Africano Jornal de Teoria e Pesquisa de } \\
\text { Comunicação (0250-0167) }\end{array}$ & $19751(1)$ & contínuo \\
\hline 18 & Communication Management Quarterly (0893-3189) & $19871(1)$ & contínuo \\
\hline 19 & Communication Quarterly / Discurso de hoje (0146-3373) & $19531(1)$ & contínuo \\
\hline 20 & Communication Research (0093-6502) & $19741(1)$ & contínuo \\
\hline
\end{tabular}


21 Comunicação (0305-4233)

22 Comunicação Ambiental: A Journal of Nature and Culture (1752-4032)

23 Comunicação de Massa e Sociedade (1520-5436)

24 Comunicação e Estudos Críticos / Cultural (1479-1420)

25 Comunicação e Medicina (1612-1783)

26 Comunicação Educação / Fala Professor (0363-4523)

27 Comunicação em Saúde (1041-0236)

28 Comunicação Escrita (0741-0883)

29 Comunicação Monografias / Monografias Speech (03637751)

30 Comunicação Política / Comunicação e persuasão política (1058-4609)

31 Comunicação Popular / (1540-5702)

32 Comunicação Review (1071-4421)

33 Comunicação Visual (1470-3572)

34 Comunicação Yearbook

35 Comunicação, Cultura e Crítica (1753-9129)

36 Comunicações: The European Journal of Communication Research (0341-2059)

37 Convergência (1354-8565)

38 Direito da Comunicação e Política (1081-1680)

39 Discurso e Sociedade (0957-9265)

40 Estudos australianos em Jornalismo (1038-6130)

41 Estudos Críticos em Media Comunicação / Estudos Críticos em Mass Communication (1529-5036)

42 Estudos de Comunicação / Central States Speech Journal (1051-0974)

43 Estudos de Jornalismo (1461-670X)

44 Estudos de Mídia Jornal / Ganett Centro Journal (1057-7416) 19871 (1) cessado
$19741(1) \quad$ cessado

20071 (1) contínuo $19981(1 / 2)$ contínuo

3, 2006 (1) contínuo

20052 (1) cessado

19521 (1) contínuo

19891 (1) contínuo

$19841(1) \quad$ contínuo

197037 (1) contínuo

$19801(1) \quad$ contínuo

20042 (3) contínuo

$19951(1) \quad$ contínuo

$20021(1) \quad$ contínuo

19771 anual

1, 2008 (3) contínuo

200227 (1) contínuo

$19951(1) \quad$ contínuo

19961 (1) contínuo

19901 (1) contínuo

19921 contínuo

19841 (1) contínuo

20001 (1) contínuo
19491 (1) contínuo 


\begin{tabular}{|c|c|c|c|}
\hline 45 & Estudos discurso crítico (1740-5912) & $3,2006(1)$ & contínuo \\
\hline 46 & Estudos em Ciências da Comunicação (1424-4896) & 20011 & contínuo \\
\hline 47 & Estudos em Comunicação & 19801 & contínuo \\
\hline 48 & Estudos sobre as Mulheres em Comunicação (0749-1409) & $19771(1)$ & contínuo \\
\hline 49 & European Journal of Communication (0267-3231) & $19861(1)$ & contínuo \\
\hline 50 & Filosofia e Retórica (0031-8213) & $19681(1)$ & contínuo \\
\hline 51 & Gazeta (0016-5492) & $197016(1)$ & contínuo \\
\hline 52 & Global Media e Comunicação (1742-7665) & $20051(1)$ & contínuo \\
\hline 53 & Harvard International Journal of Press / Politics (1081-180X) & $19961(1)$ & contínuo \\
\hline 54 & História da mídia (1368-8804) & $15,2009(1)$ & contínuo \\
\hline 55 & História Jornalismo (0094-7679) & $19741(1)$ & contínuo \\
\hline 56 & Howard Journal of Communication (1064-6175) & $19881(1)$ & contínuo \\
\hline 57 & Informação e Comunicação e Sociedade (1369-118X) & $19981(1)$ & contínuo \\
\hline 58 & International Journal of Communication (1932-8036) & 20071 & contínuo \\
\hline 59 & International Journal of Listening (1090-4018) & 19871 & contínuo \\
\hline 60 & International Journal of Press / Politics Gestão (1424-1277) & 19991 & contínuo \\
\hline 61 & $\begin{array}{l}\text { International Journal of Strategic Communication (1553- } \\
118 X)\end{array}$ & 2, 2008 & contínuo \\
\hline 62 & Javnost - O Público (1318-3222) & 19941 & contínuo \\
\hline 63 & $\begin{array}{l}\text { Jornal / Sul de Comunicação / Sul Speech Communication } \\
\text { Journal / Sul Speech Jornal / Boletim Discurso do Sul (1041- } \\
794 X)\end{array}$ & $19351(1)$ & contínuo \\
\hline 64 & Jornal Atlântico de Comunicação (1545-6970) & $200412(4)$ & contínuo \\
\hline 65 & Jornal chinês de Comunicação (1754-4750) & $20081(1)$ & contínuo \\
\hline 66 & $\begin{array}{l}\text { Jornal da Associação de Comunicação Administration } \\
\text { (00360-0939) }\end{array}$ & 19721 & cessado \\
\hline 67 & Jornal da Mídia e Religião (1534-8423) & $20021(1)$ & contínuo \\
\hline 68 & $\begin{array}{l}\text { Jornal de Comunicação Mediada por Computador (1083- } \\
6101 \text { ) }\end{array}$ & 19951 (1) & contínuo \\
\hline
\end{tabular}


69 Jornal de Língua e Social Psychology (0261-927X) Jornal de Negócios e Comunicação / Técnico lowa State

70 Journal of Business and Technical Communication (10506519)

71 Jornal de Rádio e Media Audio (1937-6529)

72 Jornal histórico de Televisão (0143-9685)

73 Jornal Internacional de Mídia e Política Cultural (1740-8296) Jornal Oeste da Comunicação / Oeste Journal of Speech

74 Communication / Speech Communication Ocidental / Speech Ocidental (1057-0314)

75 Jornalismo (1464-8849)

76 Jornalismo e Comunicação Monografias / Jornalismo Monografias (1522-6379)

77 Journal of Applied Communication Research / Journal of Applied Communications Research (0090-9882)

78 Journal of Broadcasting e Mídia Eletrônica / Journal of Broadcasting (0883-8151)

79 Journal of Business Communication (0021-9436)

80 Journal of Business Media Studies (1652-2354)

81 Journal of Children and Media (1748-2798)

82 Journal of Communication (0021-9916)

83 Journal of Communication da Família (1526-7431)

84 Journal of Film and Television Popular (0195-6051)

85 Journal of Health Communication (1081-0730)

86 Journal of Inquiry Comunicação (0169-8599)

87 Journal of Intercultural Communication (1747-5767)

88 Journal of International and Intercultural Communication (1751-3057)

89 Journal of Marketing de Comunicação (1352-7266)

90 Journal of Mass Mídia Ética (0890-0523)

91 Journal of Media Economics (0899-7764)
19821 (1) contínuo 19871 (1) contínuo 15, 2008 (1) contínuo 23, 2003 (1) contínuo

2, 2008 contínuo $19371(1)$ contínuo $20001(1) \quad$ contínuo 20012 (4) contínuo 19731 (1) contínuo 196914 (1) contínuo 19631 (1) contínuo 20041 (1) contínuo 20071 (1) contínuo 196818 (1) contínuo 20011 (1) contínuo 201038 (2) contínuo 20016 (1) contínuo 29, 2005 (1) contínuo 200635 (1) contínuo 20081 (4) contínuo 200511 (1) contínuo 19851 (1) contínuo 19903 (1) contínuo 


\begin{tabular}{|c|c|c|c|}
\hline 92 & Journal of Public Relations Research (1062-726X) & $19924(1)$ & contínuo \\
\hline 93 & Journal of Radio Studies (1095-5046) & $200310(2)$ & contínuo \\
\hline 94 & Journal of Social e Pessoal Relacionamentos (0265-4075) & $19841(1)$ & contínuo \\
\hline 95 & Journalism \& Mass Educador commmunication (1077-6958) & $200459(1)$ & contínuo \\
\hline 96 & Linguagem e Comunicação (0271-5309) & $19811(1)$ & contínuo \\
\hline 97 & Mass Comm revisão (0193-7707) & $19731(1)$ & cessado \\
\hline 98 & Mass Communication Research (1016-1007) & $200166(1)$ & contínuo \\
\hline 99 & Métodos de Comunicação e Medidas (1931-2458) & $20071(1)$ & contínuo \\
\hline 100 & Mídia Psicologia (1521-3269) & $19991(1)$ & contínuo \\
\hline 101 & Mídia, Cultura e Sociedade (0163-4437) & $19791(1)$ & contínuo \\
\hline 102 & New Media e Sociedade (1461-4448) & $19991(1)$ & contínuo \\
\hline 103 & Newspaper Research Journal (0739-5329) & $200425(5)$ & contínuo \\
\hline 104 & Nordicom revisão (0349-6244) & 19811 & contínuo \\
\hline 105 & Opinião Quarterly Pública (0033-362X) & $196630(1)$ & contínuo \\
\hline 106 & Organização Comunicação: Perspectivas Emergentes & 19861 & anual \\
\hline 107 & $\begin{array}{l}\text { Papéis de Westminster em Comunicação e Cultura (1744- } \\
6708)\end{array}$ & $20041(1)$ & contínuo \\
\hline 108 & $\begin{array}{l}\text { Pequeno Grupo de Pesquisa / Grupo Pequeno } \\
\text { Comportamento / Grupo de Estudos Comparativos (1046- } \\
\text { 4964) }\end{array}$ & $19734(1)$ & contínuo \\
\hline 109 & Pesquisa da Comunicação Humana (0360-3989) & $19741(1)$ & contínuo \\
\hline 110 & Pesquisa em Língua e Social Interaction (0835-1813) & $198720(1)$ & contínuo \\
\hline 111 & Prática de Jornalismo (1751-2786) & $20071(1)$ & contínuo \\
\hline 112 & Processos discurso (0163-853X) & $19781(1)$ & contínuo \\
\hline 113 & Progresso em Ciências da Comunicação & 19791 & cessado \\
\hline 114 & Public Relations revisão (0363-8111) & $19751(1)$ & contínuo \\
\hline 115 & $\begin{array}{l}\text { Quarterly / Comunicação Jornalismo \& Mass Journalism } \\
\text { Quarterly (1077-6990) }\end{array}$ & 197047 (1) & contínuo \\
\hline
\end{tabular}




\begin{tabular}{|c|c|c|c|}
\hline 116 & Quarterly Comunicação Empresarial (1080-5699) & 200568 & contínuo \\
\hline 117 & $\begin{array}{l}\text { Quarterly Journal of Speech / Quarterly Journal of Public } \\
\text { Speaking / Quarterly Journal of Speech Educação (0033- } \\
5630 \text { ) }\end{array}$ & $19151(1)$ & contínuo \\
\hline 118 & Quarterly Society Retórica (0277-3045) & $200636(1)$ & contínuo \\
\hline 119 & Questões em Lingüística Aplicada (1050-4273) & 19901 & contínuo \\
\hline 120 & Relações Públicas de Pesquisa e Ensino & $19841(1)$ & cessado \\
\hline 121 & Relatórios de Comunicação (0893-4215) & $19881(2)$ & contínuo \\
\hline 122 & Relatórios de Pesquisa de Comunicação (0882-4096) & $19841(1)$ & contínuo \\
\hline 123 & $\begin{array}{l}\text { Relatórios de Pesquisa Qualitativa em Comunicação (1745- } \\
\text { 9435) }\end{array}$ & $20056(1)$ & contínuo \\
\hline 124 & Retórica e Relações Públicas (1094-8392) & $19981(1)$ & contínuo \\
\hline 125 & $\begin{array}{l}\text { Revista de Comunicação e Religião / Comunicação Religiosa } \\
\text { Hoje (0894-2838) }\end{array}$ & $19781(1)$ & contínuo \\
\hline 126 & Revista Eletrônica de Comunicação (1183-5656) & $19901(1)$ & contínuo \\
\hline 127 & Revista Internacional de Mídia de Gestão (1424-1277) & 19991 & contínuo \\
\hline 128 & Rhetorica (0734-8584) & $26,2008(1)$ & contínuo \\
\hline 129 & Semiotica (0037-1998) & $19691(1)$ & contínuo \\
\hline 130 & Subjetividade operante (0193-2713) & $19771(1)$ & contínuo \\
\hline 131 & Televisão e Novas Mídias (1527-4764) & $20012(3)$ & contínuo \\
\hline 132 & Teoria da Comunicação (1050-3293) & $19911(1)$ & contínuo \\
\hline 133 & Texto e Discussão (1860-7330) & $\begin{array}{l}27,2007 \\
(5 / 6)\end{array}$ & contínuo \\
\hline 134 & Visual Communication Quarterly (1555-1393) & 15, $2008(1)$ & contínuo \\
\hline 135 & Vozes da Democracia (1932-9539) & $1,2006(1)$ & contínuo \\
\hline
\end{tabular}

Fonte: http://www.cios.org/www/aboutcomabstracts.htm 


\section{Anexo 3 - Lista de membros da LARRP - LAPTOC}

1 Arizona State University

2 University of Arizona

3 Biblioteca Inca

4 Boston College

5 Brigham Young University

6 University of California, Berkeley

7 University of California, Los Angeles

8 University of California, San Diego

9 University of California, Santa Barbara

10
Centro de Investigaciones Regionales de Mesoamerica

11 Columbia University

12 University of Connecticut

13 Cornell University

14 Dartmouth College

15 Duke University

16 Emory University

17 Florida International University

18 University of Florida

19 Harvard University
Melissa Guy

Ping Situ

Miguel Baptista

Lawrence Busenbark

Mark Grover

Carlos Delgado

Jennifer Osorio

Harold Colson

Socrates Silva

Martha Peitzner de Cuellar

Sean Knowlton

Marisol Ramos

Sean Knowlton

Jill Baron

Holly Ackerman

Phil MacLeod

Gayle Williams

Paul Losch

Lynn Shirey 
20 University of Illinois at Urbana-Champaign

21 Indiana University

22 Instituto de Estudios Peruanos

23 Inter-American Development Bank

24 University of Kansas

25 Library of Congress

26 University of Massachusetts Amherst

27 University of Miami

28 Michigan State University

29 University of Michigan

30 University of Minnesota-Twin Cities

31 University of New Mexico

32 New York University

33 University of North Carolina at Chapel Hill

34 University of Notre Dame

35 Ohio State University

36 Ohio University

37 University of Pennsylvania

38 University of Pittsburgh

39 Princeton University

40 Universidad de Puerto Rico, Rio Piedras

41 Rice University
Antonio Sotomayor

Luis Gonzalez

Virginia Garcia

Norma Palomino

Mary Raple

Georgette Dorn

Peter Stern

Meiyolet Mendez

Mary Jo Zeter

Nerea Llamas

Rafael Tarrago

Suzanne Schadl

Angela Carreno

Teresa Chapa

David Dressing

Jose Diaz

Jeffrey Ferrier

Joseph Holub

Martha Mantilla

Fernando Acosta-Rodriguez

Almaluces Figueroa

Kerry Keck 
42 Universidade Federal do Rio Grande do Sul

43 Rutgers, The State University of New Jersey

44 Universidad de San Andres

45 University of South Florida

46 University of Southern California

47 Syracuse University

48 University of Texas at Austin

49 University of Toronto

50 Tulane University

51 Vanderbilt University

52 University of the West Indies/ St. Augustine

53 University of the West Indies/ St. Augustine

54 University of Wisconsin-Madison

55 Yale University
Maria Wagner

Melissa Gasparotto

Andrea Saladino

Nancy Cunningham

Barbara Robinson

Marty Hanson

David Block

Miguel Torrens

Hortensia Calvo

Paula Covington

Floris Fraser

Kathleen Helenese-Paul

Paloma Carbajal

Jana Krentz 


\section{Anexo 4 - Critérios de classificação para periódicos impressos e eletrônicos Latindex}

\section{\#\# Periódicos eletrônicos: Características básicas}

Menção do corpo editorial - Deve-se constatar que no periódico se mencione a existência de um conselho ou comitê editorial ou um responsável cientista. O corpo editorial poderá estar formado pelo

1 diretor geral, editor responsável, editor executivo, secretário de redação, entre outros. Nos periódicos eletrônicos deverá constar na página de início diretamente ou bem com um enlace que permita aceder aos dados com um simples clique.

Conteúdo - Para qualificar positivamente, ao menos o 40\% dos documentos publicados nos fascículos a qualificar devem ser: artigos originais; artigos de revisão; informes técnicos; comunicações

2 apresentadas em congressos; comunicações breves; cartas ao editor; estados da arte; resenhas de livros, entre outros tipos de documentos. Em todos os casos deve privar o conteúdo científico ou

Antiguidade mínima de um ano - Para ser qualificada a publicação deverá cumprir dois requisitos: ter começado a editar-se ao menos

312 meses antes do momento em que se faz a análise e apresentar um mínimo de três fascículos diferentes. Em todos os casos deverá avaliar-se com os fascículos mais recentes.

4 Geração contínua de conteúdos - Deve demonstrar a geração de novos conteúdos num ano.

Indicação dos autores - Os trabalhos devem estar assinados pelos

5 autores com nome e sobrenomes ou declaração de autor institucional.

6 Local de edição - Deverá fazer-se constar em lugar visível o lugar de edição do periódico.

Entidade da Editora - Deverá fazer-se constar em lugar visível a entidade ou instituição editora do periódico. Deverá ser de toda

7 solvência, aparecerá na página de início diretamente ou bem com um enlace que permita aceder com um simples clique. Deverá fazerse constar o endereço de correio eletrônico.

8 Menção de diretor(a) - No periódico deverá constar o nome do diretor da publicação, responsável editorial ou equivalente.

Menção de URL do periódico - Deverá constar na página principal do periódico ou no navegador (browser).

Menção de endereço - Deverá indicar-se em lugar visível endereço postal ou de correio eletrônico da administração do periódico para efeitos de solicitação de assinaturas, trocas, envio de trabalhos, entre outros. acadêmico.

\section{Eletrônico Impresso}

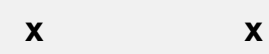

$\mathbf{x}$
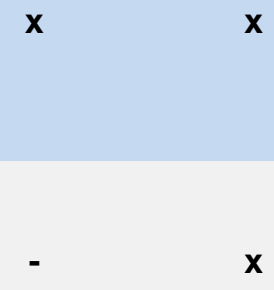

$\mathbf{x}$

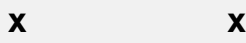

$\mathbf{x}$

$\mathbf{x}$

$\mathbf{x}$

$\mathbf{x}$

$\mathbf{X}$

$\mathbf{x}$

\#\# Periódicos eletrônicos: Características de apresentação do periódico

Página de prestação - Estas deverão incluir ao menos o título

1 completo do periódico, bem como ISSN, volume, número, data e cabeçalho bibliográfico.

Navegação e funcionalidade - Deve contar com navegação

2 estrutural que permita que com um máximo de três cliques aceder aos sumários e artigos.

Menção de periodicidade - O periódico deve indicar a sua

3 periodicidade, ou na ausência desta, o número de fascículos publicados por ano. Ou se for o caso, declaração de periodicidade continuada.

4 Sumário (índice) - Avalia-se positivamente quando em cada fascículo existe uma tabela de conteúdos, índice ou sumário nos que $\mathbf{x}$

$\mathbf{x}$

X 
constem os dados de título, autor e ao menos a página inicial.

5 Acesso aos conteúdos - Deve facilitar a presença do sumário ou de uma estrutura de acesso aos conteúdos.

6 Acesso histórico aos conteúdos - Pelo tempo de vida do periódico, ou por um tempo mínimo de três anos.

Lembrete bibliográfio ao início de cada artigo - Qualifica

7 positivamente se o lembrete bibliográfico aparece ao início de cada artigo e identifica à fonte.

Lembrete bibliográfico em todas as páginas - Qualifica

8 positivamente se o cabeçalho bibliográfico que identifica a fonte aparece em páginas pares ou ímpares do artigo, não necessariamente em ambas.

Membros do conselho editorial - Qualifica positivamente se

9 aparecem os nomes dos membros do conselho editorial do periódico.

Afiliação institucional dos membros do conselho editorial -

10 Qualifica positivamente a indicação dos nomes das instituições às que estão adscritos os membros do conselho editorial. Não basta a indicação do respectivo país.

11 Afiliação dos autores - Deverá fazer-se constar sempre a entidade à que está adscrito o autor.

12 Datas de recepção e aceitação dos originais - Qualifica-se positivamente só se indicam ambas as datas.

\#\# Periódicos eletrônicos: Características de gestão e política editorial

ISSN - Os periódicos eletrônicos devem contar com seu próprio

1 ISSN. Não é cumprido se aparece apenas o ISSN da versão impressa.

2 Apresentação do periódico - Menção, em cada fascículo, de objetivo, cobertura temática e público ao que se dirige o periódico.

3 Sistema de arbitragem - No periódico deverá constar o procedimento empregado para a seleção dos artigos a publicar.

Avaliadores externos - Se deverá mencionar que o sistema de

4 arbitragem recorre a avaliadores externos à entidade ou instituição editora do periódico.

Autores externos - Ao menos o $50 \%$ dos trabalhos publicados devem provir de autores externos à entidade editora. No caso dos

5 periódicos editados por associações se considerarão autores pertencentes à entidade editora os que fazem parte da diretora da associação ou figuram na equipe do periódico.

6 Abertura editorial - Ao menos duas terceiras partes do conselho editorial deverão ser alheias à entidade editora.

Serviços de informação - Qualifica positivamente se o periódico está incluído em algum serviço de indexação, resumos, diretórios ou

7 bases de dados. Este campo qualifica positivamente tanto se a base de dados é mencionada pelo próprio periódico como se é agregada pelo qualificador.

Cumprimento da periodicidade - Qualifica positivamente se o

8 periódico cumpre com a declaração de periodicidade que se contempla no critério 10.

\#\# Revistas eletrônicas: Características de conteúdo

Conteúdo original - Qualifica positivamente se ao menos o 40\% dos

1 artigos são trabalhos de investigação, comunicação científica ou criação original.

Intrução aos autores - Qualifica positivamente se o periódico

2 especifica ás instruções aos autores sobre o envio de originais e resumos ao menos em algum número do ano.

3 Elaboração das referencias bibliográficas - Nas instruções aos

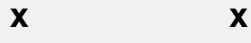

x $\quad x$

x $x$

$\mathbf{x} \quad \mathbf{x}$

$\mathbf{x} \quad \mathbf{x}$

X $\quad$ X

x $\quad$ x

X $\quad$ x

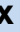

$x$

$\mathbf{x}$

$x$

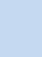


autores deverão indicar-se as normas de elaboração das referências bibliográficas.

Exigência de originalidade - Qualifica positivamente se na

4 apresentação do periódico ou nas instruções aos autores se menciona esta exigência para os trabalhos submetidos á publicação.

5 Resumo - Todos os artigos deverão ser acompanhados de um resumo na língua original do trabalho.

6 Resumo em duas línguas - Qualifica positivamente a inclusão de resumos na língua original do trabalho e noutra língua.

7 Palavras-chave - Qualifica positivamente a inclusão de palavraschave ou equivalente na língua original do trabalho.

Palavras-chave em duas línguas - Para qualificar positivamente,

8 deverão incluir-se palavras-chave ou equivalente na língua original do trabalho e noutra língua.

9 Meta etiquetas - Qualifica positivamente se aparecem meta etiquetas na página de apresentação do periódico (código fonte).

Buscadores - Qualifica positivamente a presença de algum motor de

10 busca que permita realizar buscas por palavras, por índices, utilizar operadores boléanos, entre outros.

Serviços de valor adicionado - Qualifica positivamente se a

11 periódico oferece alertas, enlaces hipertextuais, foros, guias de enlaces, entre outros.

$\mathbf{x}$

$\mathbf{x} \quad \mathbf{x}$

$\mathbf{x}$

$\mathbf{x} \quad \mathbf{x}$

$\mathbf{x}$

$\mathbf{x}$

$\mathbf{x}$ 
Anexo 5: Inexistência de documentos ou de critérios, segundo informações disponibilizadas pelas áreas.

\begin{tabular}{|c|c|c|c|c|}
\hline \multirow{2}{*}{ Área de avaliação } & \multicolumn{3}{|c|}{ Triênio do documento de área } & \multirow{2}{*}{$\begin{array}{c}\begin{array}{c}\text { Atualização do WEBQUALIS } \\
\text { (data de acesso) }\end{array} \\
2010-2012 \\
\end{array}$} \\
\hline & 2001-2003 & 2004-2006 & 2007-2009 & \\
\hline $\begin{array}{l}\text { Administração, } \\
\text { Ciências Contábeis } \\
\text { e Turismo }\end{array}$ & $\begin{array}{l}\text { "Critérios não autorizados } \\
\text { para divulgação pelo } \\
\text { Representante de Área de } \\
\text { Avaliação" }\end{array}$ & - & - & $04 / 05 / 2012$ \\
\hline $\begin{array}{l}\text { Arquitetura e } \\
\text { Urbanismo }\end{array}$ & - & $\begin{array}{c}\text { Não tinha critérios } \\
\text { publicados }\end{array}$ & - & 09/07/2012 \\
\hline $\begin{array}{c}\text { Ciências Sociais } \\
\text { Aplicadas I }\end{array}$ & - & - & - & $08 / 02 / 2013$ \\
\hline Direito & - & - & - & $22 / 02 / 2013$ \\
\hline Economia & $\begin{array}{l}\text { "Critérios não autorizados } \\
\text { para divulgação pelo } \\
\text { Representante de Área de } \\
\text { Avaliação" }\end{array}$ & $\begin{array}{c}\text { Não tinha critérios } \\
\text { publicados }\end{array}$ & - & $04 / 04 / 2013$ \\
\hline $\begin{array}{l}\text { Planejamento } \\
\text { Urbano e Regional } \\
\text { / Demografia }\end{array}$ & - & - & - & $09 / 07 / 2012$ \\
\hline Serviço Social & $\begin{array}{l}\text { "Critérios não autorizados } \\
\text { para divulgação pelo } \\
\text { Representante de Área de } \\
\text { Avaliação" }\end{array}$ & - & - & $03 / 04 / 2013$ \\
\hline
\end{tabular}


